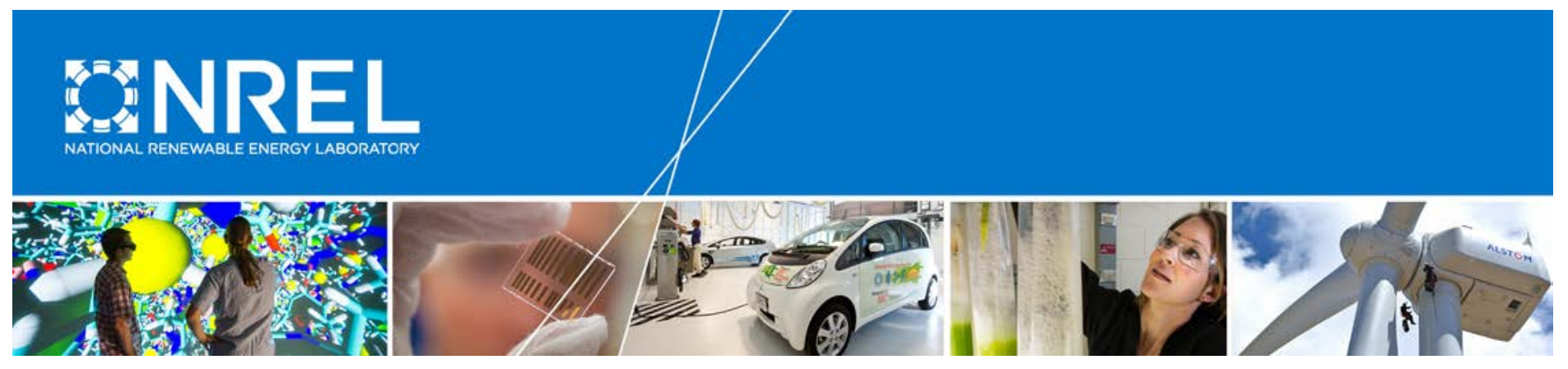

\title{
Market and Modeling Uncertainty in Distributed Solar Deployment Projections: A Multi-Model Comparison
}

Ben Sigrin and Ted Kwasnik National Renewable Energy Laboratory

Paul Spitsen

U.S. Department of Energy

Meera Fickling, Kevin Jarzomski, and Erin Boedecker U.S. Energy Information Administration

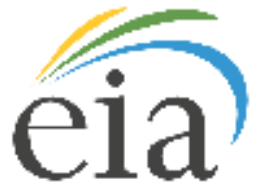

NREL is a national laboratory of the U.S. Department of Energy Office of Energy Efficiency \& Renewable Energy Operated by the Alliance for Sustainable Energy, LLC

This report is available at no cost from the National Renewable Energy Laboratory (NREL) at www.nrel.gov/publications.

Technical Report

NREL/TP-6A20-70902

September 2018 


\section{Market and Modeling Uncertainty in Distributed Solar Deployment Projections: A Multi-Model Comparison}

Ben Sigrin and Ted Kwasnik

National Renewable Energy Laboratory

Paul Spitsen

U.S. Department of Energy

Meera Fickling, Kevin Jarzomski, and Erin Boedecker

U.S. Energy Information Administration

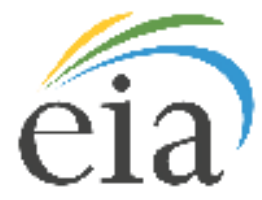

\section{Suggested Citation}

Sigrin, Ben, Ted Kwasnik, Paul Spitsen, Meera Fickling, Kevin Jarzomski, and Erin Boedecker. 2018. Market and Modeling Uncertainty in Distributed Solar Deployment Projections: A Multi-Model Comparison. Golden, CO: National Renewable Energy Laboratory. NREL/TP-6A20-70902.

https://www.nrel.gov/docs/fy180sti/70902.pdf.

NREL is a national laboratory of the U.S. Department of Energy

Office of Energy Efficiency \& Renewable Energy

Operated by the Alliance for Sustainable Energy, LLC

This report is available at no cost from the National Renewable Energy Laboratory (NREL) at www.nrel.gov/publications.

National Renewable Energy Laboratory 15013 Denver West Parkway Golden, CO 80401

303-275-3000 • www.nrel.gov

\section{Technical Report}

NREL/TP-6A20-70902

September 2018

Contract No. DE-AC36-08GO28308 


\section{NOTICE}

This work was authored by the National Renewable Energy Laboratory, operated by Alliance for Sustainable Energy, LLC, for the U.S. Department of Energy (DOE) under Contract No. DE-AC3608GO28308. Funding provided by the U.S. Energy Information Administration. The views expressed herein do not necessarily represent the views of the DOE or the U.S. Government. The U.S. Government retains and the publisher, by accepting the article for publication, acknowledges that the U.S. Government retains a nonexclusive, paid-up, irrevocable, worldwide license to publish or reproduce the published form of this work, or allow others to do so, for U.S. Government purposes.

This report is available at no cost from the National Renewable Energy Laboratory (NREL) at www.nrel.gov/publications.

U.S. Department of Energy (DOE) reports produced after 1991 and a growing number of pre-1991 documents are available free via www.OSTI.gov. 


\section{Acknowledgments}

This work was supported by the U.S. Department of Energy (DOE) under Contract No. DEAC36-08GO28308 with the National Renewable Energy Laboratory (NREL). Funding for the work was provided by the U.S. Energy Information Administration, Office of Energy Consumption and Efficiency Analysis. The authors thank Rebecca Jones-Albertus, Ben King, Janice Lent, Carolyn Moses, Kara Podkaminer, Manussawee Sukunta, and Jim Turnure for their thoughtful reviews. Opinions represented in this report are the authors' own and do not reflect the view of the U.S. Department of Energy or the U.S. government. Any remaining errors or omissions are the sole responsibility of the authors. 


\section{List of Acronyms}

$\begin{array}{ll}\text { AEO } & \text { Annual Energy Outlook } \\ \text { CBECS } & \text { Commercial Building Energy Consumption Survey } \\ \text { CDM } & \text { Commercial Demand Module (EIA NEMS) } \\ \text { CPP } & \text { Clean Power Plan } \\ \text { dGen } & \text { Distributed Generation Market Demand Model } \\ \text { DPV } & \text { distributed photovoltaics } \\ \text { DSIRE } & \text { Database of State Incentives for Renewables and Efficiency } \\ \text { EIA } & \text { U.S. Energy Information Administration } \\ \text { LBNL } & \text { Lawrence Berkeley National Laboratory } \\ \text { LCOE } & \text { Levelized Cost of Energy } \\ \text { GW } & \text { gigawatt } \\ \text { kW } & \text { kilowatt } \\ \text { MW } & \text { megawatt } \\ \text { MWh } & \text { megawatt-hour } \\ \text { NEM } & \text { net energy metering } \\ \text { NEMS } & \text { National Energy Modeling System } \\ \text { NPV } & \text { net present value } \\ \text { NREL } & \text { National Renewable Energy Laboratory } \\ \text { NSRDB } & \text { National Solar Radiation Database } \\ \text { O\&M } & \text { operation and maintenance } \\ \text { RDM } & \text { Residential Demand Module (EIA NEMS) } \\ \text { RECS } & \text { Residential Energy Consumption Survey } \\ \text { ReEDS } & \text { Regional Energy Deployment System } \\ \text { SREC } & \text { solar renewable energy certificate } \\ \text { TMY } & \text { Typical Meteorological Year } \\ \text { TWh } & \text { terawatt-hour }\end{array}$




\section{Executive Summary}

Distributed solar photovoltaic (DPV) systems that generate energy in behind-the-meter applications for residential, commercial, and other end-use sectors are a growing —and potentially disruptive-development in the U.S. power system. While less than $1 \%$ of all electricity generation in the United States came from DPV systems in 2016 (EIA 2017²), this technology has experienced rapid growth in recent years and, as of the end of 2017, over 1.6 million DPV systems had been installed (GTM 2017). Given this, projecting distributed solar deployment is increasingly pertinent-yet remains highly uncertain.

The traditional U.S. power system has historically consisted of large, centralized baseload generators connected to demand centers via a hub-and-spoke network of synchronized voltage transmission and distribution lines. Utilities have also historically financed most infrastructure with charges apportioned among customers on a volumetric basis. DPV systems disrupt both prior foundations of the U.S. electric power system. Not only are DPV systems typically low capacity, but their generation directly offsets on-site electricity consumption or is exported to the grid in the case of excess, thereby reducing electricity sales. Recent declines in DPV costs has prompted questions regarding the conditions in which consumers might find electricity sourced from DPV more economically compelling than grid-sourced electricity. Sometimes termed "grid parity”, this phenomenon could accelerate DPV adoption. Clarity about whether DPV might achieve grid parity, the timing and extent of this transition, and future levels of DPV deployment are important factors to consider for power system operational conditions, engineering and financial risk, and long-term planning of the U.S. electric grid.

To address these issues, we project trends in the net present value of residential-scale solar systems on a county-level basis from 2017 through 2050. Next, we combine the long-term projections of three national DPV adoption models to examine their short and long-term outlooks and sensitivities to future macroeconomic conditions. Finally, we also address the inherent uncertainty in projections from two distinct perspectives: (1) economic uncertainty, or the set of techno-economic factors that significantly impact the real world as well as our model projections, and (2) modeling uncertainty, or the differing implications of choices made regarding modeling methodology in computational simulations.

The analysis conducted for this report is relatively static and does not capture the full range of factors influencing electricity markets. Nevertheless, it is intended to be instructive of the range of potential DPV deployment should grid conditions remain similar to today's. Future work could consider other potentially disruptive factors, such as influence of electric vehicles, energy storage, competition between utility-scale, community-scale and distributed-scale solar systems, and impacts of integrating high levels of distributed solar into the electrical grid. For instance, distribution grid integration limits could limit the actual deployable potential or introduce new system integration costs not considered in this analysis. Perhaps most significant are "endogenous" changes; that is, evolution in retail rate design, policy, and market structure as a response to the expansion of DPV to better reflect the value of distributed generation.

\footnotetext{
${ }^{1}$ See "What is U.S. Electricity Generation by Energy Source?” data for April 2017, https://www.eia.gov/tools/faqs/faq.php?id=427\&t=3.
} 


\section{Distributed PV NPV Projections}

Customer adoption of DPV is primarily driven by the potential savings from the avoided purchase of grid-sourced electricity. We develop projections for the net present value of investing in a DPV system from the consumer's perspective as a means to understand the conditions under which consumers might perceive DPV adoption to be economically attractive. The projections incorporate county-level variation in the cost of retail electricity, solar resource, and policies affecting the value of distributed generation and use NREL's standard power systems financing assumptions (real weighted average cost of capital of 5.4\%), but do not incorporate distribution grid integration costs or feedbacks from transmission-level impacts. Also, this long-term outlook is based on two modeling assumptions, most notably that current retail rate structures do not substantially change, with the exception that excess solar generation (i.e., generation exported to grid) is modeled to eventually be valued at wholesale electricity prices (Proudlove et al. 2017). We also simulate current net metering and other financial incentives to sunset as specified in current statutes.

Our analysis suggests that residential-scale DPV systems in 2017 had a positive Net Present Value (NPV) for nearly a third of counties (29\%) in the continental United States, mostly in the Southwest and Northeast. By 2027, using NREL's 2017 Annual Technology Baseline (ATB) Mid Case PV cost reduction scenario, this ratio increases slightly to 33\% as (projected) lower costs are offset by sunsetting of current policies. By 2050, assuming continued cost reductions (ATB Mid Cost scenario) ${ }^{2}$, adoption of distributed solar could be a compelling financial proposition for consumers in $80 \%$ of U.S. counties (Figure ES-1). These long-term projections depend highly on future capital costs. For instance, with no reduction in costs in real terms from today's levels (ATB High Cost scenario) and sunsetting of current policy, we project that DPV would be economically competitive in only $1 \%$ of counties.

This analysis suggests that, with continued decreases in DPV costs, distributed solar may become economically attractive in many jurisdictions that are not currently associated with DPV activity, including wide swaths of the Midwest and portions of the Southeast. Conversely, based on current policy statutes, DPV is unlikely to become widespread in areas with low electricity prices or poor solar resource-including Washington and Idaho.

\footnotetext{
${ }^{2}$ For reference, Mid Cost residential capital costs are $\$ 1,770 / \mathrm{kW}$ in 2027 and $\$ 1,150 / \mathrm{kW}$ in 2050. See: https://data.nrel.gov/files/71/2017-ATB-data.xlsm
} 


\section{Net Present Value in 2050 by ATB Scenario}

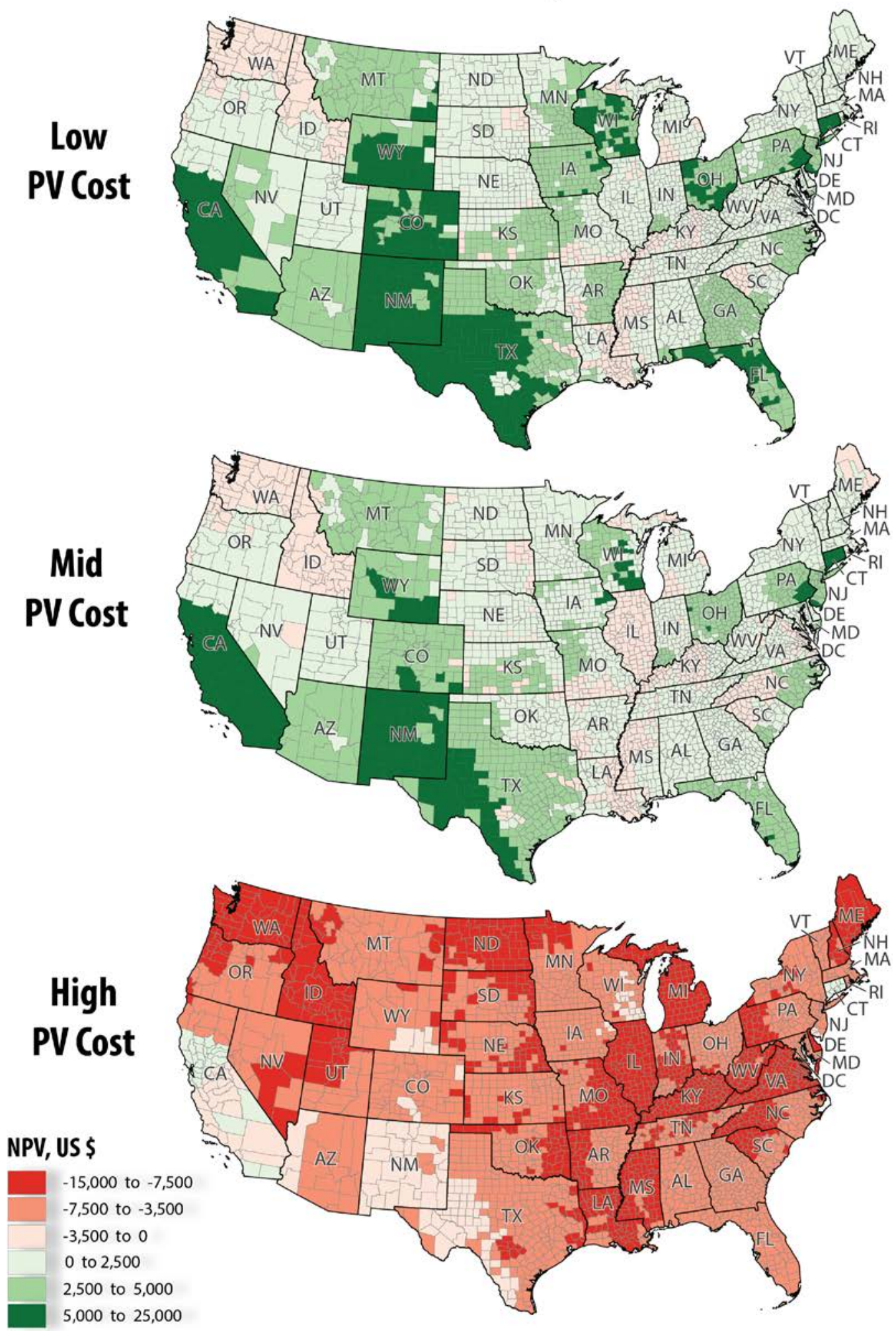

Figure ES-1. Projected net present value of a 5-kW Residential Solar System in 2050 by County and ATB Cost Scenario 


\section{DPV Deployment: Economic Uncertainty}

We address uncertainty in future DPV deployment introduced through techno-economic conditions by comparing the projections of three national DPV adoption models using a common set of input assumptions and scenarios:

- NREL's dGen model

- The U.S. Energy Information Administration's (EIA) Cash Flow Adoption model

- EIA’s Hurdle Rate Adoption model.

Each model is used to assess the Reference case and seven additional sensitivities from EIA's 2017 Annual Energy Outlook (EIA 2017) ${ }^{3}$. We find there are substantial differences in the underlying models' assumptions and, as summarized in Table ES-1, in their long-term outlook. In the Reference case, the 2050 DPV projections ranged from 148 gigawatts (GW) to 227 GW. Sensitivity of dGen projections to the set of macroeconomic conditions explored was within $\pm 10 \%$ of the Reference projection and was narrower than sensitivity to solar capital costs. The EIA models, on the other hand, project capacity increases of $5 \%$ to $12 \%$, or decreases of more than $15 \%$, in response to various macroeconomic scenarios.

Table ES-1. Comparison of Key Reference Case Outputs by Model for 2050

\begin{tabular}{lccc}
\hline Model & $\begin{array}{c}\text { Installed Capacity } \\
\text { (GW) }\end{array}$ & $\begin{array}{c}\text { Number of Systems } \\
\text { (Million) }\end{array}$ & $\begin{array}{c}\text { Annual Generation } \\
\text { (TWh) }\end{array}$ \\
\hline NREL dGen & 148 & 22.3 & 202 \\
\hline EIA Cash Flow & 165 & 14.3 & 239 \\
\hline EIA Hurdle Rate & 227 & 36.5 & 333 \\
\hline
\end{tabular}

Figure ES-2 illustrates model projection consensus is high from the present to 2026, with small differences in projected capacity. From 2026 onwards, however, the models begin different regimes of growth. In the dGen model, most currently implemented policies have expired by 2026 and, thereafter, the rate of new installations decreases due to an increasing saturation of the most-favorable sites. In contrast, growth in adoption in both EIA models increases post-2026 due to differences in the representation of current policy, as well as assumptions related to demographics and peer influence.

\footnotetext{
${ }^{3}$ See “Annual Energy Outlook 2017 with projections to 2050” report, January 5, 2017 https://www.eia.gov/outlooks/aeo/pdf/0383(2017).pdf.
} 


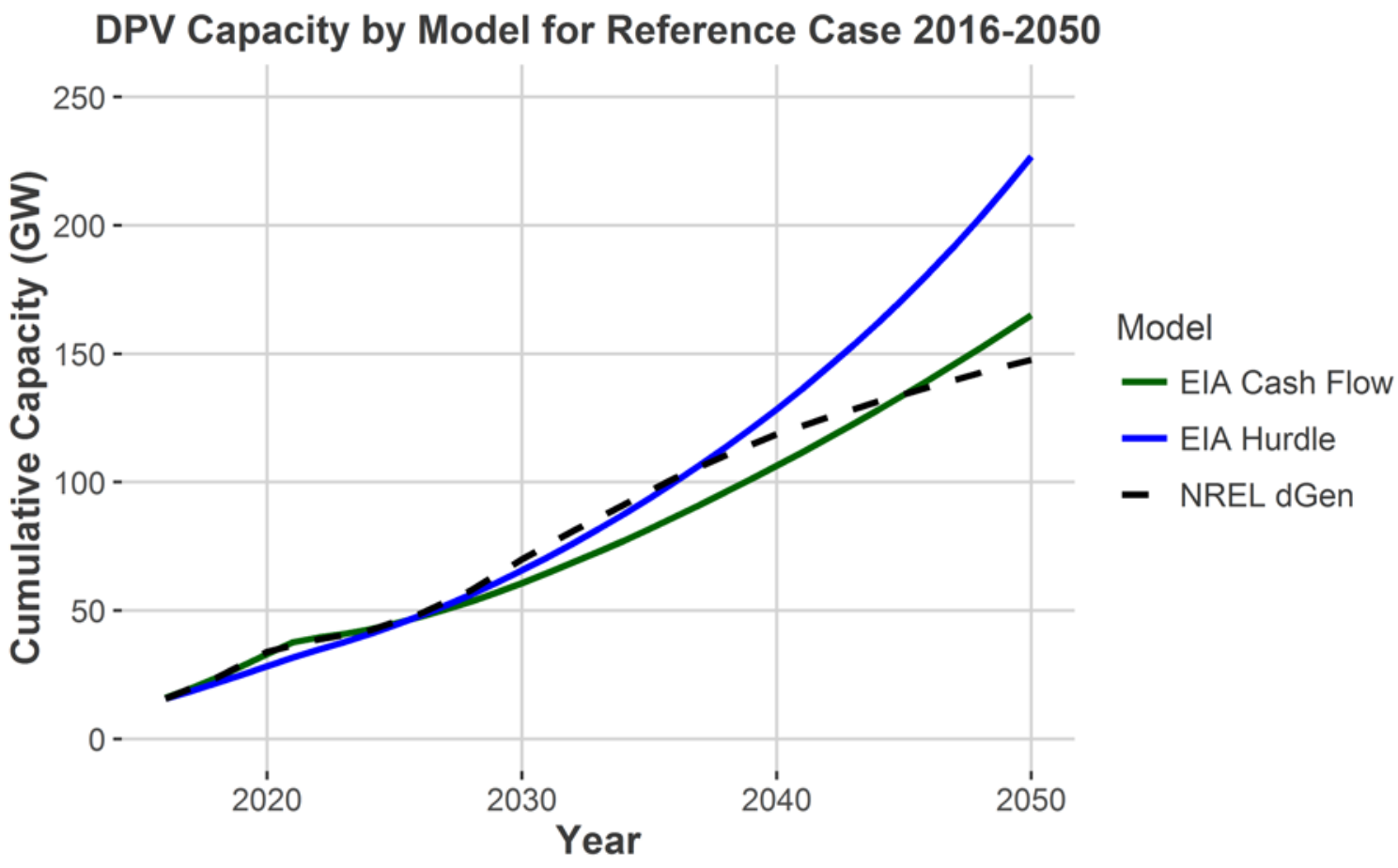

Figure ES-2. Reference Case DPV projections by modeling approach

\section{DPV Deployment: Modeling Uncertainty}

We also examine the sensitivity and uncertainty of DPV projections to model specification, including the choice of which real-world phenomena to represent, how results change through a retrospective consideration, and the quantification of uncertainty derived from stochastic processes within the dGen model.

We find that stochastic processes that populate customer profiles in dGen can introduce significant repeatability challenges in simulations with insufficient sampling rates (Figure ES-3) and that model variance decreased at larger geographic scales due to the aggregation of many smaller random processes. In practical terms, we estimate that a single national simulation using one agent per county-sector is expected to have a 5\% uncertainty for the national-level projected installed capacity. Importantly, sampling process uncertainty is additional to other modeling assumptions or projections (e.g., future natural gas prices). Sampling error was found to be higher at the state level, where the median state would have an uncertainty of $41 \%$. These errors substantially decrease as the model resolution increases, where averaging of 10 simulations results in a $1.5 \%$ error nationally and a $12.9 \%$ error for the median state; 100 simulations achieve a $0.5 \%$ error nationally and a $4.1 \%$ error for the median state. These results provide guidance on the sampling rates needed to achieve a desired level of sampling error, which is important for informing future analysis. 


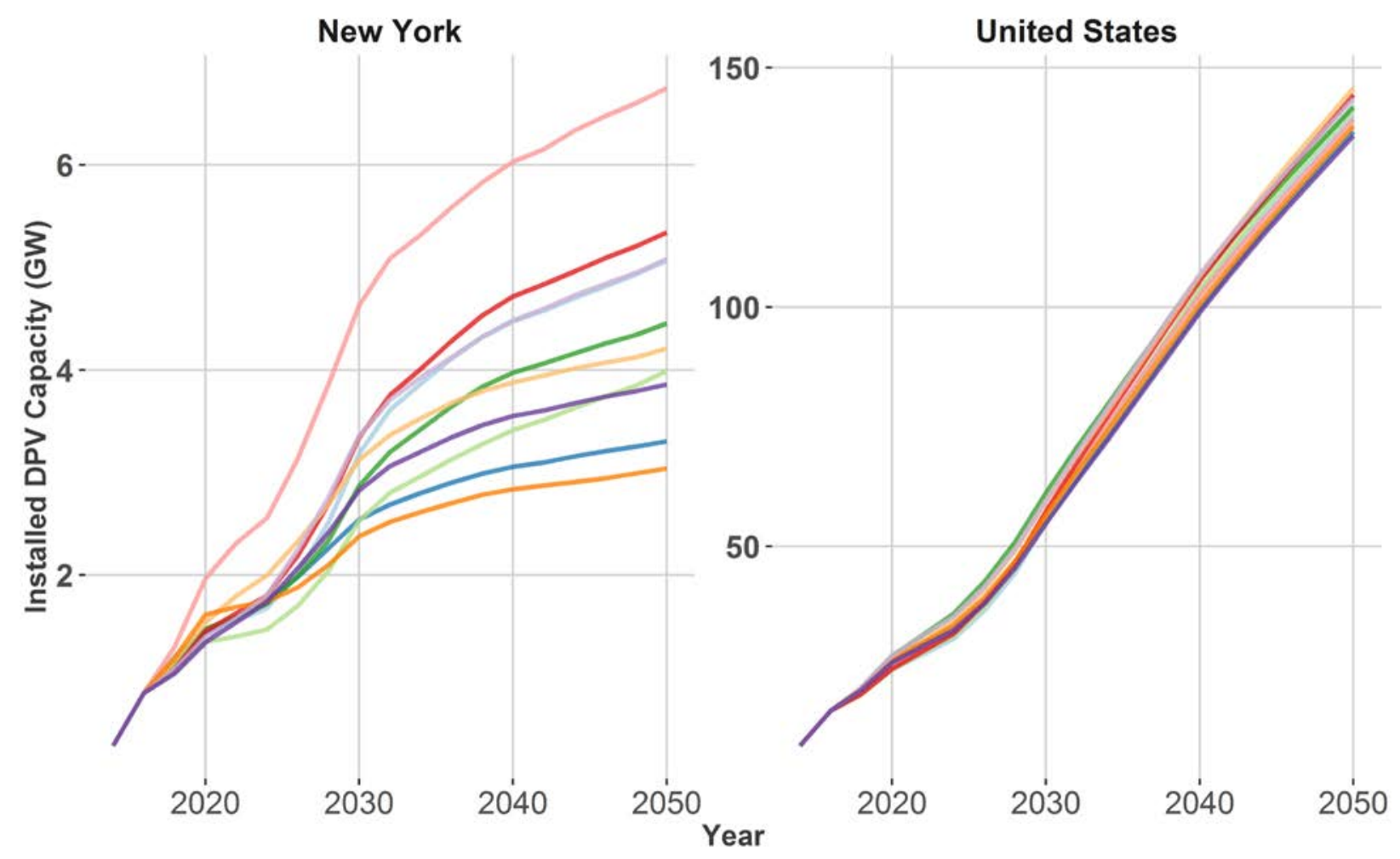

Figure ES-3: Variance in New York (left) and national-level (right) results for 10 simulations for one agent per county-sector, each using a random seed

\section{Conclusions}

In this report, we project long-term DPV cost competitiveness with grid-sourced electricity, finding that future competitiveness is sensitive to both the cost of PV systems and the value of distributed generation. While policies such as net metering affected the DPV net present value, future PV system costs were more significant. Under the ATB Mid Cost scenario, DPV could be cost-competitive for most of the United States in 2050, though conversely there are also likely to be persistent regions with low deployment.

Projections from three long-term capacity expansion models generally were consistent in the projected near-term deployment in the near term, roughly $50 \mathrm{GW}$ in 2027 in the Reference case. After 2027, the models disagree on the long-term projection, with the EIA Cash Flow and NREL dGen model projecting 148GW-165 GW of installed capacity, while the EIA Hurdle model projected $227 \mathrm{GW}$.

We also explore several dimensions to modeling uncertainty, including the choice of which realworld phenomena to represent, how results change through a retrospective consideration, and the quantification of uncertainty derived from stochastic processes within the dGen model. We find that (1) stochastic processes that populate customer profiles in dGen may introduce significant bias in simulations with insufficient sampling rates (Figure ES-3) and (2) model variance decreased at larger geographic scales due to the aggregation of many smaller sampling processes. 


\section{Table of Contents}

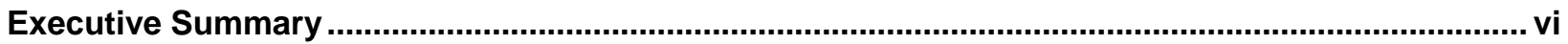

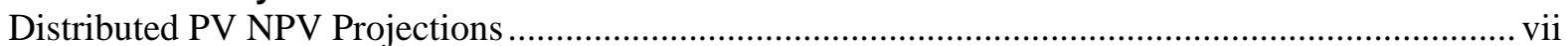

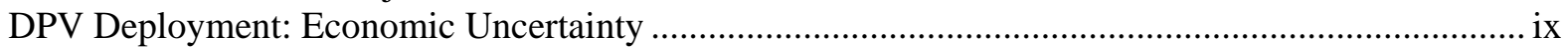

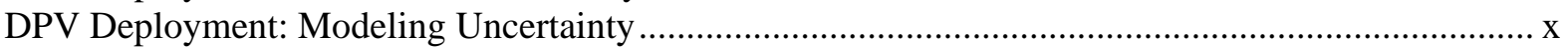

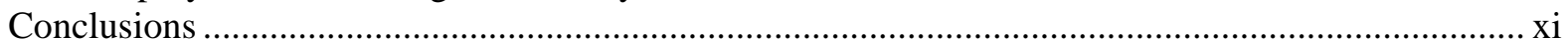

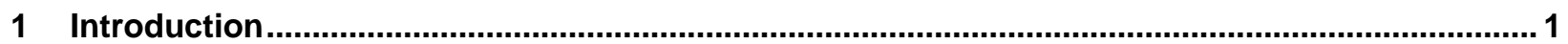

1.1 Overview of Distributed Solar in the United States ...................................................... 1

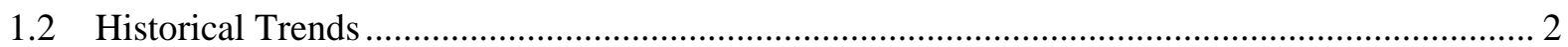

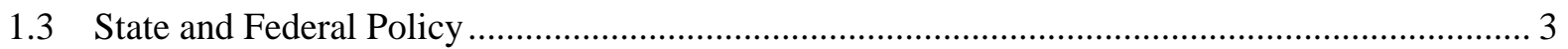

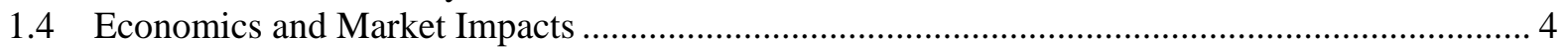

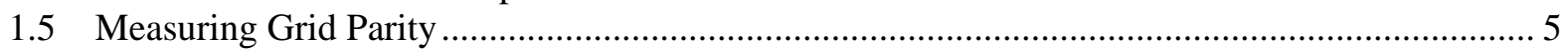

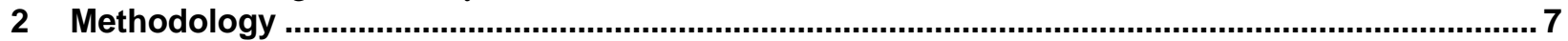

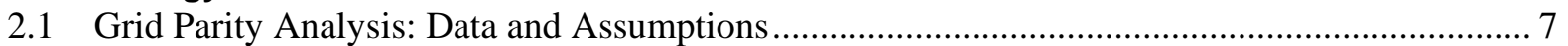

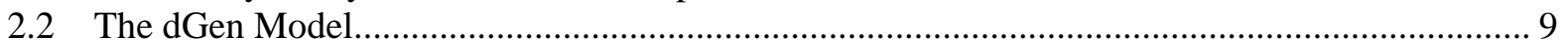

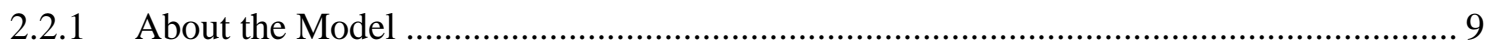

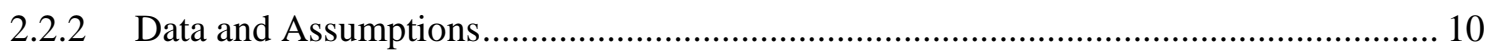

2.3 The EIA National Energy Modeling System (NEMS) ........................................................... 14

2.3.1 EIA Cash Flow Adoption Model (Commercial and pre-AEO2017 Residential)........... 14

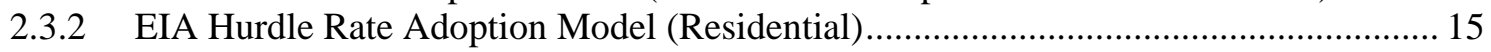

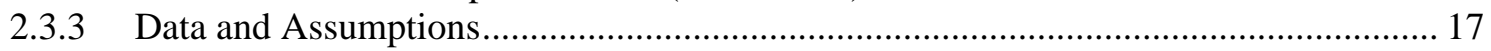

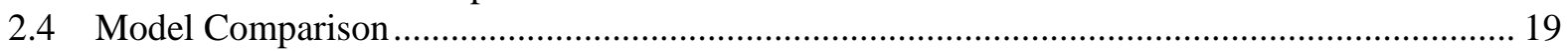

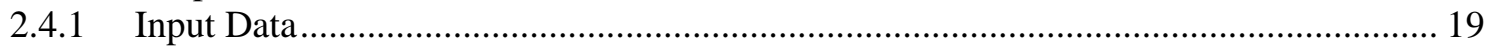

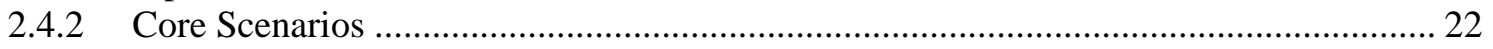

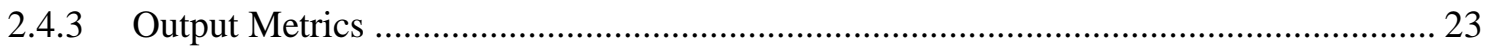

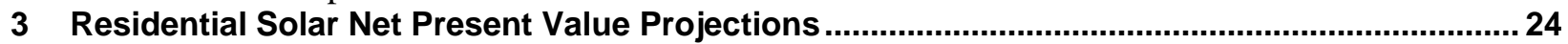

3.1 Modeled Residential Distributed Solar NPV in 2017 ........................................................... 24

3.2 Projected Residential Distributed Solar NPV in 2027 ...................................................... 25

3.3 Projected Residential Distributed Solar NPV in 2050 ....................................................... 27

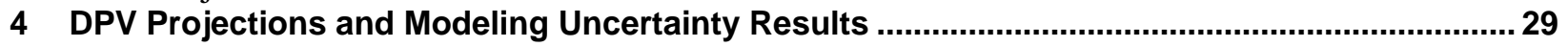

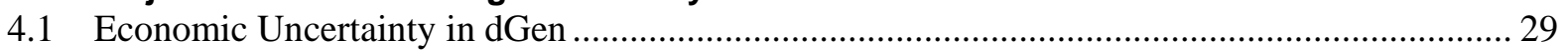

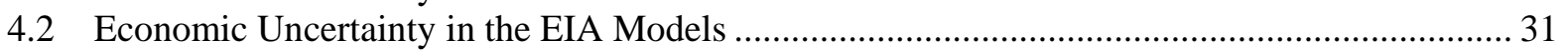

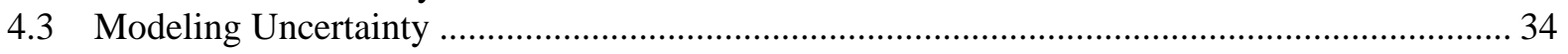

4.3.1 Differences between Modeling Approaches ........................................................ 34

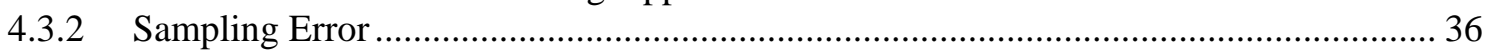

4.3.3 Retrospective Analysis ........................................................................................ 39

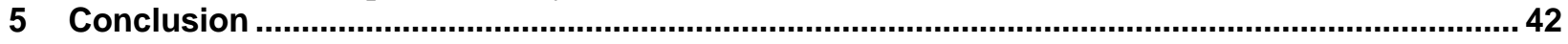

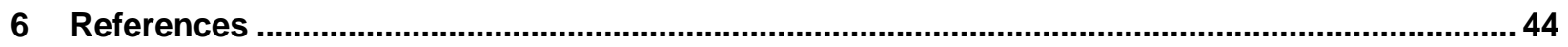

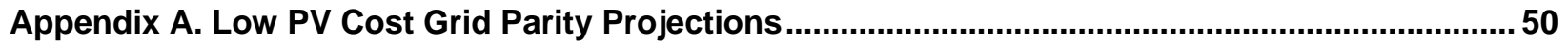

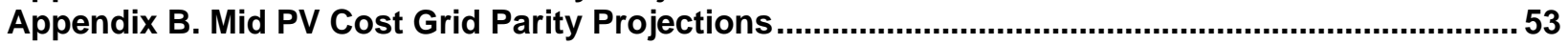

Appendix C. High PV Cost Grid Parity Projections ..........................................................................56

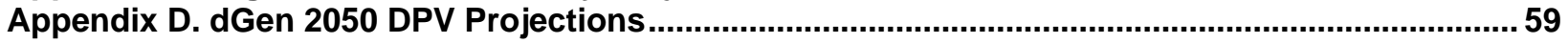

Appendix E. EIA Cash Flow Adoption Model DPV Projections................................................61 61

Appendix F. EIA Hurdle Rate Adoption Model DPV Projections ................................................62 


\section{List of Figures}

Figure ES-1. Projected net present value of a 5-kW Residential Solar System in 2050 by County and ATB Cost Scenario ...................................................................................................................... vii

Figure ES-2. Reference Case DPV projections by modeling approach.................................................

Figure ES-3: Variance in New York (left) and national-level (right) results for 10 simulations for one agent per county-sector, each using a random seed .............................................................. xi

Figure 1. Cumulative DPV penetration by sector, nationally, and for the 10 most-populated states ........... 2

Figure 2. Willingness-to-pay curves for residential and commercial agents ........................................... 10

Figure 3. Installed cost projections ..................................................................................................... 12

Figure 4. New construction DPV penetration rate curves for selected payback times ............................. 15

Figure 5. Simulated NPV for 5-kW resiential system by county in 2017..............................................24

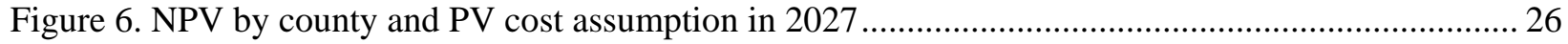

Figure 7. NPV by county and PV cost assumption in 2050 ............................................................. 28

Figure 8. Cumulative installed capacity by core scenario, 2014-2050, according to NREL's dGen Model

Figure 9. Cumulative installed capacity by core scenario, 2014-2050, according to the EIA Cash Flow

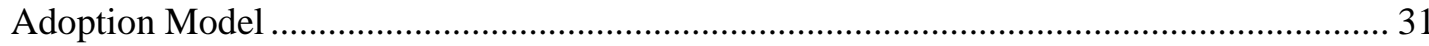

Figure 10. Cumulative installed capacity by core scenario, 2014-2050, according to the EIA Hurdle Rate

Adoption Model ....................................................................................................................... 32

Figure 11. Comparison of DPV adoption projections for the Reference Case by model ......................... 35

Figure 12. Variance in state (New York) and national-level simulations for 10 random seeds for one agent

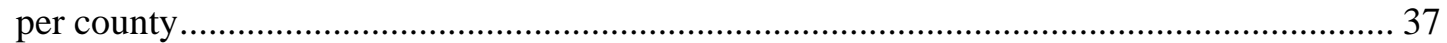

Figure 13. Sequential projection of annual installations nationally as function of available data .............. 40

\section{List of Tables}

Table ES-1. Comparison of Key Reference Case Outputs by Model for 2050 ........................................ ix

Table 1. Grid Parity and dGen Financial Parameters............................................................................... 8

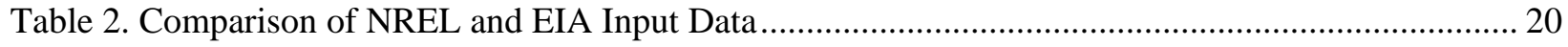

Table 3. Eight Core Annual Energy Outlook 2017 Scenario Descriptions................................................ 22

Table A-1. Projected State-level Grid Parity Metrics for Low Cost scenario............................................ 50

Table B-1. Projected State-level Grid Parity Metrics for Mid Cost scenario ............................................. 53

Table C-1. Projected State-level Grid Parity Metrics for High Cost scenario ........................................... 56

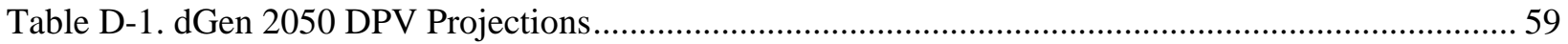

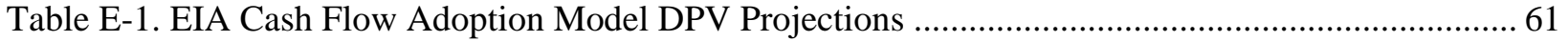

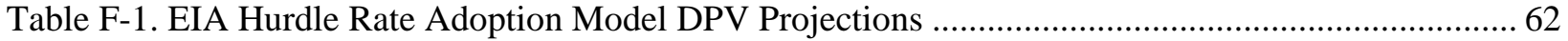




\section{Introduction}

\subsection{Overview of Distributed Solar in the United States}

Distributed solar photovoltaic (DPV) systems constitute an important and growing source of new electrical generation in the United States. DPV generates energy in behind-the-meter applications for residential, commercial, and other end-user sectors, ${ }^{4}$ reducing those sectors' net electrical demand, and thereby reducing electricity bill expenditures. However, as DPV deployment grows, it disrupts two historical tenets of the U.S. power system. First, the traditional U.S. power system has consisted of large, centralized baseload generators connected hub-and-spoke via transmission and distribution lines. DPV projects are typically smaller capacity and sited behind-the-meter, so either their generation directly offsets on-site consumption or excess energy is exported to the grid. Second, utilities have historically financed most infrastructure costs with charges apportioned among customers on a volumetric basis. By reducing retail electricity sales through on-site generation, DPV circumvents the revenue channels on which utilities typically rely for cost recovery. These forces make accurately projecting the adoption of DPV and analyzing its potential market impacts increasingly important. In particular, should residential PV costs continue to decline, distributed solar generation may be increasingly cost-competitive with gridsourced electricity.

Financial comparisons between the costs of distributed solar generation and grid-sourced electricity is often referred to as "grid parity". Many researchers have analyzed this dynamic postulating that, once the levelized cost of solar generation becomes more competitive than purchasing electricity from the grid, customers adoption might accelerate. To the extent that regulatory mechanisms do not decouple the reduced retail sales from fixed infrastructure cost recovery, continued DPV adoption could induce a feedback loop where the revenue base to pay off infrastructure decreases, prompting higher rates and thereby spurring additional DPV adoption.

Thus, the amount of distributed solar adopted is increasingly pertinent for power systems planning, but also highly uncertain. In this report, we consider two categories of uncertaintyeconomic and modeling uncertainty. On the economic side, numerous time-dependent factors, both exogenous and endogenous, influence DPV expansion. These include but are not limited to future solar capital costs, capital and operating costs of competing technologies, macroeconomic factors such as inflation and load growth, and future energy policy.

However, even if future market conditions could be perfectly known, projections would still be uncertain because mathematical models are inherently imprecise. Imprecision is introduced through imperfect input data (e.g., the exact number of suitable roofs for solar or the exact profile of energy consumption). Significant portions of DPV adoption models are simply incompletely parameterized, as technology adoption is inherently a function of human behavior,

\footnotetext{
${ }^{4}$ Distributed generation may also be located in front-of-the-meter applications, which are directly tied to the distribution network and therefore do not offset a user's consumption. This report does not consider such installations.
} 
and not deterministic. Though no model can perfectly forecast market outcomes, increased transparency regarding the possible range of outcomes can inform planning decisions.

\subsection{Historical Trends}

While less than 1\% of all electricity generation in the United States in 2016 came from DPV (EIA 20175), as illustrated in Figure 1, the technology has experienced rapid growth in recent years both in the commercial and residential sectors. In 2016 alone, over 4 GW of DPV capacity was installed, a 25\% year-on-year increase and more than seven times the capacity installed in 2010 (GTM 2017). By year-end 2017, over 1.6 million DPV installations had been completed (GTM 2017).

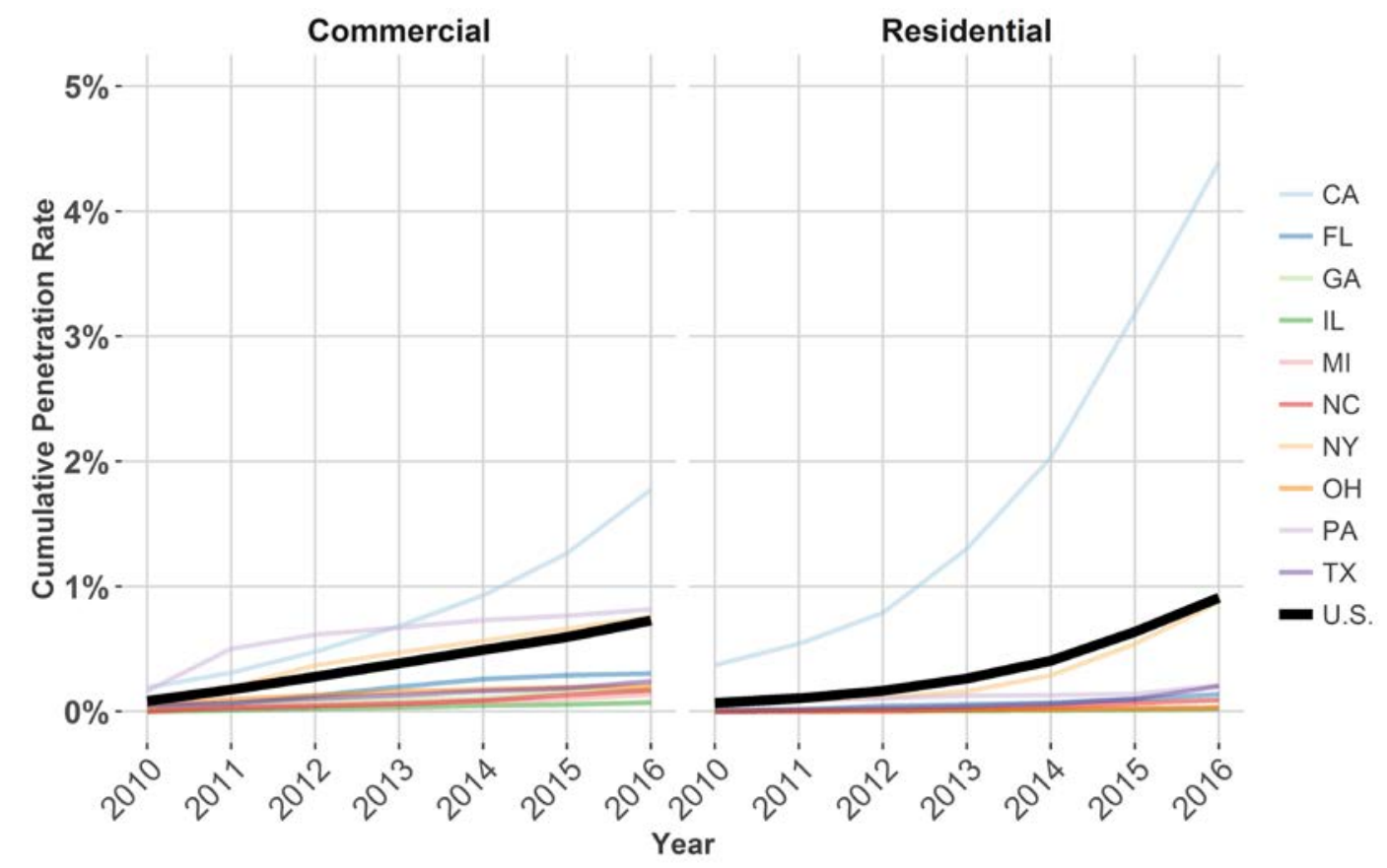

Penetration is defined by the count of DPV systems as a fraction of business establishments and residential housing units (U.S. Census Bureau 2017).

Figure 1. Cumulative DPV penetration by sector, nationally, and for the $\mathbf{1 0}$ most-populated states

Current deployment of DPV in the United States is primarily concentrated among a few states with high retail costs of electricity, policies encouraging the expansion of DPV, or favorable solar resource. Though 27 states in United States had at least 50 megawatts (MW) of DPV capacity as of 2016, seven states (California, New Jersey, Massachusetts, Arizona, New York, Maryland, and Hawaii) accounted for $80 \%$ of the U.S. installed capacity (GTM 2017).

California, a highly populated state, is the nation's leader in installed capacity, with over 6,500 MWDC of capacity as of 2016. Deployment in California can be explained by a combination of strong solar resource, some of the nation's highest cost of electricity (OpenEI 2017), and a long history of solar-related policy (DSIRE 2017).

\footnotetext{
${ }^{5}$ See "What is U.S. Electricity Generation by Energy Source?” data for April 2017, https://www.eia.gov/tools/faqs/faq.php?id=427\&t=3.
} 
New Jersey has the second-most cumulative installed DPV, with over 1,600 MWDC. Compared to the national average, New Jersey has below-average solar resource. State policy-including a renewable portfolio standard, a solar carve-out and an accompanying solar renewable energy credit (SREC), mandatory net metering, and other polices-help explain high DPV deployment. A similar rationale explains high deployment in three of the other top-seven statesMassachusetts (1,441 MW), New York (848 MW), and Maryland (603 MW).

As an early leader in DPV adoption, Hawaii has the highest residential market penetration, with solar PV installed on nearly one in five homes (Gorak 2016). The state also has the nation's highest cost of electricity, and retail prices are largely set by the cost of imported oil (Mulkern 2013). In contrast, Arizona's declining policy support and lower cost of electricity are offset by the state's exceptional solar resource. Arizona (968 MW) is also notable for evolution of its solar policy; for example, it revised the valuation of solar energy under its net metering policy as a reaction to increasing deployment levels (DSIRE 2017)

As the DPV market matures, early state leaders in the residential sector are showing signs of decelerating growth and new focal points are emerging. For example, 2017 was the first year in which new residential capacity nationally did not exceed the previous year's (GTM 2017). Some of the decreased demand for DPV instead is being channeled to community solar and other shared solar arrangements (GTM 2017). At the same time, falling PV prices are fueling growth in many states with currently modest levels of deployment. At least eight states-Colorado, Delaware, Florida, New Mexico, Oregon, Pennsylvania, Texas, and Vermont-are projected to have at least 25\% year-on-year growth and more than $10 \mathrm{MW}$ in annual deployment in the residential sector (GTM 2017). Conversely, it is important to note that DPV is not a widespread phenomenon in several states. For example, through 2017, approximately 15 states had less than $10 \mathrm{MW}$ of installed residential capacity. Low retail prices and enacted policy in those states likely explain the lack of adoption. Moezzi et al. (2017) also note that residential solar is not viewed as a universally positive technology by all households.

\subsection{State and Federal Policy}

Expansion of DPV in the United States, and renewable energy more broadly, has largely been driven by a blend of policy at the federal and state levels. These include both financial incentives (e.g., federal investment tax Credit (ITC)), but also state-level or utility-level policies to incentivize renewable energy deployment (e.g., renewable portfolio standards and net energy metering). The nominal rationale for these public expenditures and policies has been that they would foster learning and innovation that enables DPV technologies to reach parity on an unsubsidized basis (Nemet 2009; Taylor 2008). Though it is difficult to identify the effect of any individual policy, rapid decreases in PV prices have prompted redesign of policy that can enable distributed generation to compete freely in markets.

Many financial incentives exist in state or substate jurisdictions to incentivize DPV adoption. However, two incentives - the ITC and solar renewable energy credits (SRECs) - currently have the greatest impact on the national market outlook. The ITC, which was enacted in 2005, provides a credit of $30 \%$ of qualifying costs for select energy technologies, including solar energy. The ITC is realized once a system begins operation, and it vests over a five-year period (Bolinger et al. 2009). Credit for the ITC is monetized through reduced tax liability. In at least two cases, the ITC may not be monetized for the full value. First, some commercial and 
residential owners may not have sufficient tax liability to fully monetize the credit's full value, and in these cases, "tax equity" investors can provide monetization at a cost. Second, in cases of third-party ownership, the full ITC value may not be passed through to the consumer in the form of lower prices (Dong, Wiser, and Rai 2014). The credit has gone through several extensions since its inception, and the current statute allows phase-down to $10 \%$ for commercially owned systems and 0\% for residential systems in 2022 (Mai et al. 2016). Expiration of the ITC is expected to represent a significant headwind to DPV expansion post-2022.

SRECs are a production-based incentive generated for each megawatt-hour of solar electricity produced. These certificates are legislated by state renewable portfolio standards and represent a market-facing compliance mechanism for valuing the environmental benefits of solar generation. The credits are bought and sold among entities seeking compliance with renewable procurement regulations or voluntary goals. Currently, Delaware, Maryland, Massachusetts, New Jersey, Ohio, Pennsylvania, and Washington, D.C. have established SREC markets. SREC prices are extremely volatile and their value varies substantially by state, based on supply and demand conditions. As of November 2017, prices ranged from \$3.50 per megawatt-hour (MWh) (Ohio) to $\$ 410 /$ MWh (District of Columbia) (SRECTrade 2017). Though the future value of these credits is uncertain, for key markets they provide substantial economic benefits to DPV system owners.

\subsection{Economics and Market Impacts}

The rise of distributed solar and other demand-side technologies has prompted utilities and regulators to reconsider how the costs of operating the electrical grid are passed along to consumers via retail electricity tariffs. Increased deployment of DPV impacts electrical systems in many ways, such as lower electricity demand and thus reduced retail sales by utilities (Bird et al. 2013). Flat or reduced revenue challenges the recovery of costs for utility capacity and energy (i.e., the existing generation fleet) investments, as well as for transmission and distribution assets, which comprise a substantial portion of retail costs (Fares and King 2017).

As DPV deployment rises, there is growing consensus of the need to establish an efficient and holistic compensation framework for determining the value of DPV generation and other grid services provided. Historically, net energy metering (NEM) has been the primary billing mechanism used to account for DPV value. Though there are many possible formulations of NEM, in its simplest expression, it compensates a system owner for generation not used on-site, at a set rate, typically the retail rate. NEM policies have contributed to the growth of DPV markets by providing a reliable and intuitive metric for the expected revenues of a DPV system. NEM availability is currently widespread, though the landscape is quickly shifting; there were 41 state-level policy actions in 2017 relating to distributed generation-the majority of which seek to revise distributed generation compensation downward (NCCETL 2017).

The primary critique of net metering policies is that it could allow PV customers to pay less than their full share of fixed utility infrastructure costs (e.g., transmission, distribution, and utility operations), thereby raising retail rates for remaining rate payers. Others find the notion of compensating distributed generation at retail rates inefficient, as the opportunity cost of wholesale energy is a fraction of the current cost of DPV. Proponents of net metering argue that, at least at low levels of solar penetration, solar customers provide net benefits to the grid (e.g., avoided environmental damages, resiliency, and avoided infrastructure costs) that exceed the 
retail value. Finally, other research explores the long-term dynamic, with cause for caution. For instance, the impacts of net metering on retail prices are likely overshadowed by other uncertainties, such as misforecasting the price of natural gas (Barbose 2017).

Effectively evaluating the value of distributed solar is a complex and evolving endeavor because solar's value varies by level of solar penetration, local grid characteristics, and coincidence of solar generation with regional load profiles (Bird et al. 2013). The more straightforward DPV benefits include the energy and capacity value of solar generation, but the more-nuanced benefits may not be captured in retail rates (e.g., deferral of transmission and distribution investments, reduced transmission losses, risk hedging, and environmental and health benefits). Costs include integration of PV generation into planning, interconnection to the grid, and capital cost differences between DPV and comparable utility-scale sources (Bird et al. 2013). Ensuring retail rates provide a full account of the financial and non-financial benefit is both a contentious topic and one for which stakeholders are unlikely to find easy solutions (Wood et al. 2016).

Looking forward, increased levels of DPV penetration—and variable energy resources more generally-are likely to raise new grid integration issues that, if unaddressed, could increase the societal cost of solar generation. Affecting integration at the transmission level or the bulk power level are issues relating to the non-dispatchable nature of solar energy, and a lack of visibility into distributed generation for system operators. These current limitations could lead to curtailment of solar generation (Cole et al. 2016) and declining capacity and generation value (Mills and Wiser 2012; Denholm, Clark, and O’Connell 2016). Addressing these issues would likely require additional levels of grid coordination and flexibility, including, market transformation, enhanced communication between load and distributed resources, additional transmission linkage, energy storage, and others. Conversely, distributed-level grid integration issues include investment in grid infrastructure to facilitate bi-directional power flow, regulatory improvements to interconnection processes, and modernized compensation schemes that reflect distribution-level costs and benefits (Palmintier et al. 2016; Hledik, Lazar, and Schwartz 2016; De Martini, Kristov, and Schwartz 2016).

\subsection{Measuring Grid Parity}

The rapid decline of DPV costs has prompted many to assert that electricity generated from DPV may soon reach cost competitiveness with retail electricity prices, thereby increasing the likelihood of future large-scale deployment across the United States (IRENA 2012; Reichelstein and Yorston 2013; Shahan 2014; Jacobs 2014; Honeyman 2016). Grid parity signifies when a novel technology has achieved cost competitiveness with incumbent technologies operating on the grid. For utility-scale technologies, parity describes the ability of an energy technology to sell electricity at a price equal to or lower than other technologies in the same wholesale market. For behind-the-meter technologies such as DPV, grid parity refers to the point in time when it is economically preferable for a residential or commercial customer to install a DPV system to selfgenerate electricity rather than purchase some or all their electricity from the grid.

Most published grid parity evaluations focus on the PV cost needed to provide a levelized cost of energy equal to the average cost of retail electricity. Some analyses (Reichelstein and Yorston 2013; Shah and Booream-Phelps 2014) include incentives in their cost calculations to reflect the real-world market environment, while other studies exclude incentives under the assumption that 
current incentives are transient, focusing on long-term (i.e., unsubsidized) economic comparisons (Farrell 2012; Shah and Booream-Phelps 2015; Hagerman, Jaramillo, and Morgan 2016).

Grid parity metrics put forth in this report address a shortcoming in the literature by which DPV competitiveness is analyzed solely on levelized costs and fails to capture important nuances in the economic evaluation. Here, we calculate the savings relative to the avoided cost of retail electricity (EIA 2013). These marginal values vary geographically according to the retail rate structure, availability of net energy metering, and existing incentives (Ong, Denholm, and Clark 2012; Honeyman 2016; Bevan and Donovan 2017). When using this more holistic approach, Honeyman (2016) found that in a business-as-usual scenario, 20 states reached grid parity in terms of first-year bill savings in 2016. However, when assuming including a \$50 monthly fixed charge that was meant to ensure fixed infrastructure cost recovery, Honeyman (2016) found that DPV would be at parity in only two states in 2016. Bevan and Donovan (2017) found that comparing DPV's LCOE to a static average electricity rate fails to account for dynamic residential retail tariffs (e.g., time-of-use rates) that vary throughout the year. To address this deficiency, they proposed a new threshold, "firm power parity," that is achieved when energy systems (DPV potentially coupled with storage) provide a service (electricity provision) at an equal or lower cost than conventional service providers.

Widespread grid defection stemming from distributed solar diffusion is possible, though unlikely, due to the rapidly evolving electrical grid. With new information technology and metering, grid costs can be accounted for far more accurately. Nevertheless, as technology costs continue to decline, market share of distributed generation may increase. Ultimately, we argue that the customer decision to adopt DPV (or not) is better modeled using net present value (NPV), as opposed to a levelized cost comparison. Grid parity is not a monolithic construct, and parity estimations are influenced by a variety of factors. These could include comparisons with other generation sources, such as utility-scale solar or utility-managed community solar.

While many grid parity estimates focus on levelized cost (with many excluding subsidies and the impacts of tariff structures), this analysis examines whether DPV has reached parity from the point of the view of the consumer and considering the lifecycle economics of the system, including revenue impacts driven by real-world retail tariff structures and the projected availability of incentives and net metering. To that end, we project county-level NPV for 2017, 2027, and 2050 for three long-term DPV cost trajectories (Section 2). Taken together, these projections provide a more accurate outlook of where and when DPV markets may emerge and grow. 


\section{Methodology}

This section provides an overview of the methods, data, and assumptions used in the two analyses for this study. The first analysis conducts county-level projections of grid parity completed using NREL's SAM model (Section 2.1). The second analysis exercises three DPV deployment models: NREL's dGen (Section 2.2), EIA's Cash Flow Adoption Model (Section 2.3), and EIA's Hurdle Rate Adoption Model (Section 2.3), to contrast each model's projections under different macroeconomic conditions. Parameters of the grid parity analysis are also stated below.

\subsection{Grid Parity Analysis: Data and Assumptions}

We evaluate the cost competitiveness of a hypothetical residential 5-kWDC south-facing roofmounted DPV system for each county in the continental United States using the NPV of projected system cash flows (\$) assuming a 5.4\% discount rate. This method evaluates the combined effects of net energy metering, retail tariff structures, incentives, and the time value of money on lifetime DPV system economics.

This analysis uses NREL's System Advisor Model Version 2017.9.5 (Blair et al. 2016) and PVWatts (Dobos 2014) calculator, along with the following techno-economic assumptions, to determine the lifetime economics by means of a discounted cash flow model.

\section{Solar Resource}

County-level solar resource profiles are based on the centroid of each county in the continental United States. SAM uses Typical Meteorological Year (TMY) data based on average hourly solar radiation values and meteorological conditions from NREL's National Solar Radiation Database (NSRDB) to determine each location's solar resource and potential energy production.

\section{System Size and Performance}

For consistency, all distributed solar systems in this analysis are south-facing 5-kWDC fixed-axis roof-mounted arrays that are tilted to match each location's latitude. All systems are modeled to use standard mono-silicon modules that are roughly 15\% efficient. Systems include 96\% efficient inverters and are modeled with $14 \%$ total system losses and $0.5 \%$ annual system degradation rates.

\section{System Cost}

DPV capital cost $\left(\$ / \mathrm{W}_{\mathrm{DC}}\right)$ and operating and maintenance $(\mathrm{O} \& \mathrm{M})$ cost $(\$ / \mathrm{kW}$ DC-year) are based on NREL’s 2017 Annual Technology Baseline (ATB) (NREL 2017). The ATB’s High, Mid, and Low solar cost projections are used to determine how sensitive parity metrics are to potential cost changes. For reference, capital costs are $\$ 2,932 / \mathrm{kW}$ in 2016 and by 2050 the Low scenario projects costs fall to $\$ 967 / \mathrm{kW}$, the Mid scenario projects cost fall to $\$ 1,150 / \mathrm{kW}$, and the High scenario projects cost remain constant at $\$ 2,932 / \mathrm{kW}$. 


\section{Financing}

Financing assumptions, including assumptions about debt fraction, loan term, loan rate, weighted average cost of capital, inflation rate, and discount rate are based on residential solar parameters from the 2017 ATB (NREL 2017). Financial data from the ATB are derived from expert elicitation, using a common set of financial parameters to evaluate all energy technologies.

Table 1. Grid Parity and dGen Financial Parameters

\begin{tabular}{lc}
\hline Category & Value \\
\hline Loan term & 20 years \\
Loan rate & $5.4 \%$ \\
Debt fraction & $60 \%$ \\
Discount rate & $10 \%$ \\
Tax rate & $40 \%$ \\
Annual inflation & $2.5 \%$ \\
\hline
\end{tabular}

\section{Incentives}

The 30\% ITC is modeled to decrease as currently defined in the Consolidate Appropriations Act, 2016 (i.e., it expires for residential DPV owners on December 31, 2021). Available state-level incentives were compiled using the DSIRE database, though no substate incentives are modeled. Specifically, we modeled current state-level incentives to linearly decline in value to zero through 2027. This specification is based on an outlook in which very few states have wellspecified renewable portfolio standard policies through 2050, as well as the modeling assumption that as DPV cost competitiveness increases, states would accordingly phase-out incentives.

\section{Tariff Structure}

Utility rates for the NPV calculation are determined for each county by first determining the number of electric service providers in each county and then identifying which utility served the largest number of residential customers based on EIA-861 survey data. ${ }^{6}$ After selecting eligible residential tariffs for a single-family homeowner with DPV from NREL's Utility Rate Database, ${ }^{7}$ the (eligible) tariff that minimized the customer's electrical bill without solar is selected. The assumption that consumers selects tariffs that minimize their bills implies customers actively consider the tariff options available to them, which may not be true. Also, it is a conservative assumption, as it minimizes the potential solar bill savings (as compared to savings with non-optimal tariffs). Approximately $80 \%$ of load is covered by utilities with rates in the rate database; for counties without coverage, rates from the nearest service territory are used.

Statutes in place at the time of publication were used to determine the availability of net energy metering for each year and location. Most of these statutes do not explicitly delineate the date of

\footnotetext{
${ }^{6}$ See "Electric Power Sales, Revenue, and Energy Efficiency Form EIA-861 Detailed Data Files," data for 2016, August 14, 2017, https://www.eia.gov/electricity/data/eia861/.

${ }^{7}$ The Utility Rate Database is hosted on the Open Energy Information (OpenEI) platform at https://openei.org/wiki/Utility_Rate_Database.
} 
NEM expiration, though many do specify sunset conditions based on distributed energy resources reaching a set percentage of non-coincident load or some other measure of penetration. For states with NEM constraints, we simulate the year of expiration based on projections from the dGen model. For states with NEM but without specified expiration clauses, NEM is modeled to exist indefinitely and distributed generation is valued at the full retail rate. In states and years in which NEM is modeled to not exist, because it either expired or never existed in the first place, DPV systems are compensated at the retail rate for self-consumed generated and at wholesale rates for exported generation. Future wholesale electricity prices are based on wholesale electricity price taken from the Reference case in the 2017 NREL Standard Scenarios (Cole et al. 2017) and using NREL’s Regional Energy Deployment System (ReEDS) model (Eurek et al. 2016).

\section{Energy Consumption}

A single, residential hourly load profile-from the U.S. Department of Energy's Buildings Technology Office's data set of Commercial and Residential Hourly Load Profiles for all TMY locations in the United States that is hosted on NREL's OpenEI platform (DOE 2013)—was selected to represent all counties in a given state. Future work should examine the interaction of regional load shapes with distributed PV economics.

\subsection{The dGen Model}

\subsubsection{About the Model}

The dGen model uses an agent-based simulation of customer adoption of DPV from 2014 to 2050. After initial agent creation, DPV adoption trends are resolved over two-year time intervals through a multi-step process that assesses the technical, economic, and market viability of adoption, translating these metrics into county-level adoption rates.

During agent creation, each county in United States is seeded with sets of residential, commercial, and industrial agents, each instantiated at population-weighted random locations within the county's geographic boundaries. Agents are referenced against geographic data sets to establish a load profile, solar resource availability, a feasible utility rate structure, and other techno-economic attributes specific to the agent's location. Each agent is assigned a weight that is proportional to the number of customers the agent represents in its county. In this context, agents can be understood as statistically representative population clusters and do not represent individual entities.

At each time step, a cash flow analysis estimates the payback period and net present value of a solar energy system sized according to rooftop availability and energy consumption. Financial calculations are inclusive of state net metering policies, as well as prominent state and federal financial incentives.

After establishing an agent's payback period through cash flow analysis, the model estimates market adoption in two stages, based on the Bass Diffusion Model (Bass 1969) and associated willingness-to-pay literature. In the first estimation stage, annual adoption counts by state and sector from 1999 to 2016 are fitted to the Bass Diffusion Model using the non-linear least squares method (Srinivasan and Mason 1986; Dong, Sigrin, and Brinkman 2017). The initial year of diffusion is defined as the first year of at least five system installations, and starting 
conditions for the non-linear least squares regression are obtained via a genetic algorithm. The first stage is only used to estimate diffusion growth parameters (i.e., $p$ and $q$ ), and not overall market potential (i.e., $m$ ), which is estimated separately via consumer willingness-to-pay surveys (Paidipati et al. 2008; Sigrin and Drury 2014). The market potential parameter can be interpreted as the terminal fraction of technically eligible agents that would adopt the new technology at a given payback period level.

This formulation embodies several conceptual assumptions about the nature of technology adoption. Based on the "diffusion of innovations” framework (Bass 1969; Rogers 2003), we assume new technologies are sequentially adopted by different classes of adopters (i.e., consumers). This framework posits that early adopters are willing to accept higher payback periods in exchange for early access to the technology. Once costs have declined further, mainstream adopters drive rapid growth of the technology until market penetration is mostly reached. After this point, late adopters contribute to small gains in growth. For example, as shown in Figure 2, at 15 years payback, 12\% of potential residential agents and 1\% of possible commercial agent would be expected to (eventually) adopt the distributed energy resource system. The willingness-to-pay curve also enforces the logic that, while economic factors are the primary divers of DPV adoption, complete market saturation is never reached because a small number of customers do not find beneficial use for the technology.

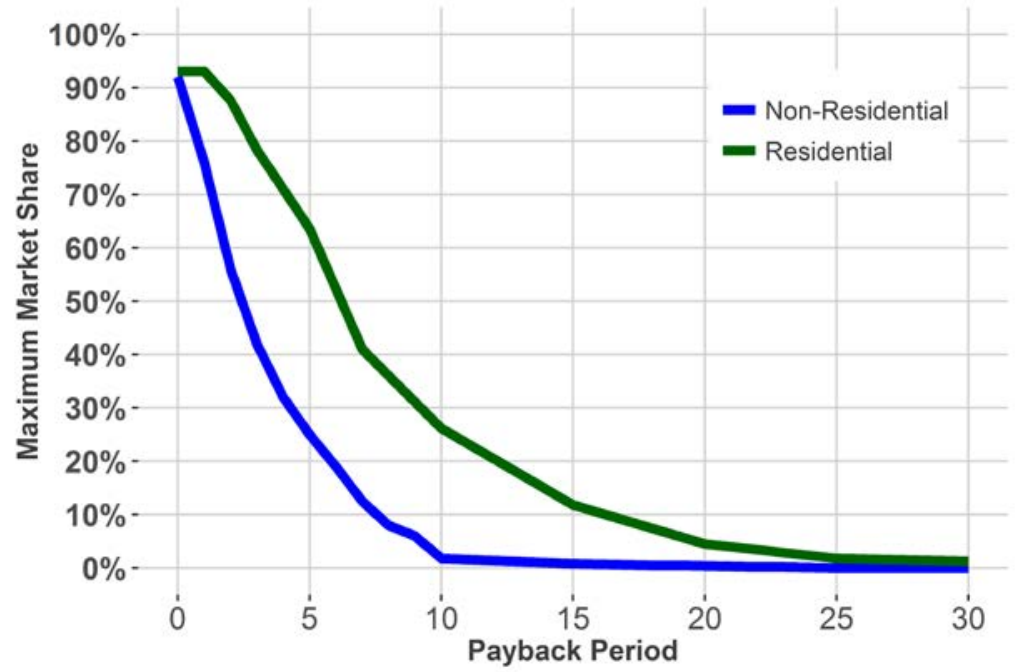

Figure 2. Willingness-to-pay curves for residential and commercial agents

\subsubsection{Data and Assumptions}

The dGen model uses the following data sets and assumptions.

\section{Agent Characteristics}

County geographic boundaries and county demographics derived from the 2010 U.S. Census ${ }^{8}$ are used in agent instantiation. From these data, the number of owner-occupied detached buildings in the county, which typically constitute about $70 \%$ of all buildings, is used to determine the

${ }^{8} 2010$ Census Summary File 1; see “U.S. Geographic Summary Data and Boundary Files,” National Historical Geographic Information System, http://www.nhgis.org. 
number of constituents represented by each residential, commercial and industrial agent. Each agent is assigned a population-weighted random location, sampled from a $200 \mathrm{~m}$ x $200 \mathrm{~m}$ grid for the continental United States that correlates with several attributes by means of a simple spatial intersection with spatially resolved data sets (see Sigrin et al. 2016 for details).

Model growth parameters are estimated from historical adoption data from the last 20 years (1999-2017) to calibrate and validate projected model growth parameters and current model starting conditions (i.e., the existing base of installation). Existing adoption counts are sourced jointly from the LBNL OpenPV Tracking the Sun (LBNL 2017) data set for adoption pre-2010 and from the GreenTech Media Solar Market Insight report data set (GreenTech Media 2017) for more recent years (2010+). The Tracking the Sun report contains system-level interconnection records compiled from various state and utility incentive programs; however, it is not considered a comprehensive source of existing installations, as more and more systems are interconnected without state or local incentives.

\section{Solar Resource and Roof Characteristics}

Solar resource data are sourced from the NSRDB 10-km Gridded Hourly Solar Database (George et al. 2007), which consists of hourly solar radiation estimates for approximately 91,500 grid cells in the continental United States at a $10-\mathrm{km}^{2}$ spatial resolution. The hourly radiation values for each grid cell are based on typical meteorological year data (TMY3) (DOE 2013) from 1998 through 2005.

Roof characteristics, including unshaded area, azimuth, and slope, are important determinants of a building's technical suitability for solar. Using lidar-based aerial imagery (Gagnon et al. 2016), rooftop characteristics are assigned to agents via a stochastic process as documented in Sigrin et al. (2016, Appendix A).

\section{Retail Electricity Rates}

Utility rates are sourced from the NREL's Utility Rate Database. Rates are assigned to agents based on a ranking algorithm that considers their location, sector, and voltage limits. If multiple tariffs are available, agents are assigned the tariff with the lowest cost of energy from those available to their class. Also, in the case of missing utility coverage, agents are supplied rates from the nearest covered utility.

\section{Electricity Load Profiles and Load Growth}

Annual electricity consumption by agent is determined by sampling with replacement from EIA’s Residential Energy Consumption Survey (RECS) (EIA 2009) and EIA's Commercial Building Energy Consumption Survey (CBECS) (EIA 2012). The sampling is filtered on the region and is proportional to the sample weights. Electrical load is further constrained to match county-level customer counts and annual loads from Ventyx (2012). To ensure county-level load constraints are maintained, the sampled electric-load values are treated as intensity measures rather than absolute values, and agent-level demand is scaled appropriately. Though this method is inexact, it preserves agent-level variability in consumption and ensures county-level aggregate consumption is accurate.

Hourly normalized residential and commercial load profiles are used to scale the agent's annual consumption based on local weather patterns. Profiles are simulated by weather station $(n=79)$ 
for 15 commercial building types and one residential building type (Ong et al. 2012; Davidson et al. 2015). All residential agents in a single region thus are assigned a single hourly consumption reflecting weather patterns, where annual electrical consumption is sampled from RECS microdata. Because commercial and industrial agents have more profiles from which to choose, these agents are assigned consumption patterns by first mapping building types to the primary building activities and then sampling from CBECS microdata to determine annual electrical consumption.

\section{Technology Costs and System Specifications}

PV costs and technical performance were sourced from the 2017 ATB Mid Cost scenario (NREL 2017). As shown in Figure 3, residential installed costs in this scenario reach $\$ 1,475 / \mathrm{W}$ in 2030 and $\$ 1,150 / \mathrm{W}$ in 2050, and with commercial installed costs of $\$ 1,176 / \mathrm{W}$ and $\$ 965 / \mathrm{W}$ in 2030 and 2050, respectively. Systems were modeled with a constant $0.5 \%$ annual degradation rate and 14.9-20.4 W/m² power density from 2016 to 2050. PV systems are sized heuristically to offset 95\% of consumption on an annual basis in states and years in which net metering is applied; otherwise, systems are scaled to offset $50 \%$ of consumption. These sizing ratios were selected based on observations of historic system sizing ratios (Davidson and Margolis 2015). However, in the Standard Scenarios 2018 version of dGen agents will select the optimal PV system size based on tariff structure and DPV generation value. PV system sizes are also constrained based on the agent's modeled roof size, when applicable.

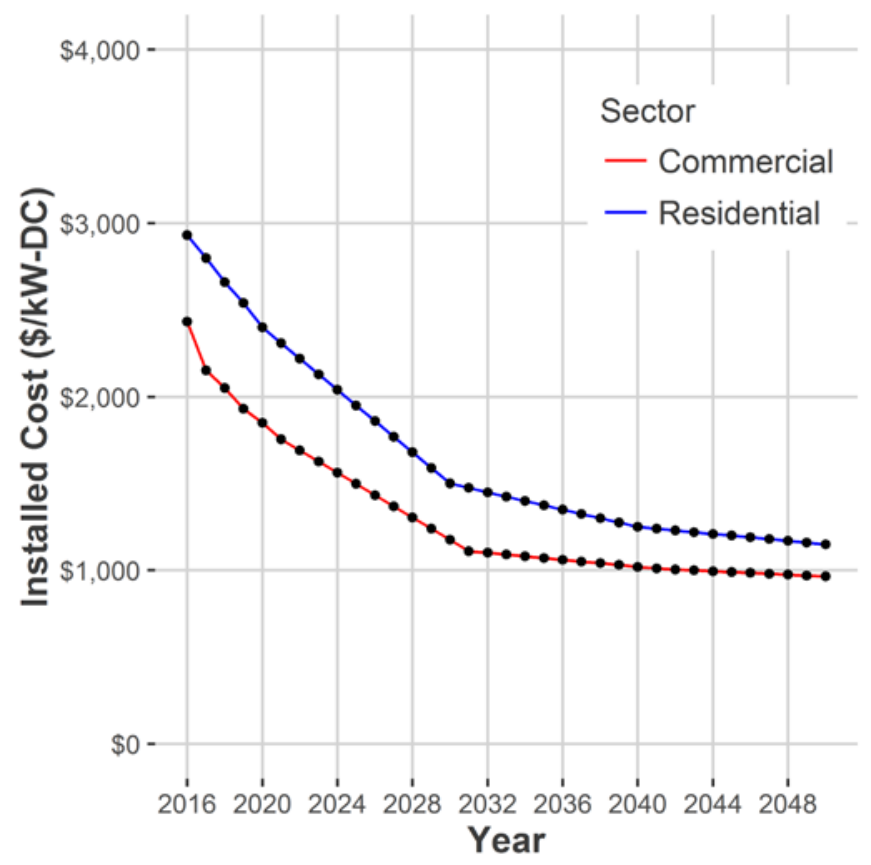

Cole et al. 2017

Figure 3. Installed cost projections

\section{Financing Terms}

Financial parameters are based on the 2017 ATB (NREL 2017) (Table 1). 


\section{Federal and State Incentives}

Though there are a wide range of existing financial and non-financial incentives for DPV owners, challenges to data collection mean dGen only represents federal-level and state-level incentives. At the federal level, the ITC, which currently provides a tax credit of $30 \%$ of installed costs, is the predominant incentive. It is expected to scale down to $10 \%$ for commercial and industrial agents and $0 \%$ for residential agents by 2022. Systems are also depreciated following the Modified Accelerated Cost Recovery System (MACRS).

Where applicable, state-level incentives were applied, though not at the substate level. Incentive types considered were production-based incentives, investment incentives, grants, rebates, and SRECs as captured in DSIRE. Where data were available and applicable, financial incentive calculations made use of system size limitations, incentive caps per project, and valid date range constraints. Where end dates were not known, state incentives are assumed to expire in 2027. Also, incentive values were modeled to linearly decrease to zero by their expiration date based on an assumed phase-out as solar deployment increases.

SRECs are difficult to reconcile within long-term projections because their historical prices are highly volatile, yet they also provide a compelling source of revenue for system owners to exclude from the model. Starting values for SRECS were referenced to the January 2017 average state bid price as reported by SRECTrade (SRECTrade 2017). In Delaware, SREC values referenced to the average weighted bid price from 2017 SREC Procurement auction. To be consistent with other modeling choices in the report and simplify assumptions, SREC values were modeled to linearly decline to zero by 2027 — though we acknowledge this as a simplifying assumption.

\section{Net Metering/Value of Generation}

State net metering policies were sourced from the Database of State Incentives for Renewables and Efficiency (DSIRE 2017). The complex and rapidly changing policy landscape prevents us from fully representing all current net metering implementations. We simplify by representing existing NEM policies by assuming all generation is credited at the retail electricity rate up to the stated system capacity limit. In states without net metering, or where NEM was modeled to have expired, self-consumed energy was valued at the retail rate and exported generation at the state's wholesale cost of electricity. This assumption is based on an emerging trend for states that have enacted net metering successor tariffs (i.e., net billing, valuing non-self-consumed energy at an avoided cost) (Proudlove et al. 2017). Wholesale electricity rates were based on the 2017 Standard Scenarios mid-case (Cole et al. 2017).

Future availability of net metering is an important, but also uncertain, determinant of overall market potential. State-level availability was projected endogenously within dGen based on current regulations specifying the policy limits, as a fixed date, cumulative state distributed energy resource capacity limits, or fraction of the state's peak demand. After being triggered, net metering was modeled as expired through 2050. In states with active net metering policies but no specified expiration, the policy is assumed to persist through 2050. 


\subsection{The EIA National Energy Modeling System (NEMS)}

EIA's National Energy Modeling System (NEMS) uses two different methodologies to project new DPV installations in the residential and commercial sectors. Like the dGen model, the Commercial Demand Module (CDM) uses a cash flow analysis coupled with a logistic penetration curve to project DPV penetration. Furthermore, CDM assumes all non-residential DPV is allocated to the commercial sector because the industrial sector does not model DPV generation separately in NEMS. The Residential Demand Module (RDM) used a similar approach prior to AEO2017. Beginning with AEO2017, however, the EIA Cash Flow Adoption Model for residential solar PV penetration was replaced by an econometric hurdle model using ZIP code-level input data. The Cash Flow Adoption Model remains as an option, allowing users to compare results from both models with the same set of input assumptions. The models are described in the next two sections.

\subsubsection{ElA Cash Flow Adoption Model (Commercial and pre-AEO2017 Residential)}

The Commercial Demand Module (CDM) uses a 30-year cash flow analysis that determines the number of new solar installations in each year based on their projected economic return. For solar installations on newly constructed commercial buildings, penetration rates are calculated based on the number of years required to achieve investment payback using an internal rate of return approach. The calculations include the costs (down payments, loan payments, maintenance costs, and fuel costs) and returns (tax deductions for expenses and depreciation, tax credits, and energy cost savings) from the investment. The approach used by the Residential Demand Module (RDM) prior to AEO2017 defines investment payback as the number of years required to achieve a positive cash flow rather than using internal rate of return.

Calculating the payback times with internal rate of return gives greater weight to financial costs and benefits that are incurred or received earlier in the cash flow horizon. For residential new construction, DPV investments are financed through the home mortgage, with the homeowner receiving a tax savings in the year following the payment that are relative to home mortgage deductibility. The NEMS Macroeconomic Activity Module determines mortgage rates.

DPV penetration is calculated as a function of the payback period and an assumed maximum penetration limit. The penetration function for PV installations is assumed to have a logistic or Scurve shape as shown in Figure 4, with slow initial penetration followed by rapid growth that eventually tapers as the technology matures. For AEO2017, penetration was limited to 75\% of newly constructed buildings, even for investments with paybacks less than one year, as distributed generation is assumed to be inappropriate for some buildings regardless of payback time. Penetration into existing buildings is assumed to be limited to a much lower rate due to the added complexities of installing a distributed generation system onto an existing building. The limit is the lesser of either $0.5 \%$ or $10 \%$ of the new construction penetration rate for the CDM, and the lesser of either $0.5 \%$ or $2.5 \%$ of the new construction penetration rate for the RDM. 


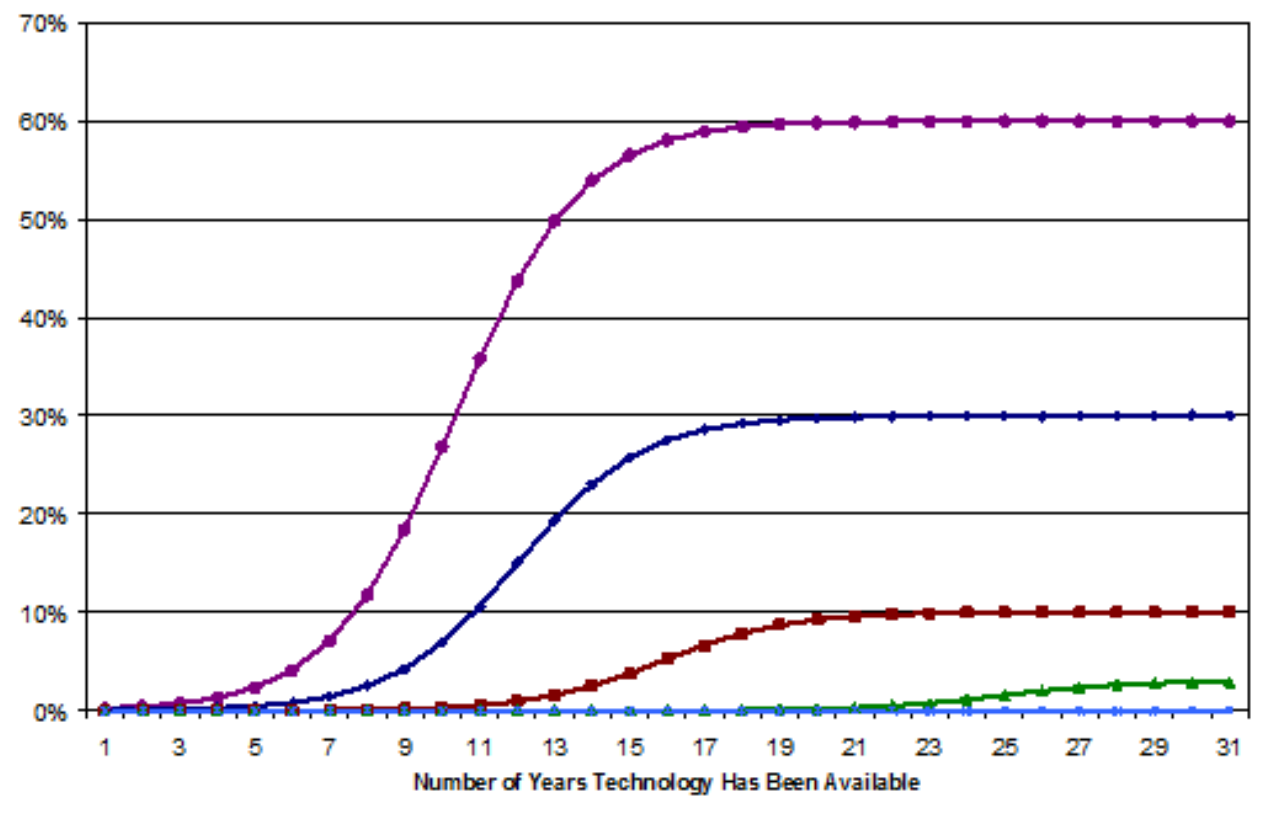

$\rightarrow-0.5$ Years $\rightarrow 1$ Year $\rightarrow-3$ Years $\rightarrow 10$ Years $\rightarrow 29$ Years

Figure 4. New construction DPV penetration rate curves for selected payback times

Detailed assumptions for the EIA Cash Flow Adoption Model are described in Section 2.3.3.

\subsubsection{ElA Hurdle Rate Adoption Model (Residential)}

The EIA Hurdle Rate Adoption Model derives in part from studies indicating a contagion effect to solar PV installations, including Rothfield (2010). These studies find that the presence of solar PV installations in a given ZIP code, among other factors such as income and education, is a significant predictor of future installations. Usable ZIP code-level data on PV installations is currently available for five states-Arizona, California, Massachusetts, Maryland, and New Jersey - through NREL's Open PV Database and state databases. ${ }^{9}$ Because these states represent a variety of solar irradiation, income, and education levels, they may be used to estimate historical PV installations and generation for ZIP codes throughout the rest of the country.

To impute historical installations in other ZIP codes, each ZIP code in a state without available data (target ZIP code) is matched with a ZIP code in a data-replete state (data ZIP code) that minimizes the Euclidean distance between standardized covariate vectors for the two ZIP codes (i.e., median income, solar irradiation, retail electricity rates, and number of households). To obtain the installation count for each target ZIP code, the installation count from the matched data ZIP code is adjusted by the ratio of fitted values from a hurdle model (described in the paragraphs below), as well as by the ratio of number of households in the two ZIP codes. These historical estimates were calibrated to historical PV data based on the Solar Energy Industries Association's total capacity data by census division (GTM 2017).

The hurdle model is also used to project future solar installations in all ZIP codes. This econometric model has two components. A logistic regression component predicts the

\footnotetext{
${ }^{9}$ Model coefficients were fitted using data from Arizona for 2000-2015, data from New Jersey for 2001-2015, and data from California, Maryland, and Massachusetts for 2007-2015.
} 
probability (a number between zero and one) that at least one solar PV installation will be observed within a given ZIP code $z$ during year $t$. At the model fitting stage, the dependent variable for this component is binary, with a value of zero indicating no installations and a value of one indicating at least one installation. A zero-truncated negative binomial regression component predicts the number of new installations, given that at least one installation occurred. Negative binomial models are commonly used for modeling count data. The predicted number of installations in each ZIP code/year combination is the probability from the logistic regression model multiplied by the conditional number of installations predicted by the negative binomial model. The GAMLSS package in $\mathrm{R}$ is used to fit both models to the available ZIP code-level data. Model covariates for both components include:

- Median household income based on the U.S. Census Bureau's American Community Survey and decennial census data

- Annual average solar irradiation (kWh per square meter per day), as estimated by NREL

- Retail electricity rate (cents per kWh)

- Number of households based on the American Community Survey and decennial census

- Monthly payment per kW $\quad$ DC of installed PV capacity, estimated based on the installed price of solar PV panels and the annual average mortgage interest rate in year $t$

- Population density (households per square mile), estimated by dividing the number of households in ZIP code $z$ by the land area in ZIP code $z$

- Social spillover, which is represented as the lagged number of new installations observed in the previous year. This covariate is only used to model whether at least one solar installation will be observed (the logit component); it is not used in modeling the number of installations (the negative binomial component).

Certain covariates were tested and not used. For example, household energy consumption was found to be insignificant due to its high correlation with electricity prices. Additionally, covariates were limited to those variables that could be projected in NEMS. The fitted coefficients for the covariates above are applied to NEMS projections for the covariate variables to project future residential PV installations. Although this model projects installations at the ZIP code level, NEMS aggregates and outputs these estimates at the census division level. ${ }^{10}$

The effects of various state policies are not currently accounted for in the Hurdle Rate Adoption Model due to the difficulty in teasing out these policy effects from the effects of other factors (e.g., income and solar irradiation) in the states. Rather, net metering is implicitly assumed for all states in that retail electricity rates, not wholesale rates, are used as an input to the projections.

Between 2009 (the last year of fully published housing characteristic and consumption microdata from RECS) and 2015, PV penetration model projections are calibrated to the Solar Energy Industries Association's total capacity data by census division using a factor that is added to the modeled projection total. This factor is carried forward and added to model projections throughout the projection period.

\footnotetext{
${ }^{10}$ For more information on the EIA Hurdle Rate Adoption Model, see Lent (2017).
} 


\subsubsection{Data and Assumptions}

The EIA models report outcomes based on the following data inputs and assumptions.

Solar Resource and Regional Characteristics

For the Cash Flow Adoption Model, solar insolation is estimated by overlaying CBECS/RECS climate zones within each census division onto a map of PV solar radiation developed by NREL. Each census division includes two to four solar insolation niches. Niches are further subdivided into high, medium, and low electricity price regions. For the RDM cash flow model, niche variables also include the census division share of housing units within a niche, average annual electricity use (in $\mathrm{kWh}$ ) per single-family housing unit, and average roof area per single-family housing unit. The Hurdle Rate Adoption Model, by contrast, considers solar insolation at the ZIP code level.

\section{Roof Characteristics}

Available roof area per building is also used as an input for calculating the size of systems that may be installed in the Cash Flow Adoption Model. In the commercial model, the ratio of roof area to building square feet is derived from CBECS and applied to building square footage projections. Based on factors such as shading and rooftop equipment, $40 \%$ of commercial roof area is assumed to be suitable for PV. The residential cash flow model compares usable roof area with optimized system capacity and footprint to calculate total roof area available for PV in a census division. Approximately 50\% of households are assumed to have a suitable southwestfacing to southeast-facing roof surface, and of these, half of the roof area is south-facing. Shading and other roof impediments are assumed to make $40 \%$ of this area unavailable. The optimal size of individual household installations is calculated by assuming $80 \%$ of a house's optimally oriented roof area will be available and $40 \%$ of this roof area will be suitable for PV. Additionally, effective available roof area is assumed to be $75 \%$ of this potential maximum area, to account for the share of residential roofs that are relatively or entirely flat.

As modules become more efficient, they take up less space for a given system capacity; therefore, the amount of capacity that can fit on a given roof space is assumed to increase over time. Projected increases in PV efficiency are derived from Leidos (2015). Efficiency for both residential and commercial modules is assumed to reach $28.1 \%$ by 2050 .

As a top-down econometric model, the residential Hurdle Rate Adoption Model does not consider individual roof characteristics; rather, solar PV system sizes are set exogenously. There is an $80 \%$ cap on the number of households in each ZIP code that can install PV systems as distributed generation is assumed to be inappropriate for some households regardless of payback time.

\section{Retail Electricity Rates}

The NEMS Electricity Market Module calculates retail electricity rates endogenously for 22 supply regions, and end-use prices are provided to the RDM and CDM. The rates for space cooling are used as inputs for both the Cash Flow Adoption Model projections and Hurdle Rate Adoption Model projections to reflect average prices when PV output is at its highest.

Applying the change in Electricity Market Module-calculated rates to the historical electricity rate data underpinning the Hurdle Rate Adoption Model yields electricity rates in the Hurdle 
Rate Adoption Model. To compute ZIP code-level electricity rate estimates, NREL estimates of ZIP code-level rates for 2011 were benchmarked to average state-level rates from EIA-861 for each year. ${ }^{11}$

\section{Technology Costs and System Specifications}

Historical installed PV system costs through 2015 were sourced from LBNL's Tracking the Sun 10 report (Barbose and Darghouth 2017) for AEO2017. For years 2016 and beyond, capital costs are assumed to decline at the five-year incremental rates projected in the 2016 NREL ATB Mid Cost scenario. In the residential sector, the per-kW $\mathrm{WC}_{\mathrm{DC}}$ cost of PV equipment decreases from $\$ 8,406$ in 2009 to $\$ 1,463$ in 2050. In the commercial sector, the per-kW $W_{D C}$ cost decreases from $\$ 5,096$ in 2012 to $\$ 1,464$ in 2050 for a $40-\mathrm{kW}_{\text {DC }}$ system. These prices serve as an upper bound to the solar costs derived from the learning cost function, described below. For the Cash Flow Adoption Model, residential and commercial distributed generation technology menus include fixed economic assumptions, including tax rates and inflation rates, and financing assumptions such as down payment percentages and loan terms. The Hurdle Model uses national-level annual mortgage interest rates and solar PV prices to compute an average monthly payment for solar PV systems. These payment levels are constant across census divisions but change over time (Lent 2017). Other system specifications throughout the projection period were obtained from Leidos (2015).

The model assumes learning by doing; installed costs are expected to fall as cumulative shipments increase. Parameter assumptions for AEO2017 result in a 13\% reduction in capital costs each time the installed PV capacity (including residential, commercial, and utility-scale systems) doubles. The model sets the capital cost of PV equal to the lesser of the result of the learning cost function and the PV prices derived from the LBNL and NREL sources.

In the Cash Flow Adoption Model, PV system sizes are constrained by an exogenously imposed minimum and maximum (for residential, this is between 1 and $10 \mathrm{~kW}$ DC; for commercial, this is between 2 and $400 \mathrm{kWDC}$ ). These limits were derived from the range of capacities historically installed (Barbose and Darghouth 2017) Within this range, the commercial module sets system size equal to the lesser of the following: the maximum size possible given assumptions regarding suitable roof space and installation efficiency; or the average annual electricity consumption for the building type, size, and niche. The residential cash flow module sets system size equal to the lesser of the maximum installation size possible given assumptions regarding suitable roof space and installation efficiency, or the maximum installation size eligible for a tax credit. For the Hurdle Rate Adoption Model, average system sizes are set exogenously-in AEO2017, they were assumed to equal a constant 5-kWDC per system.

\section{Federal Policies}

Like the dGen model, NEMS calculates the installed cost of PV systems net of the current 30\% federal ITC. Based on current legislation, this credit is scaled back to 26\% in 2020 and 22\% in

\footnotetext{
11 ZIP code-level estimates were developed by NREL using inputs from EIA and Ventyx Research, Inc. Estimates and documentation are available at https://catalog.data.gov/dataset/u-s-electric-utility-companies-and-rates-look-upby-zipcode-feb-2011 (“U.S. Electric Utility Companies and Rates: Look-up by Zipcode (Feb 2011),” last updated August 29, 2017).
} 
2021. It then drops to $10 \%$ for commercial and industrial agents and $0 \%$ for residential agents by 2022. Commercial PV systems are depreciated in accordance with MACRS.

\section{Net Metering and State Policies Affecting Interconnection}

The presence or absence of net metering is not explicitly represented in either of the AEO2017 models. In the Cash Flow Adoption Model, excess generation beyond own use is sold back to the grid at the marginal price for utility purchases in all census divisions. The presence of net metering also is not included as a covariate variable in the Hurdle Rate Adoption Model; it is instead implicitly assumed for all census divisions. ${ }^{12}$ However, for both models, EIA has assigned scores ranging from zero (closed to interconnection) to one (completely open to interconnection) that reflect each state's suite of policies on distributed generation. Scores are based on information from the DSIRE ${ }^{13}$ and on updates posted to state legislative and public utility commission websites. Components include state-level renewable portfolio standards or goals; public benefit funds that support renewable resources; the existence of net-metering and interconnection standards and rules; and the existence of solar or wind access laws. State-level scores are then aggregated into population-weighted census division-wide interconnection factors. The number of new installations calculated by either the Cash Flow Adoption Model or the Hurdle Rate Adoption Model is multiplied by these interconnection factors in both the RDM and the CDM. Interconnection limitations are assumed to ease over time with all census divisions open to interconnection by the end of the projection period.

\subsection{Model Comparison}

This section summarizes similarities and differences among data and assumptions used in simulations with the NREL dGen model and EIA Cash Flow Adoption Model and Hurdle Rate Adoption Model.

\subsubsection{Input Data}

Table 2 lists and compares key input data for each model analyzed in the report. Each modeling team was permitted flexibility to parameterize the models with assumptions based on the team's analytical judgment, where the primary aim was to elicit a range of modeling results. Though models differ in key input data, they were aligned based on scenarios (see Section 2.4.2, Core Scenarios).

\footnotetext{
${ }^{12}$ The residential hurdle rate adoption model currently uses the projected change in the space cooling electricity price to project the change in ZIP code-level retail rates from year to year.

${ }^{13}$ Database of State Incentives for Renewables \& Efficiency (DSIRE), Raleigh, North Caroline, accessed July 2015: http://www.dsireusa.org/.
} 
Table 2. Comparison of NREL and EIA Input Data

\begin{tabular}{|c|c|c|}
\hline Metric & NREL & EIA \\
\hline $\begin{array}{l}\text { Number of } \\
\text { customers with } \\
\text { technical capability } \\
\text { to adopt solar }\end{array}$ & $\begin{array}{l}\text { Technical suitability is based on a } \\
\text { statistical model derived from lidar } \\
\text { rooftop imagery of individual } \\
\text { buildings (Gagnon et al. 2016; Sigrin } \\
\text { et al. } 2016 \text { Appendix A). This model } \\
\text { estimates probability distributions of } \\
\text { the unshaded area, azimuth, and tilt } \\
\text { of building stock by county. Solar } \\
\text { adoption in the residential sector is } \\
\text { limited to owner-occupied single- } \\
\text { family buildings. In the commercial } \\
\text { sector adoption is limited to owner- } \\
\text { occupied buildings and one-third of } \\
\text { leased buildings. } \\
\text { For } 2018, \text { we model } 7.22 \text { billion } \\
\text { square meters of available roof } \\
\text { space over } 70.2 \text { million buildings } \\
\text { nationally. }\end{array}$ & $\begin{array}{l}\text { In the EIA Cash Flow Adoption Model, } \\
\text { the overall penetration of solar on new } \\
\text { construction is limited to } 75 \% \text {. For } \\
\text { existing buildings, the limit is the lesser } \\
\text { of } 0.5 \% \text { of the building stock or } 10 \% \text { of } \\
\text { the new construction penetration rate } \\
\text { for the CDM, and the lesser of } 0.5 \% \text { of } \\
\text { existing single-family households or } \\
2.5 \% \text { of the new construction } \\
\text { penetration rate for the RDM. } \\
\text { The RDM also assumes only } 50 \% \text { of } \\
\text { households would have a suitable } \\
\text { southwest-facing to southeast-facing } \\
\text { roof surface, and both the CDM and the } \\
\text { RDM impose further limits on the roof } \\
\text { space that can accommodate solar (see } \\
\text { Section } 2.3 .3 .2 \text { ). } \\
\text { In the EIA Hurdle Rate Adoption Model, } \\
\text { the penetration rate is bound by the } \\
\text { number of households and population } \\
\text { density. }\end{array}$ \\
\hline $\begin{array}{l}\text { Amount of electrical } \\
\text { demand for } \\
\text { customers with } \\
\text { technical capability } \\
\text { to adopt solar }\end{array}$ & $\begin{array}{l}\text { Electricity demand is based on a } \\
\text { combination of current county-level } \\
\text { demand using ABB Velocity Suite } \\
\text { and random sampling with } \\
\text { replacement from EIA RECS and } \\
\text { CBECS microdata to assign per- } \\
\text { agent consumption. Future demand } \\
\text { is calculated by multiplicatively } \\
\text { scaling with AEO2017 demand } \\
\text { growth escalations. } \\
\text { In the Reference case, annual } \\
\text { consumption of customers with } \\
\text { technical capacity to adopt solar is } \\
2,819 \text { terawatt-hours (TWh) in } 2018 \text {. }\end{array}$ & $\begin{array}{l}\text { Electricity demand is determined } \\
\text { endogenously by the NEMS Residential } \\
\text { and Commercial Demand Modules, } \\
\text { using a bottom-up engineering } \\
\text { approach. }\end{array}$ \\
\hline Capital costs & $\begin{array}{l}\text { Capital costs are based on the NREL } \\
2017 \text { ATB Mid Cost scenario. Under } \\
\text { this case, residential and commercial } \\
\text { costs in } 2050 \text { are } \$ 1,150 / \mathrm{kW}_{\mathrm{DC}} \text { and } \\
\$ 965 / \mathrm{kW} \text { DC respectively }\end{array}$ & $\begin{array}{l}\text { The average per-kWDC cost of } \\
\text { residential PV equipment decreases } \\
\text { from } \$ 8,406 \text { in } 2009 \text { to } \$ 1,463 \text { in } 2050 \text {. } \\
\text { In the commercial sector, the per-kWDC } \\
\text { cost decreases from } \$ 5,096 \text { in } 2012 \text { to } \\
\$ 1,464 \text { in } 2050 \text {. }\end{array}$ \\
\hline
\end{tabular}




\begin{tabular}{|c|c|c|}
\hline Metric & NREL & EIA \\
\hline Electricity rates & $\begin{array}{l}\text { Retail rates are based on data in } \\
\text { NREL's Utility Rate Database and } \\
\text { are calculated based on hourly } \\
\text { vectors of consumption and system } \\
\text { generation. These calculations } \\
\text { include consideration of demand and } \\
\text { fixed charges, and other complex } \\
\text { elements affecting marginal value of } \\
\text { generation. Rates are assigned to } \\
\text { agents based on the nearest utility } \\
\text { with data coverage, selecting the } \\
\text { tariff that minimizes the agent's pre- } \\
\text { adoption electricity expenditure. } \\
\text { Future rates are calculated by } \\
\text { multiplicatively scaling with } \\
\text { AEO2017 retail rate escalations. }\end{array}$ & 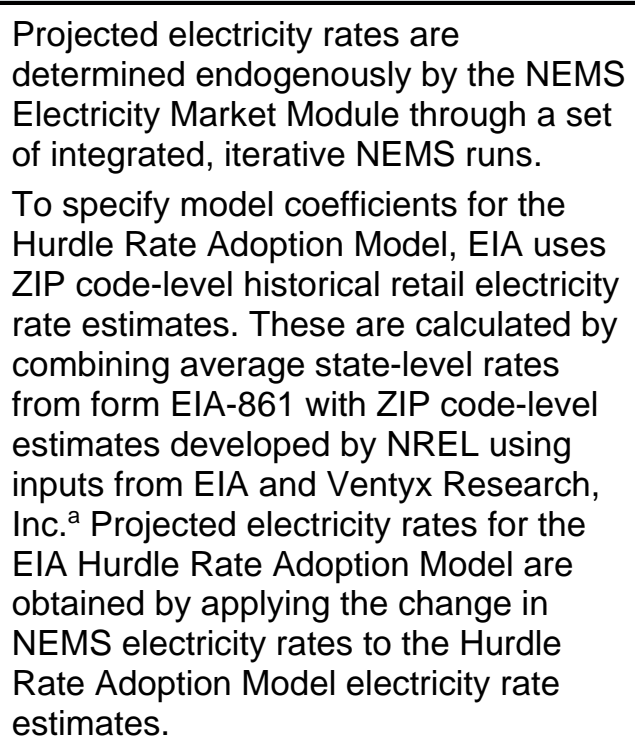 \\
\hline $\begin{array}{l}\text { Net metering and } \\
\text { policies affecting } \\
\text { ease of } \\
\text { interconnection }\end{array}$ & $\begin{array}{l}\text { Current net metering policies are } \\
\text { represented at the state-level by } \\
\text { sector. Future net metering } \\
\text { availability is endogenously } \\
\text { determined based on current statute. } \\
\text { If available and no sunsetting details } \\
\text { are listed NEM is assumed to exist in } \\
\text { perpetuity. For states without net } \\
\text { metering, self-consumed generation } \\
\text { is valued at retail rates and exported } \\
\text { generation at the wholesale rate. } \\
\text { Interconnection costs are not directly } \\
\text { represented. }\end{array}$ & $\begin{array}{l}\text { The presence or absence of net } \\
\text { metering is not explicitly represented in } \\
\text { the EIA models. EIA assigns scores } \\
\text { ranging from zero (closed to } \\
\text { interconnection) to one (completely } \\
\text { open to interconnection) to reflect each } \\
\text { state's policies on distributed } \\
\text { generation. State scores are } \\
\text { aggregated into census division-wide } \\
\text { interconnection limitation factors, which } \\
\text { are used to adjust the number of } \\
\text { projected installations in both models. }\end{array}$ \\
\hline
\end{tabular}

${ }^{a}$ Estimates and documentation are available at https://catalog.data.gov/dataset/u-s-electric-utilitycompanies-and-rates-look-up-by-zipcode-feb-2011 ("U.S. Electric Utility Companies and Rates: Look-up by ZIP code (Feb 2011)," last updated August 29, 2017). 


\subsubsection{Core Scenarios}

Scenarios were based on the core cases from the U.S. Energy Information Administration Annual Energy Outlook 2017 (EIA 2017 ${ }^{14}$ ). Details of each scenario are summarized in Table 3.

Table 3. Eight Core Annual Energy Outlook 2017 Scenario Descriptions

\begin{tabular}{|c|c|}
\hline $\begin{array}{l}\text { Scenario } \\
\text { Name }\end{array}$ & Description \\
\hline Reference & $\begin{array}{l}\text { The Reference case provides a conservative load growth baseline against which } \\
\text { alternative scenarios can be compared. Retail and wholesale electricity prices, as well } \\
\text { as PV installed costs, draw from NREL's } 2017 \text { ATB Mid Cost scenarios. Brent crude oil } \\
\text { prices are assumed to rise at an average annual rate of } 2.1 \% \text {, reaching } \$ 117 \text { per barrel } \\
\text { in } 2050 \text {. }\end{array}$ \\
\hline $\begin{array}{l}\text { High Oil and } \\
\text { Gas Price }\end{array}$ & $\begin{array}{l}\text { The High Oil and Gas Price case deviates from the Reference case in that it assumes } \\
\text { load growth and retail energy prices projection assuming crude oil prices reach } \$ 241 \\
\text { per barrel by } 2050 \text {. }\end{array}$ \\
\hline $\begin{array}{l}\text { Low Oil and } \\
\text { Gas Price }\end{array}$ & $\begin{array}{l}\text { The Low Oil and Gas Price case assumes load growth and retail energy prices in line } \\
\text { with Brent light sweet crude oil prices remaining below } \$ 50 \text { per barrel through } 2050 \text {. }\end{array}$ \\
\hline $\begin{array}{l}\text { High Oil and } \\
\text { Gas } \\
\text { Resource } \\
\text { and } \\
\text { Technology }\end{array}$ & $\begin{array}{l}\text { The High Oil and Gas Resource and Technology case deviates from the Reference } \\
\text { case in that it assumes load growth and retail energy prices that are representative of } \\
\text { the United States having access to 50\% more shale gas, tight gas, tight oil well, and } \\
\text { offshore resource domestically than in the Reference case. Cost reductions and } \\
\text { productivity are also 50\% more favorable than in the Reference case. }\end{array}$ \\
\hline $\begin{array}{l}\text { Low Oil and } \\
\text { Gas } \\
\text { Resource } \\
\text { and } \\
\text { Technology }\end{array}$ & $\begin{array}{l}\text { The Low Oil and Gas Resource and Technology case deviates from the Reference } \\
\text { case in that it assumes load growth and retail energy prices representative of the } \\
\text { United States having access to } 50 \% \text { less shale gas, tight gas, tight oil well, and offshore } \\
\text { resource domestically than in the Reference case. Cost reductions and productivity are } \\
\text { also 50\% less favorable than in the Reference case. }\end{array}$ \\
\hline $\begin{array}{l}\text { High } \\
\text { Economic } \\
\text { Growth }\end{array}$ & $\begin{array}{l}\text { The High Economic Growth case substitutes load growth and retail electricity price } \\
\text { projections from the Reference case, with those reflective of real gross domestic } \\
\text { product growing at an average annual rate of } 2.6 \% \text { from } 2016 \text { to } 2050 \text {. }\end{array}$ \\
\hline $\begin{array}{l}\text { Low } \\
\text { Economic } \\
\text { Growth }\end{array}$ & $\begin{array}{l}\text { The Low Economic Growth case substitutes load growth and retail electricity price } \\
\text { projections from the Reference case, with those reflective of real gross domestic } \\
\text { product growing at an average annual rate of } 1.6 \% \text { from } 2016 \text { to } 2050 \text {. }\end{array}$ \\
\hline $\begin{array}{l}\text { No Clean } \\
\text { Power Plan }\end{array}$ & $\begin{array}{l}\text { The scenario that models the absence of the Clean Power Plan or similar greenhouse } \\
\text { gas emissions restrictions as compared with the Reference case. }{ }^{\text {a }}\end{array}$ \\
\hline
\end{tabular}

a Because this report uses scenarios from AEO2017, policies modeled under the Reference case include the Clean Power Plan. The Clean Power Plan was not included in the AEO2018 Reference case, which was released after the analysis for this report was completed

\footnotetext{
${ }^{14}$ See “Annual Energy Outlook 2017 with projections to 2050” report, January 5, 2017 https://www.eia.gov/outlooks/aeo/pdf/0383(2017).pdf.
} 


\subsubsection{Output Metrics}

The NREL and EIA model simulations reported DPV deployment in terms of cumulative installed capacity, aggregate number of systems, and annual generation. Across all scenarios, reported statistics are for the first-time adoption (i.e., that systems are repowered at the end of their financial lifetime).

- Installed Capacity: the aggregate installed solar PV capacity in MW in United States, reported biennially until 2050

- Number of Systems: the aggregate number of combined solar and storage systems installed nationally, reported biennially until 2050

- Generation: the estimated annual energy production from all distributed solar PV systems aggregated at the national level, reported biennially until 2050. 


\section{Residential Solar Net Present Value Projections}

This section describes projections of county-level Net Present Value (NPV) for a typical 5-kWDC residential system in 2017, 2027, and 2050. The modeling framework is based on two principles: i) Evaluate the economic attractiveness based on the lifetime costs and revenue of DPV ownership from the consumer's perspective, i.e. savings as compared to consuming grid-sourced electricity; ii) Discount the projected cash flows at 5.4\% as a basis for evaluating when DPV might be cost-competitive with grid-sourced electricity. This discount rate is part of the standard financing assumptions used in NREL power system capacity expansion analyses.

The net present value projections are based on technology cost and performance parameters from the NREL 2017 Annual Technology Baseline, e.g. a 25-year investment term and 5.4\% weighted average cost of capital. The projections reflect current state and federal policy statutes, which provide regional variantion in the level of policy support for DPV. Significantly, the projections intentionally do not consider how retail tariffs could evolve in the future, for instance as a reaction to increased DPV deployment, as the purpose is to understand the situations in which distributed solar might achieve grid parity under business-as-usual conditions--even if evolution of tariffs is likely. Tables of the full results can be found in Appendices A (Low DPV Prices), B (Mid DPV Prices), and C (High DPV Prices).

\subsection{Modeled Residential Distributed Solar NPV in 2017}

We estimate that in 2017 the Net Present Value of a residential solar investment was positive in 906 counties (29\%) of the total 3,108 counties in the continental United States, based on existing policies and current technology prices (Figure 5). Similarly, we estimate 13 states ${ }^{15}$ had positive NPV in at least two-thirds of counties.

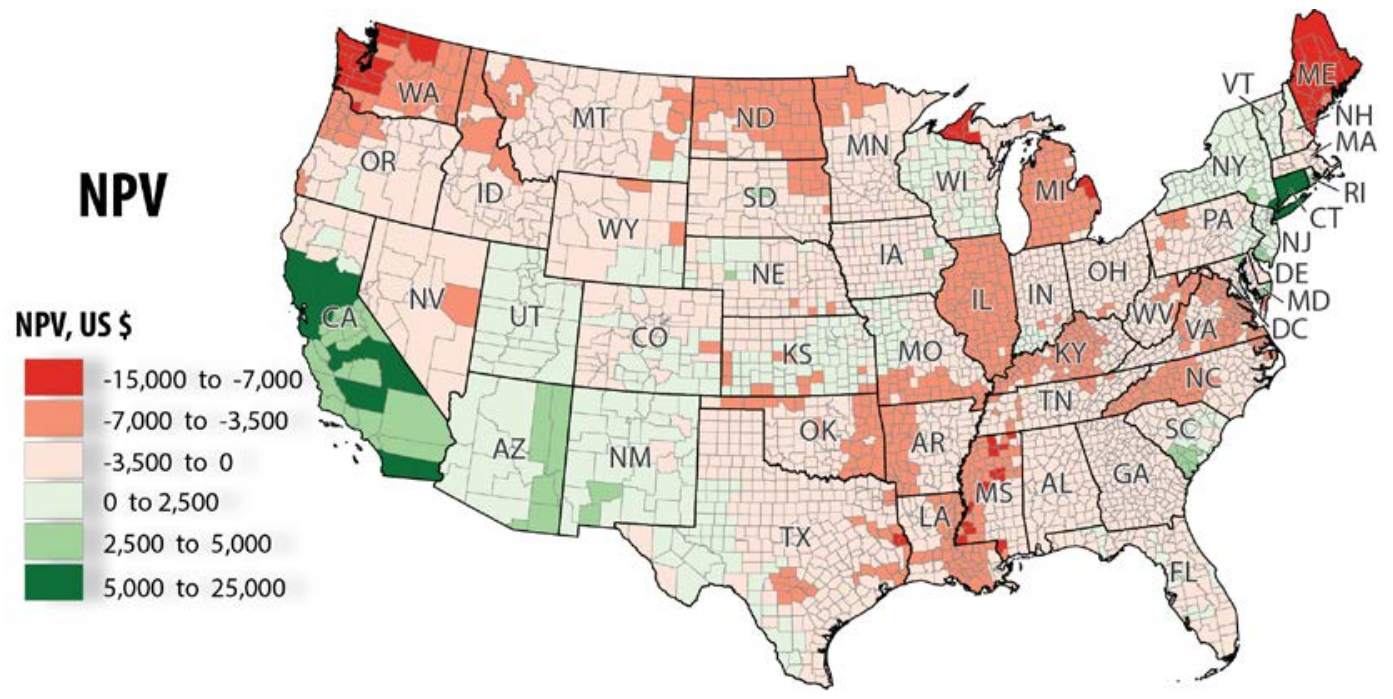

Figure 5. Simulated NPV for 5-kW resiential system by county in 2017

These findings highlight that DPV may be an attractive investment for consumers in select portions of the county_mainly the Southwest and Northeast—and for those with sufficient

\footnotetext{
${ }^{15}$ Arizona, California, Colorado, Connecticut, Massachusetts, New Jersey, New Mexico, New York, Rhode Island, Texas, Utah, Vermont, and Washington, D.C.
} 
electricity consumption and roof availability. Higher levels of economic return in these areas are primarily being driven by a combination of high solar irradiance (e.g., the Southwest), the availability of net energy metering, state-level incentives, and high-cost retail electricity. Low retail power prices in the Northwest and Southeast generally incentivize customers to continue to source electricity from the grid rather than DPV systems. We also note that a $5.4 \%$ rate of return may not be a sufficient threshhold for widespread adoption; some consumers may require higher rates of return before investing (Rai and Sigrin 2013), as the implicit cost of information searching and perceived risks are incorporated into consumer decision-making (Moezzi et al. 2017).

\subsection{Projected Residential Distributed Solar NPV in 2027}

Projections of residential distributed solar NPV for 2027 (Figure 6) are made for three capital cost trajectories. With no additional cost reductions (High Cost scenario) the number of counties with a positive NPV ( $n=27,1 \%)$ is lower than in 2017 because of the modeled expiration of state and federal-level policies incentivizing solar (e.g., federal ITC, state-level net metering, state-level SRECS). However, under the Mid Cost scenario (i.e. continued cost decline) 33\% ( $n$ $=1,010$ ) of counties are modeled to have a positive NPV; under the Low Cost scenario (i.e. accelerated cost decline) $72 \%(n=2,218)$ of counties are modeled to have a positive NPV.

Aside from costs, uncertainty about future state and federal policies is an influential factor in the projections of grid parity. For instance, current statutes suggests that, sans reenactment, net metering policies in New York, Massachusetts, and Vermont will have expired by 2027. Though DPV currently has a positive NPV in a majority of counties in these states, the potential expiration of enacted policy leads to a minority of counties with positive NPVs in 2027. In contrast, a majority of counties were modeled to have a positive NPV in neighboring Connecticut, where net metering was projected to persist beyond 2027. Thus, readers are urged to apply caution in interpreting these results, considering the possible range of potential future policy actions. Finally, many states show stability in NPV trends as compared to 2017, (e.g., California, New Mexico, and portions of South Carolina) whiles others show persistently negative NPV (e.g., Washington, Idaho, and Louisiana). 


\section{Net Present Value in 2027 by ATB Scenario}

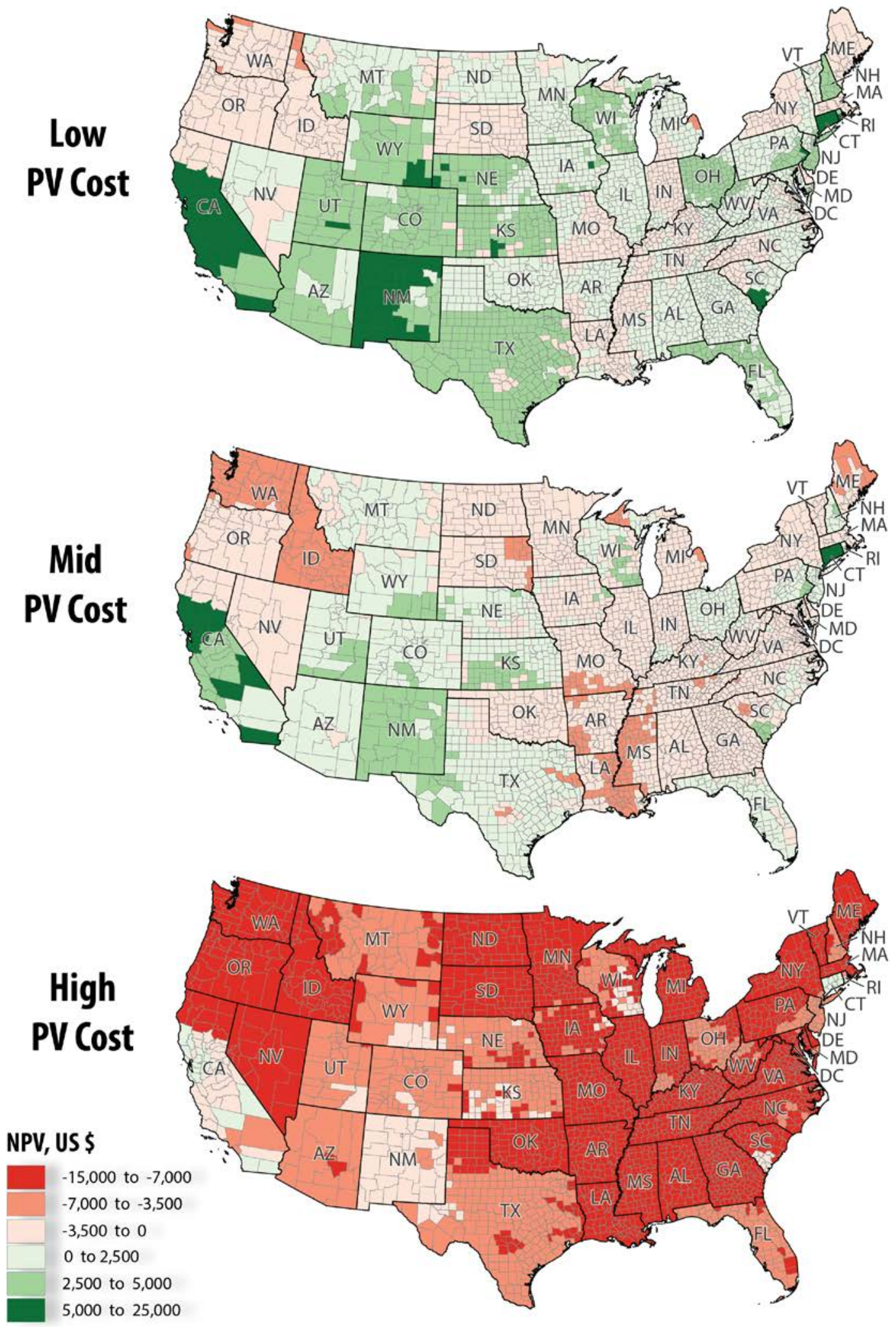

Figure 6. NPV by county and PV cost assumption in 2027 


\subsection{Projected Residential Distributed Solar NPV in 2050}

Projections of residential distributed solar NPV for 2027 (Figure 7) are made for three capital cost trajectories and net metering and discount rate sensitivities. By 2050, in the Mid Cost scenario $\left(\$ 1,150 / \mathrm{kW}_{\mathrm{DC}}\right) 80 \%$ of U.S. counties $(n=2,487)$ are estimated to have a positive NPV, while in the Low Cost scenario $\left(\$ 967 / \mathrm{kW}_{\mathrm{DC}}\right) 89 \%$ of counties $(n=2,772)$ had positive NPVs. In contrast, should PV costs remain constant until 2050, only $1 \%$ of counties would have a positive NPV. Figure 7 illustrates that by 2050, many markets in the Northeast that are competitive in 2017_-but lose competitiveness in 2027 due to expiring policies_transition back to competitive. In these scenarios, cost reductions enhance DPV cost competitiveness in areas already competitive in 2027. Relative to 2027, and with moderate PV cost declines, 23 additional states (a total of 40) are expected to reach the point where more than $66 \%$ of counties in each state have a positive NPV for DPV. Conversely, eight states, mostly in the Pacific Northwest and South, are projected to have at least a third of counties with unfavorable economics.

We also considered two side scenarios to understand sensitivities to parameters chosen for the model. In the first, each state was modeled to have full net metering through 2050. This scenario is not a reflection of current policy, and it is intended to control for the effect of individual-state policies. Under this assumption and Mid Cost scenario, 1,392 counties (45\%) would be at parity in 2027 and 2,780 counties (89\%) would be at parity by 2050. In contrast with what was described in Section 3.2, all counties in Massachusetts and Vermont and half of New York's counties were at parity in 2027 in this sensitivity. These results suggest that policy and retail rate representation is an important variable for long-term outlooks.

The second sensitivity considered the influence of consumers using a $10.2 \%$ all-equity weighted average cost of capital (instead of 5.4\%) as the satisficing criterion for economic competitiveness. This sensitivity can be interpreted as the consumer requiring a higher economic threshold before adopting. Under this assumption and Mid-case costs, 18 counties $(<1 \%)$ are simulated to have positive NPVs in 2027 and 528 counties (17\%) by 2050. These results suggest that consumer perception of economic attractiveness, especially the financing structures utilized, could have a significant influence on the adoption of DPV.

Projections of economic competitiveness result in three basic conclusions. First, widespread economic competitiveness by 2050 depends on further PV cost reductions-at current costs and sans new enacted policy, DPV is unlikely to be widely competitive. Importantly, these 2050 projections should be considered in the context of uncertainty in future technology costs, retail electricity prices, and policies. There are likely to be future economic drivers, and new technologies not modeled in this report that could impact the competitiveness of DPV. Secondly, under the Mid Cost projection, a substantial percentage of the counties in the United States could have distributed solar investment returns $>5.4 \%$, i.e. a positive NPV. In this model, the Southwest and Northeast are particularly seen as competitive. Finally, and conversely, some sections of the country are unlikely to be economically competitive for DPV in 2050, particularly northwestern and southern states, even under aggressive cost reduction, due to a combination of current policy statute and low retail electricity rates. 


\section{Net Present Value in 2050 by ATB Scenario}

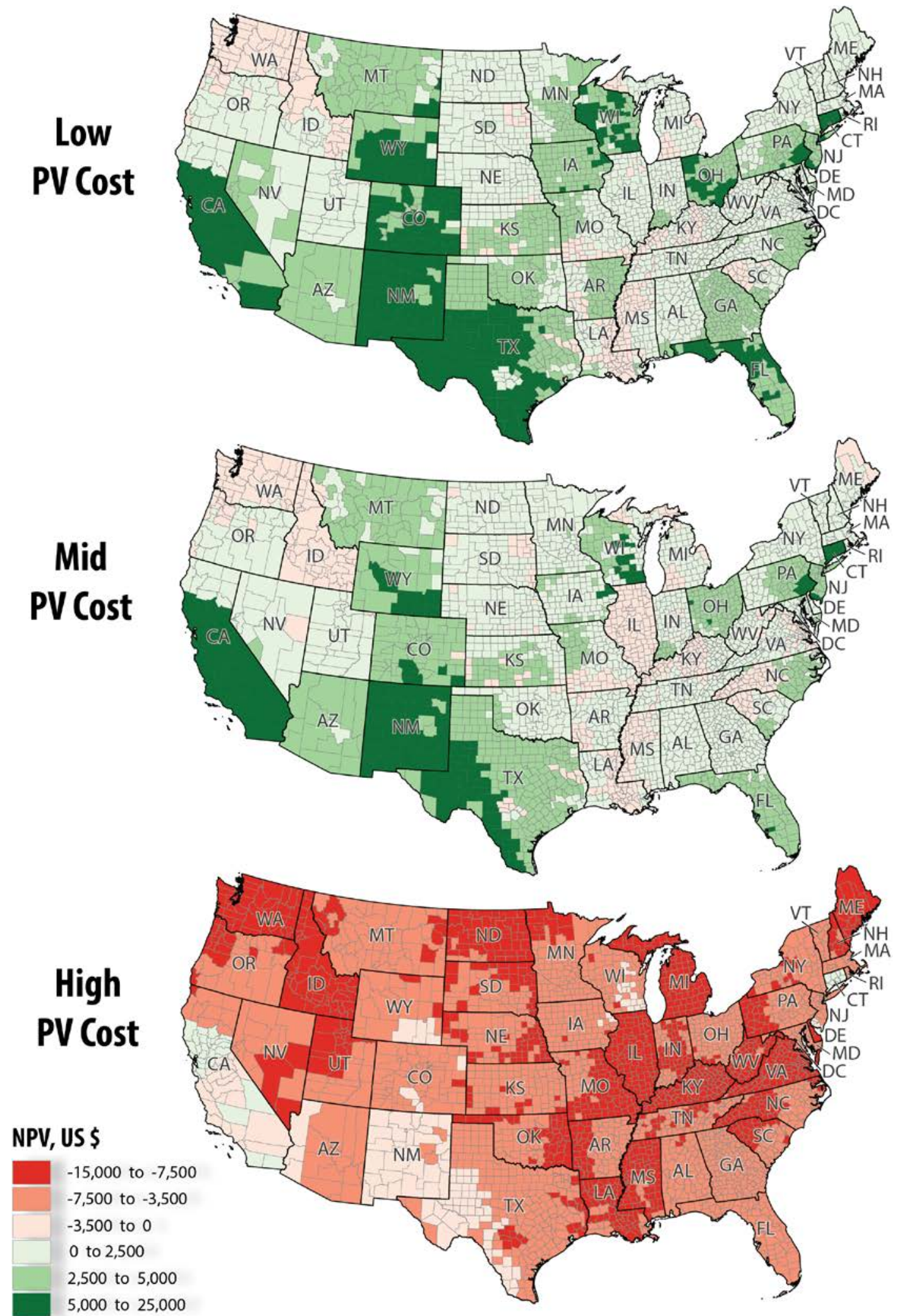

Figure 7. NPV by county and PV cost assumption in 2050 


\section{DPV Projections and Modeling Uncertainty Results}

This section compares model projections for the eight scenarios (see Section 2.4.2) jointly modeled by the NREL dGen model, the EIA Cash Flow Adoption model, and the EIA Hurdle Rate Adoption model. In this section, estimates of future deployed capacity, numbers of deployed systems, total annual generation, and percent saturation of the developable market are provided and compared to the Reference case to understand the implications of modeling approaches as well as exogenous conditions on DPV adoption. See Appendix D for results in tabular form.

\subsection{Economic Uncertainty in dGen}

This section summarizes the results from the dGen model for the eight scenarios modeled as shown in Figure 8.

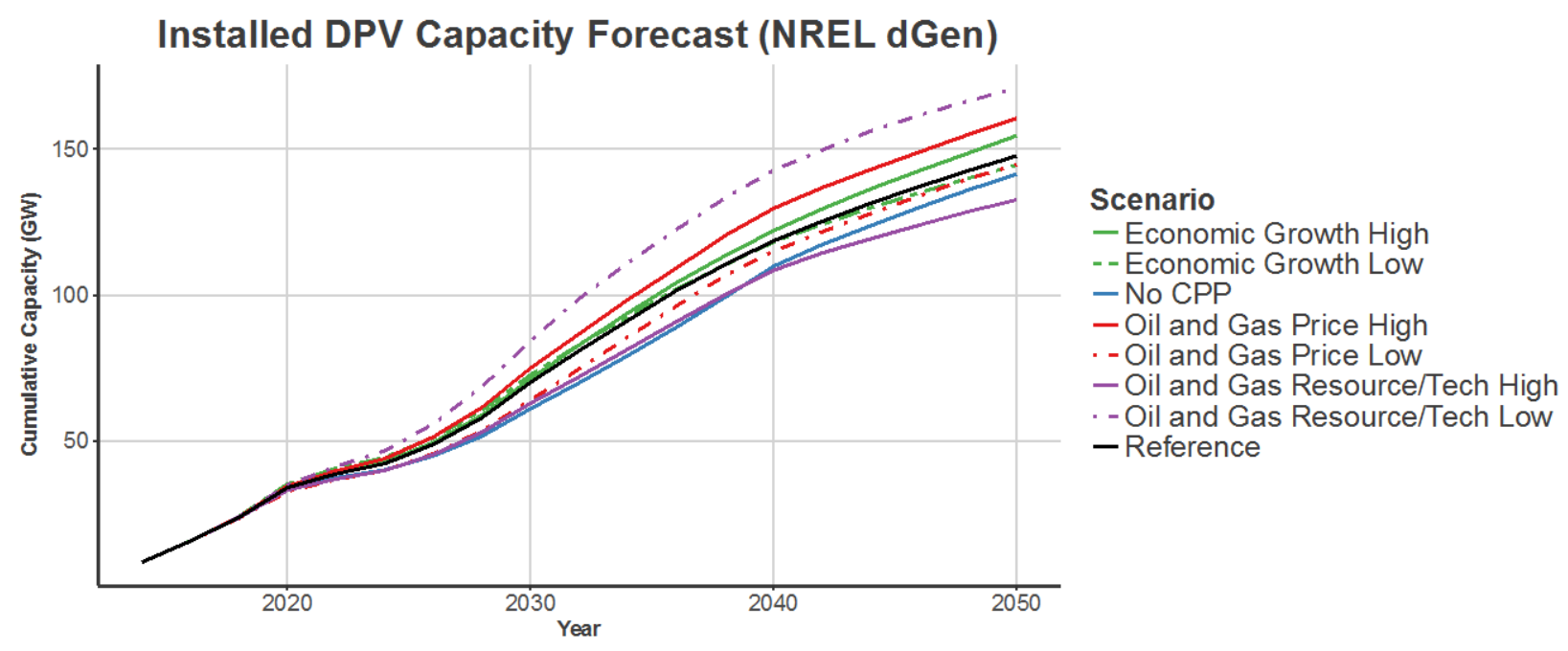

Figure 8. Cumulative installed capacity by core scenario, 2014-2050, according to NREL's dGen Model

\section{Reference}

By 2050, the Reference case projects 22.3 million operational DPV systems, accounting for 148 GW of cumulative capacity. Total electricity generation from these systems is projected to exceed 202 TWh annually.

At this time, the developable DPV market is modeled to be $31 \%$ saturated. The residential sector, where one out of every four homes has installed a DPV system, has the greatest DPV market penetration, accounting for two-thirds of all DPV capacity. Moreover, the commercial sector will account for about a quarter of capacity, while the industrial sector accounts for less than $10 \%$.

\section{No Clean Power Plan}

In the case where the Clean Power Plan (CPP) or similar greenhouse gas emissions restrictions are not implemented, cumulative installed DPV capacity are simulated to reach 141 GW by 2050 nationally, which is about 5\% lower than in the Reference case. Likewise, total installation is simulated to be reduced by 1.7 million systems compared to the Reference case and cumulative generation is simulated to be reduced by about $11 \mathrm{TWh}$. In the No CPP scenario, future 
electricity and natural gas prices are lower than in the Reference scenario, which reduces the economic motivation for customers in dGen to adopt DPV. The penetration of the developable market and the distribution of DPV systems among sectors is consistent with the Reference case.

\section{Oil and Gas Resource}

Oil and gas resource availability scenarios deviate the most from the Reference case, and among the macroeconomic conditions modeled, they constituted the greatest source of economic uncertainty in DPV adoption. ${ }^{16}$ In the case of High Oil and Gas Resource and Technology, cumulative installed DPV capacity is simulated to reach 133 GW by 2050 nationally. This is the lowest projected capacity of the core scenarios modeled-- about $90 \%$ of the capacity projected in the Reference case. This scenario likewise projects about 20 million systems installed nationally that annually produce 180 TWh of electricity.

Alternatively, in the Low Oil and Gas Resource case, cumulative installed DPV capacity is simulated to reach $171 \mathrm{GW}$ by 2050 nationally, the aggregate capacity of 26 million systems capable of producing 235 TWh of electricity annually. With 37\% saturation of developable capacity, these economic conditions contribute to the greatest modeled market penetration of any scenario. Neither scenario is significantly alters the modeled distribution of DPV systems among sectors.

\section{Oil and Gas Price}

Oil and gas price variability accounts for the second-greatest source of macroeconomic uncertainty. In the Low Oil and Gas Price case, cumulative installed capacity is simulated to reach 145 GW by 2050 nationally. While market penetration rates are similar to the Reference case, this capacity represents slightly lower DPV adoption compared to the Reference case, in that it reduces electricity generation by 5 TWh and total system installations by about a half million systems.

In the High Oil and Gas Price case, the cumulative capacity of $161 \mathrm{GW}$ is $9 \%$ higher than the Reference case, but it is lower than the Low Oil and Gas Resource projection. The capacity translates to about 24.3 million individual systems producing 220 TWh annually, and a market penetration of about $28 \%$.

\section{Economic Growth}

The economic growth uncertainty projections align closest with the Reference case projections, suggesting that dGen simulations are insensitive to the impact of economic growth. In the Low Economic Growth case, cumulative installed capacity is simulated to reach 145 GW by 2050 nationally, whereas in the High Economic Growth case, cumulative installed capacity is expected to reach 155 GW by 2050 nationally. While low economic growth slows simulated DPV adoption and high economic growth somewhat accelerates growth, the projected number of systems installed does not change substantially, and the amount of energy produced does not fluctuate more than $10 \mathrm{TWh}$. Likewise, the penetration of the developable market and the distribution of DPV systems among sectors remain consistent with the Reference case.

\footnotetext{
${ }^{16}$ As is evident from the previous section, future technology costs constitute a far larger uncertainty.
} 


\subsection{Economic Uncertainty in the EIA Models}

This section summarizes the results of the EIA Cash Flow Adoption Model and the EIA Hurdle Rate Adoption Model for the eight modeled scenarios as illustrated in Figures 9 and 10 (below). See Appendix E and $\mathrm{F}$ for results in tabular form.

\section{Reference}

In the Reference case, using the Hurdle Rate Adoption Model for residential PV, NEMS projects 227 GW of cumulative installed PV capacity in the residential and commercial sectors by 2050 . The installed capacity represents over 36.5 million systems that are operational in 2050, with annual electricity generation from these systems projected to total $333 \mathrm{TWh}$. DPV electricity generation for direct use meets $9 \%$ of electricity needs in buildings in 2050 in this case (13\% of residential electricity requirements and $4 \%$ of commercial electricity requirements).

Projections made using the Cash Flow Adoption Model for residential PV are significantly lower than they are for projections from the Hurdle Rate Adoption Model. By 2050, 165 GW of cumulative capacity is installed, with an annual generation of $239 \mathrm{TWh}$. Total installations are projected to reach 14.3 million PV systems in 2050, accounting for $8 \%$ of residential electricity consumption and $4 \%$ of commercial. Much of the divergence between the Cash Flow Adoption Model and the Hurdle Rate Adoption Model occurs in the last 10 years of the projection period and mostly with the residential sector. During this time, the Hurdle Rate Adoption Model projections accelerate due to both the spillover effects of earlier PV adoption and rising incomes. Meanwhile, the Cash Flow Adoption Model projections remain steady in later years.

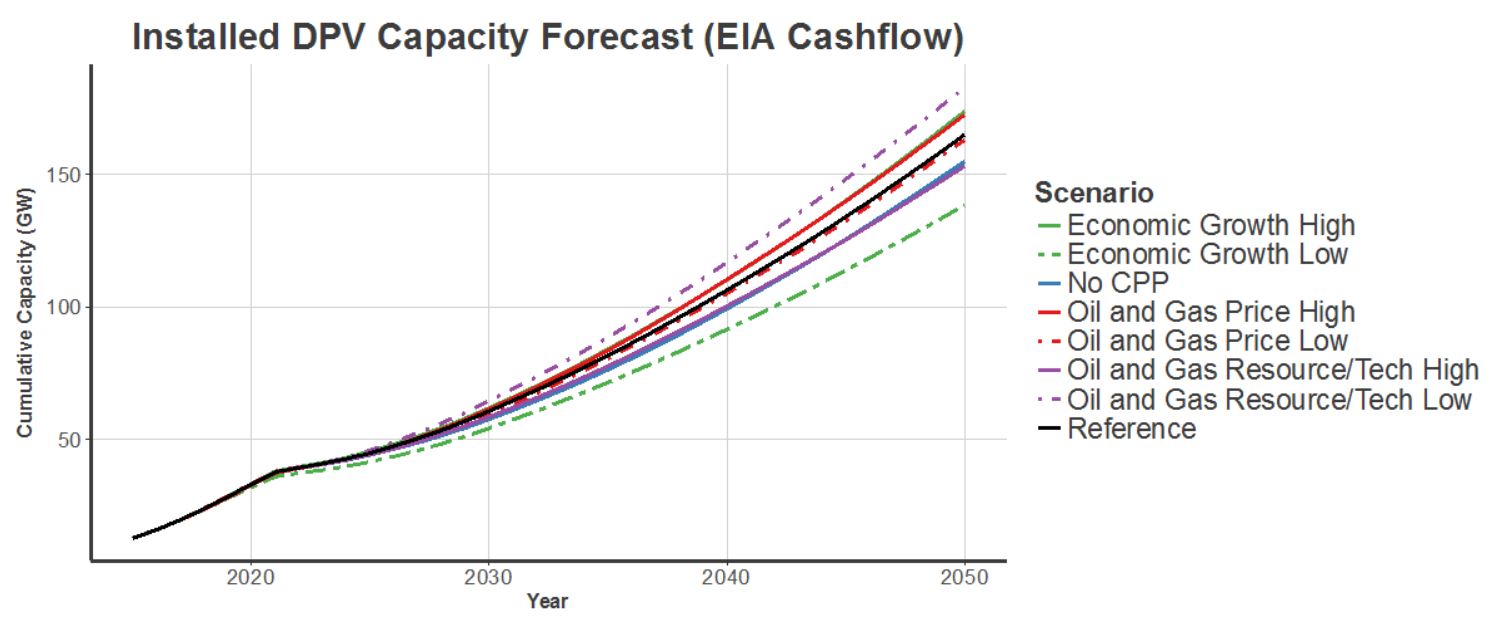

Figure 9. Cumulative installed capacity by core scenario, 2014-2050, according to the EIA Cash Flow Adoption Model 


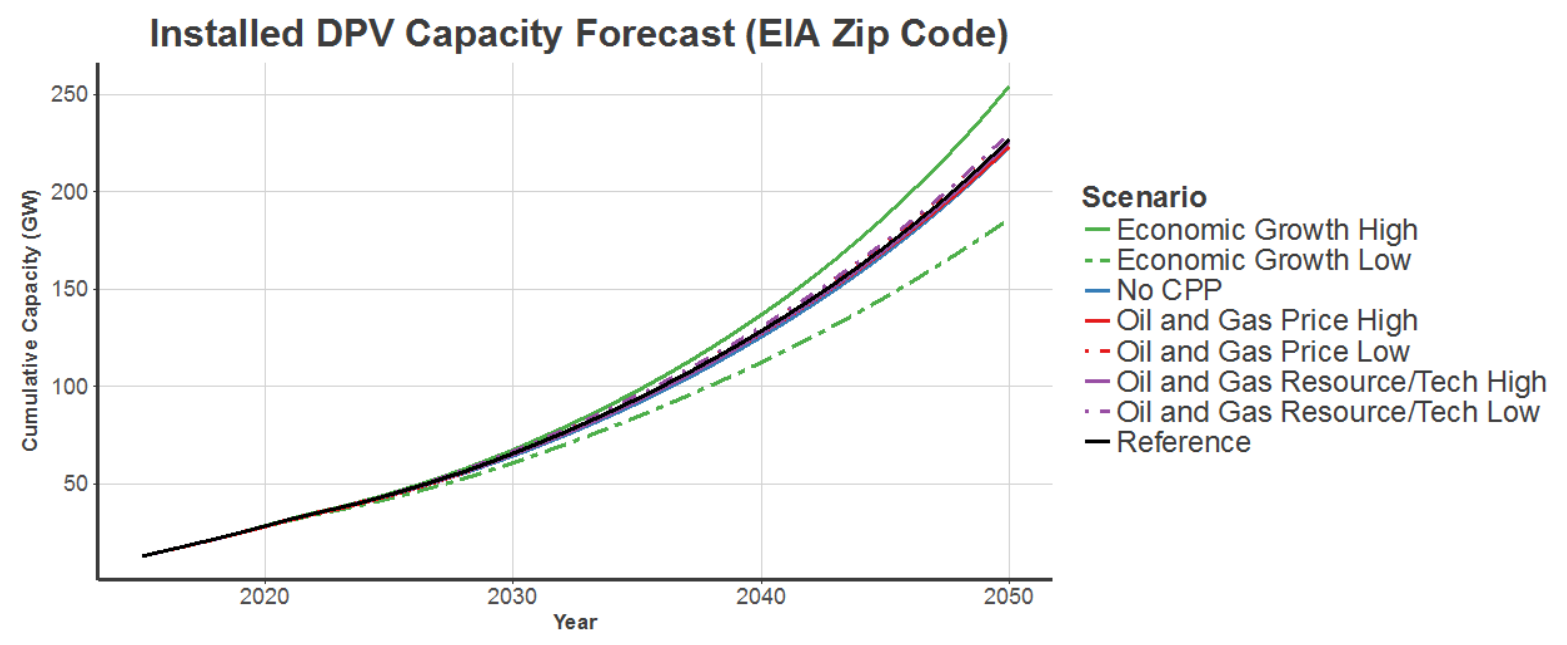

Figure 10. Cumulative installed capacity by core scenario, 2014-2050, according to the EIA Hurdle Rate Adoption Model

\section{No Clean Power Plan}

Although the Hurdle Rate Adoption Model projects fewer distributed PV installations without the CPP or similar greenhouse gas emissions restrictions, the effect of removing this policy is modest. In the absence of the CPP, using the Hurdle Rate Adoption Model for residential PV, cumulative installed distributed PV capacity reaches $223 \mathrm{GW}$ by 2050, which is $1.7 \%$ lower than in the Reference case. Annual PV generation totals $328 \mathrm{TWh}$ in 2050, which is also $1.7 \%$ lower than in the Reference case. By 2050, 36.1 million systems are installed in the No CPP case, which is $1.2 \%$ fewer than in the Reference case. This modest impact reflects the importance of income to the Hurdle Rate Adoption Model's projections. The CPP has only a small effect on income - without the CPP in effect, real disposable personal income is only 0.3\% higher in 2050.

When the Cash Flow Adoption Model is used for residential PV projections, the absence of the CPP or similar greenhouse gas emissions restrictions results in a larger difference from the Reference case than when the Hurdle Rate Adoption Model is used. Cumulative PV capacity in 2050 without the CPP is $6 \%$ lower, totaling $155 \mathrm{GW}$ with the residential Cash Flow Adoption Model. Generation and number of systems also decrease by $6 \%$ relative to the reference scenario, to 225 TWh and 13.5 million systems, respectively, in 2050. This difference reflects the CPP's effect on retail electricity prices, a key input into the model's cash flow projections. Without the CPP, electricity prices are about $5 \%$ lower in both the residential and commercial sectors, making distributed PV relatively less attractive to consumers.

\section{Oil and Gas Resource and Technology}

When the Hurdle Rate Adoption Model is applied, the Oil and Gas Resource cases have only a small effect on the projections. Relative to the Reference case, the High Resource and Technology case reduces projected capacity and generation by $0.6 \%$ and $0.5 \%$, respectively, in 2050. The Low Resource and Technology case increases both projected metrics by $1.4 \%$. Both scenarios increase the number of systems by $0.3 \%$. Although the lower oil prices under the High resource case should decrease the incentive for homes and businesses to install solar panels, this effect is offset by higher effective incomes, which increase the incentive to invest, as well as 
lower inflation and interest rates, which decrease the cost of financing PV investments. The reverse is true for the Low Resource case. The result is a minor effect in each case.

Impacts are more significant using the residential Cash Flow Adoption Model, which is more sensitive to electricity prices. Of all the scenarios modeled, the High and Low Resource and Technology cases have the largest impact on electricity prices; the high case decreases residential and commercial retail electricity prices by $10 \%$ and $9 \%$, respectively, while the low case increases prices by $12 \%$ to $13 \%$. Therefore, in the High Resource and Technology case, all metrics projected - capacity, generation, and number of systems - decrease by 7\% relative to the Reference case in 2050 when using the Cash Flow Adoption Model. Capacity is projected to reach $153 \mathrm{GW}$ in this year. The same metrics increase by $11 \%$ in the Low Resource case relative to the Reference case in 2050, and capacity reaches 183 MW in 2050.

\section{Oil and Gas Price}

The NEMS Oil Price cases have a small effect on projections using either model. Compared with the Reference case, the Hurdle Rate Adoption Model's capacity projections are $1.6 \%$ lower in the High Oil Price case and 1.4\% higher in the Low Oil Price case in 2050, reaching 223 GW and $230 \mathrm{GW}$, respectively. Similarly, changes in projections of generation and PV systems installed are $2 \%$ or less.

The impact of the Low Oil Price case on projections using the residential Cash Flow Adoption Model is also small. Compared with the Reference case, capacity, generation, and number of systems decrease by $1 \%$ or less. The High Oil Price case, however, has a larger effect: capacity, generation, and the number of systems all increase by about $4.5 \%$.

The Oil Price cases highlight the relative importance of different factors in the Hurdle Rate Adoption Model and residential Cash Flow Adoption Model. While high oil prices cause PV growth to increase under the Cash Flow Adoption Model because of higher electricity prices, lower disposable income results in slightly lower PV growth in the High Oil Price case using the Hurdle Rate Adoption Model. Changes in both electricity prices and income are small in these scenarios, however, and lead to modest impacts in both models.

\section{Economic Growth}

Economic growth has the largest impact of any of the scenarios modeled, particularly when using the Hurdle Rate Adoption Model. With high economic growth and the Hurdle Rate Adoption Model, capacity is projected to be $12 \%$ higher than in the Reference case in 2050, reaching $254 \mathrm{GW}$. When economic growth is lower, capacity reaches only $186 \mathrm{GW}, 18 \%$ lower than the Reference case. Projections for generation and number of systems installed show similar results. Generation and systems installed in the Reference case and Growth case are 13\% higher and 14\% higher in 2050 than in the Reference case, respectively. Lower economic growth, on the other hand, reduces both metrics by approximately one-fifth. The Hurdle Rate Adoption Model therefore suggests the long-term rate of economic growth could potentially significantly affect the growth of distributed solar PV.

With the Cash Flow Adoption Model applied to the residential sector, the impacts of economic growth are smaller but significant. High economic growth is projected to boost capacity, generation, and the number of installed systems by about 5\% over Reference case levels in 2050 . 
Capacity reaches $174 \mathrm{GW}$ in this year. With low economic growth, capacity and generation are $16 \%$ lower, and the number of systems installed is 19\% lower than in the Reference case.

\subsection{Modeling Uncertainty}

Though prior analyses have examined the sensitivity of DPV projections to various economic drivers (e.g., future technology or fuel costs), few have explicitly considered the role that model specification plays in the long-term uncertainty of a projection. Here we refer to economic uncertainty to mean the set of techno-economic factors that significantly impact our model's projections but are ultimately unknowable. As explored already in Sections 4.1 and 4.2 these include but are not limited to technology costs, economic growth, fuel costs, and demand for electricity. We contrast this with modeling uncertainty, which has an epistemic quality - these are parameters that are knowable, but unknown to a modeler, either because of the difficulty of collecting them or fully representing them quantitatively. For instance, many models use the central tendency of a variable (e.g., annual electricity consumption), with the awareness that the central tendency does not reflect the full range of outcomes but is easily observed. Alternatively, models may intentionally be resolved at a low-spatial resolution because of computational infeasibility or ease of maintenance.

We explore three dimensions to modeling uncertainty in the models used: (1) how improvements to model features affect its performance, (2) quantification of uncertainty derived from stochastic processes, and (3) how results change through a retrospective consideration. Though economic uncertainty is likely a far larger source of uncertainty, the notion of determinism is endemic within modeling communities, and attempts to better quantify imperfections in methodology help advance the state of the art.

\subsubsection{Differences between Modeling Approaches}

The dGen, EIA Cash Flow Adoption Model and EIA Hurdle Rate Adoption Models adoption projections share commonalities, especially in the near term, though they differed in the longterm (2050) projected deployment as well as the relative influence of market factors on deployment.

Figure 11 compares projected deployment across the three models for the Reference case and show similar near-term projections. For example, the dGen and EIA Cash Flow Adoption Model both reflect the impact of the federal ITC and its expiration through an early bump and subsequent lag in DPV deployment that recovers by 2025. Furthermore, until 2044, the EIA Cash Flow Adoption Model estimates about 7\% lower adoption than dGen, and until 2036 the EIA Hurdle Rate Adoption Model projects only about 5\% lower installed capacity on average than dGen. Higher deployment levels in dGen are likely due to the inclusion of state incentives in the early years of the modeled period. 


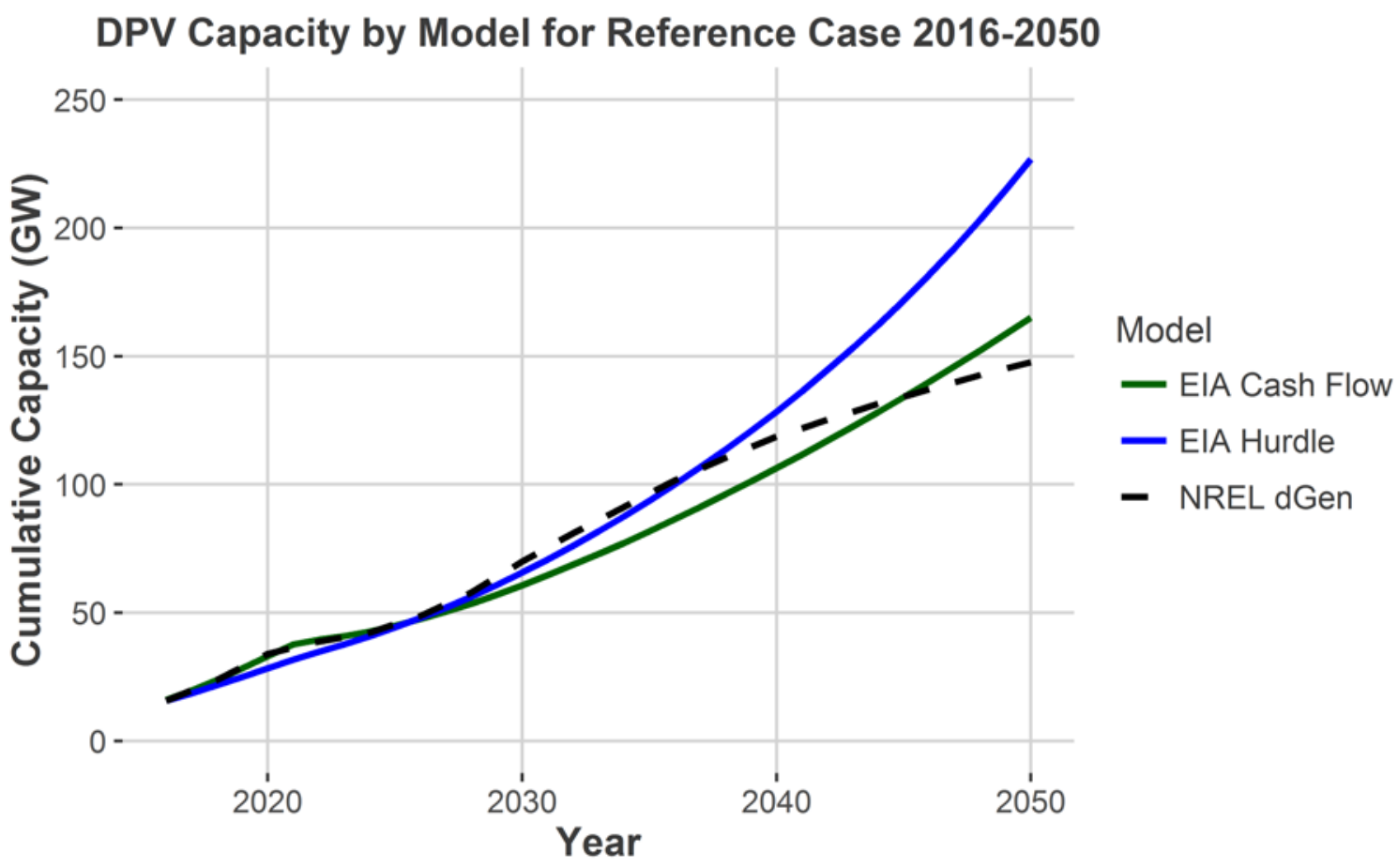

Figure 11. Comparison of DPV adoption projections for the Reference Case by model

From 2026 onwards, however, the models begin different regimes of growth. In the dGen model, most currently implemented policies have expired by 2026 and, thereafter, the rate of new installations is projected to decrease due to an increasing saturation of the most-favorable sites. In contrast, projected growth in adoption in both EIA models accelerates post-2026 due to differences in modeling approaches. For instance, because the EIA models do not model net metering expiration, they continue to assess trends under favorable economic assumptions. Deployment within the EIA Hurdle Rate Adoption Model accelerates throughout the entire modeled period, reflecting one of its underlying premises - that the presence of solar in a certain ZIP code area begets more solar in that same area due to social contagion. The EIA Hurdle Rate Adoption Model is also driven more by macroeconomic factors than by PV prices, and installations therefore grow as income increases over time.

Interestingly, in the Reference case at 2050, dGen and the EIA Cash Flow Adoption Model arrive at similar projected cumulative installed DPV capacity levels (within about $10 \%$ of each other), while the EIA Hurdle Rate Adoption Model projects significantly more adoption. It projects about 50\% more deployment in 2050 than dGen and over a third more installed capacity than the EIA Cash Flow Adoption Model, demonstrating that the inclusion of contagion effect provides a more optimistic DPV projection than financial calculations alone suggest.

Comparisons of modeled scenarios to the Reference case reveal that all models are aligned in suggesting the absence of the CPP or similar greenhouse gas emissions restrictions could modestly reduce DPV deployment (on the order of $2.0 \%-6.0 \%$ ) in relation to the Reference case. All models assume no additional subsidies are deployed for distributed renewable generation under the CPP; changes in DPV deployment therefore are solely due to changes in retail 
electricity prices and economic growth. The application of the CPP is projected to increase retail electricity prices by approximately $6 \%$ in both sectors by 2050 . This price increase makes distributed generation more economically attractive in the EIA Cash Flow Adoption Model and the NREL dGen model. CPP impacts on economic growth and income are much smaller-in NEMS, the CPP decreases real disposable personal income by only $0.2 \%$ by 2050 . As a result, the effect of the CPP on the results of the EIA Hurdle Rate Adoption Model, which is more dependent on macroeconomic variables, is much smaller than on the EIA Cash Flow Adoption Model and the NREL dGen model.

Moreover, dGen and the EIA Cash Flow Adoption Model both simulate oil and gas resource and technology variability to have a notable impact on future deployment trends. In the Low Oil and Gas Resource and Technology scenario, both models predict an increase in cumulative deployment of 11\%-15\% compared to the Reference case, while in the High Oil and Gas scenario, the models predict decreases in deployment of $7 \%-11 \%$. These effects are due to electricity price changes. The Low Oil and Gas resource scenario causes electricity prices to increase significantly, by over $10 \%$, making solar PV installations more economically attractive; conversely, electricity prices are much lower under the High Oil and Gas Resource case, making solar PV installations less attractive to consumers. Interestingly, the EIA Hurdle Rate Adoption Model does not suggest a notable change from the mean in this scenario, as deployment in this model depends on macroeconomic factors more than retail electricity prices.

Also, while dGen bounds macroeconomic effects to be within 5\% of the Reference case, both the EIA Hurdle Rate Adoption Model and EIA Cash Flow Adoption Model suggest these forces will have a more dramatic impact on adoption. The EIA models suggest these market conditions will either increase DPV deployment by $5 \%-12 \%$ or reduce it by more than $15 \%$.

\subsubsection{Sampling Error}

Attributes of customers represented in dGen (i.e., agents) are determined by sampling with replacement from spatially resolved probability distributions. Specifying customer attributes in this manner reflects the principle that new technology adoption first occurs in customer segments with high levels of innovativeness, or, customers for whom the technology would provide substantially more value than the average customer. For DPV specifically, these early adopters could represent customers with high electricity prices, high solar irradiance, and large southfacing roofs. Properly identifying these outliers would be infeasible using only the central tendency of the population because, by definition, these customers represent the tails of a distribution. This formulation is not comparable to traditional deterministic capacity expansion models (e.g., ReEDS), which tend to use central tendencies.

Accordingly, error in dGen is introduced via sampling error in the sense that an infinite number of draws would be required to perfectly reproduce the underlying population, or the full set of possible combinations of agent characteristics. Sampling error can variously be reduced either by increasing the number of agents sampled per geographic region or by averaging the results of multiple runs, with each run using a different random seed. Each additional agent or model run increases accuracy with the tradeoff of additional processing time and computing resource burden. 
At a conceptual level, sampling error is introduced by overrepresenting or underrepresenting specific combinations of techno-economic factors that influence the economic feasibility for an agent. These primarily include per-agent roof characteristic and the amount of annual electrical consumption. Because the number of agents sampled per county in dGen is currently a fixed quantity, and it is not weighted by population, high-population counties are represented at a lower resolution than low-population areas and are more prone to sampling error. ${ }^{17}$ This section explores the tradeoffs of different sampling strategies and their resultant impact on model uncertainty.

To measure the variability among projected DPV trends we ran 10 national dGen model simulations of the Reference case, each instantiated with a unique random seed value (Figure 12). Over these 10 runs, the mean model projection within one standard deviation in 2050 was 140.6 \pm 3.3 GW nationally, and $4.51 \pm 1.09 \mathrm{GW}$ in New York, which was selected as an example of a state with high sampling uncertainty. A Shapiro-Wilk test was run for United States $(w=$ 0.97, $p=0.90$, and $n=10)$ and New York $(w=0.95, p=.72$, and $n=10)$ samples, both of which fail to reject the null hypothesis of normality.

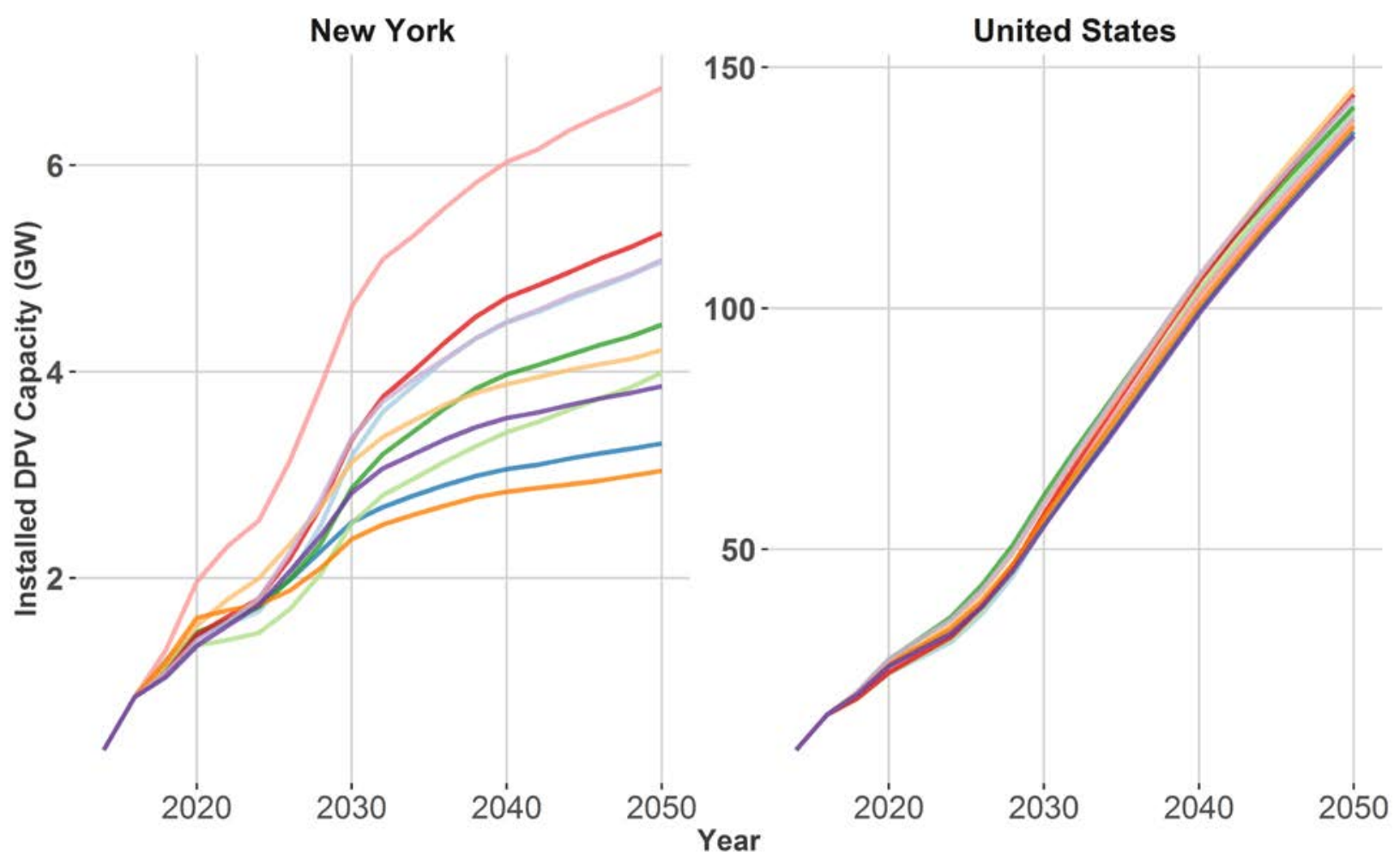

Figure 12. Variance in state (New York) and national-level simulations for 10 random seeds for one
agent per county

Based on the assumption of normality, a confidence interval can be constructed to determine the population mean at a 95\% confidence level (i.e., having confidence of the true model results were it to be run with infinite sampling). Let $\bar{x}$ and $\bar{\sigma}$ be the sample mean and standard deviation

\footnotetext{
${ }^{17}$ As an illustrative example, this might be realized if all residential customers were substantiated with roofs unsuitable for solar or were substantiated with very high electrical demand.
} 
calculated with $n$ samples, $\mu$ be the population mean, and $\sigma$ the population standard deviation, which we estimate directly as $\bar{\sigma}$. By the central limit theorem, the expected value of $\bar{x}$ is $\mu$, and the standard error of $\bar{x}$ is given by (1):

$$
S D(\bar{x})=\frac{\sigma}{\sqrt{n}}
$$

Based on (1), a 95\% confidence for the population mean is approximately $2 * \operatorname{SD}(\bar{x})$. For the 10 run United States model, the two standard errors for the 2050 projection are $2.108 \mathrm{GW}$, or $1.50 \%$ of the 2050 sample mean. Error for the 10-run N.Y. model is much higher, where the two standard errors for the 2050 projection are $692 \mathrm{MW}$, or $15.3 \%$ of the 2050 sample mean. Accordingly, we estimate that the installed capacity in 2050 for a single U.S. simulation using one agent per county can be said to be known within $4.74 \%$ at a $95 \%$ degree of confidence. However, a single New York simulation at the same sampling rate would have a 95\% confidence of a $48.5 \%$ error. Across all states, the median state has a $95 \%$ probability of a $40.7 \%$ error or less. These errors substantially decrease as the model resolution increases, where averaging 10 simulations results in a $1.5 \%$ error nationally and a $12.9 \%$ error for the median state; 100 simulations achieve a $0.5 \%$ error nationally and a $4.1 \%$ error for the median state.

At the national level, variance between model runs is the largest early on in the model. From 2018, when projections are first calculated in place of historical trends, to 2024, the coefficient of variation among projected total installed capacities for the same year doubles from 0.027 to 0.053 , before steadily decreasing to 0.024 by 2050 . These results suggest the cumulative effect of stochastic processes on agents within the dGen model is greatest in the earliest modeled years and will asymptotically settle to a stable value over long enough timeframes.

The national trends in variability are mimicked at subnational levels, yet the magnitude and timing of peak variability differ. The timing of greatest variability for any state typically follows the period of mass adoption; or in other words, variance is largest during the years when markets are growing fastest. For example, in Montana, variability in modeled cumulative installed capacity exponentially increases to 0.54 in 2050 because mass adoption is not expected to occur in this state until the latest modeled years.

Furthermore, several states (Delaware, Massachusetts, New York, and Nevada) deviate from the national trend and their variability inflates during later model years. These are states with incentives whose relative value linearly decrease over the modeled period. In these cases, as incentive values decrease, more variability in underlying rate structures is exposed.

These results demonstrate that the error for the national-level results alone is very reasonable, but a substantially higher sampling rate is needed for state-level or substate-level analysis. However, substantially higher sampling rates are eminently feasible for state-level results because of the reduced computational burden as compared to the national-level model. Future work will explore the role of different sampling techniques (e.g., population-weighted techniques), the trade-off of higher per-county sampling as compared to more simulations at lower resolutions, and analysis of the underlying sources of sampling error and how these might be improved. 


\subsubsection{Retrospective Analysis}

Over the last decade, distributed-scale and utility-scale solar have experienced rapid growth, often exceeding the range of experts' previous projections. These discrepancies between modeled and actual deployment highlight the inherent uncertainty of forward-looking projections, as well as the risk of model overfitting based on limited data. Differences between actual and modeled results can attributed to both unexpected changes in the economic attractiveness of DPV (e.g., accelerated cost reduction and introduction of new policies) as well as customer acceptance of new technology. Here we conduct retrospective analysis over the last six years as part of the broader exploration of modeling uncertainty.

Using historical time series of actual adoption counts for the residential and commercial sector, we compare how projections of DPV growth have updated over time, simply as a factor of having access to more-recent market data. Projections are based only on a simple Bass Diffusion Model (Srinivasan and Mason 1986) and not the NREL or EIA models. The Bass Diffusion Model estimates the coefficients of imitation $(q)$ and innovations $(p)$, which govern the shape of diffusion, and the market size $(m)$ parameter, which governs the total addressable market. A notable feature of this specification is that the annual adoption must follow a symmetric Gaussian form - that is, a market can only "peak" once, and the method is not well-suited to understand transient changes in market activity.

Bass parameters were estimated for each state and sector from 1998 to 2016 for each state with at least five system installations. Adoption trends for 1998-2010 were obtained from the OpenPV Tracking the Sun data set (LBNL 2017), which is a compilation of system-level trends from state incentive programs. For 2010-2016, we used data from GreenTech Media's Solar Market Insight report (GTM 2017), because program data alone are not comprehensive for recent years. The regression technique is based on the non-linear least squares method (Srinivasan and Mason 1986; Dong, Sigrin, and Brinkman 2017), and it does not include information on the historical economic attractiveness or level of marketing.

Figure 13 shows how projections of annual national adoption based on the existing data available at that time have evolved. The retrospective projections are made using the Bass Diffusion Model and with an overlay of the actual historical amount of adoption. Projections that would have been completed in 2010-2012 would have significantly underestimated future adoption, instead projecting that market growth would peak in 2018-2020. Conversely, 2013-2015 project a secular change in market activity, with substantially higher projections and, notably, not predicting peak market activity prior to 2020. The last retrospective projection (2016) simulates more modest annual growth than projections made in 2013-2015, with an acceleration in later years. 


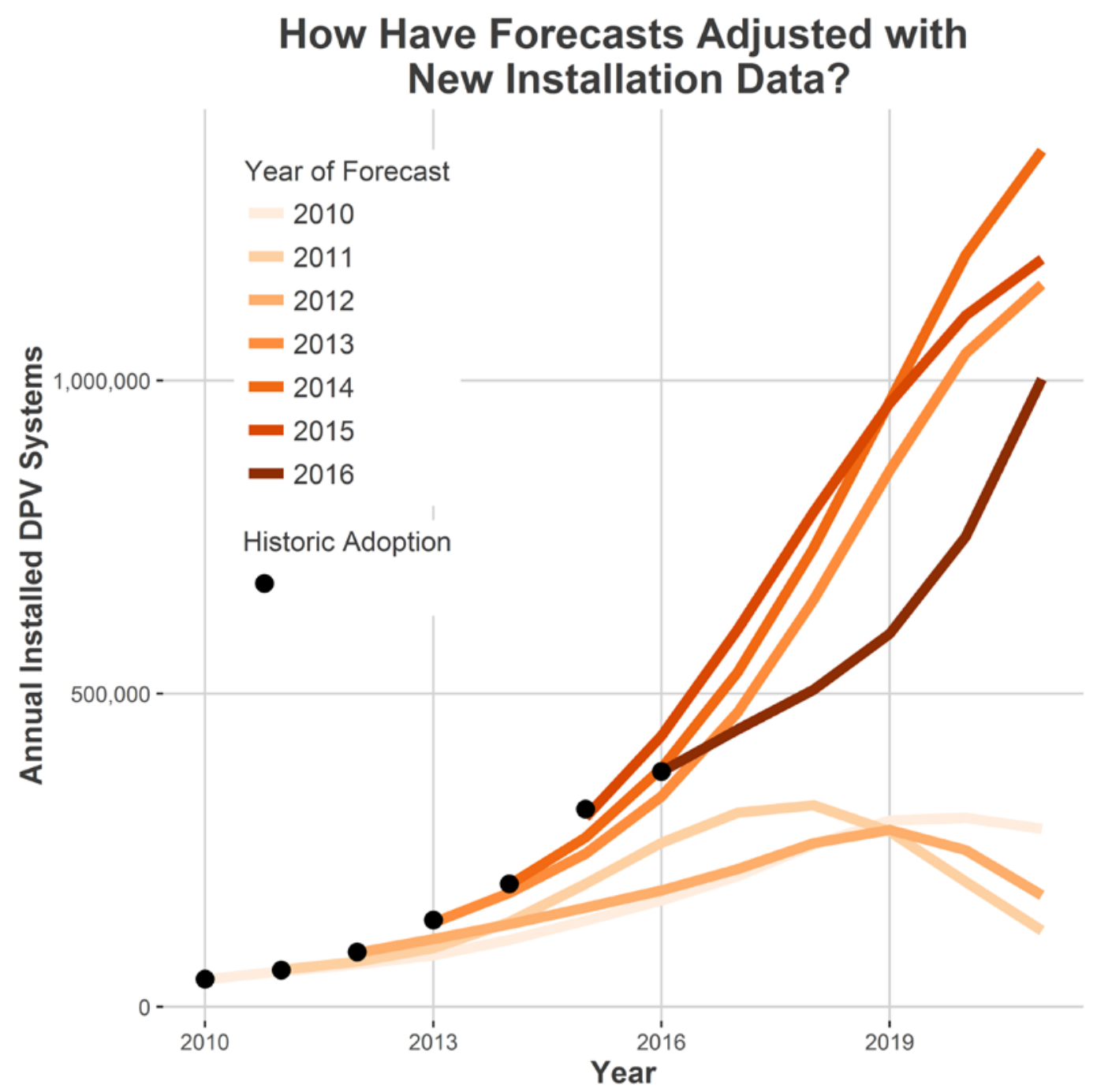

Figure 13. Sequential projection of annual installations nationally as function of available data

These results illustrate the difficulty of accurately projecting long-term market activity and clarify the importance of the difference between "projections" and "forecasts". Forecasting is the science of predicting near-term outcomes. In contrast, projections are meant to be an internallyconsistent framework for comparing "what-if" scenarios - in which the purpose is to determine the comparative impact of a specific policy/outcome, but less to be quantitative accurate. All three of the models in this report seek to develop projections and should not be interpreted to be forecasts.

The retrospective analysis demonstrates two take-aways. First, the models used in this report could be expected to be reasonably accurate for one-year to two-year outlooks and should not be considered forecasts. The uptake in DPV growth for 2013 - 2015 models the rises of solar leases in those years, where 2012 was the first year for zero-down leases to constitute $>50 \%$ of new residential systems (GTM 2017). That is, models need to reflect market structure, in addition to cost to represent technology diffusion. Heightened uncertainty in the current DPV market complicates future projections. For instance, 2017 was the first year in which annual deployment decreased year-on-year (GTM 2017) —and this introduces uncertainty for the range of adoption 
in the next few years. Though costs for DPV have generally continued to decline, challenges include a reduced rate of DPV cost decline-particularly from customer acquisition challenges, policy action that disincentivizes adoption, a refocus from project developers on profitability not growth, and an exit of major industry actors (Feldman, Hoskins, and Margolis 2017). 


\section{Conclusion}

Growth of distributed energy resources are disrupting business-as-usual in the U.S. power system, prompting a re-examination of the build-out and operation of the electrical grid. The future of DPV is highly uncertain, with future costs, policies, retail rates, macroeconomic conditions, and customer acceptance among the factors that will impact its long-term future. In this report, we examine uncertainty in the timing and extent of DPV cost competitiveness with grid-sourced electricity. We also compare methods developed by two modeling teams to better understand how differences in modeling approaches and specifications impact deployment estimates.

Our results suggest that DPV could be marginally more cost-competitive in 2027, despite continued cost declines, if current policy expires at its statutory limits assuming 2017 ATB Mid Cost PV costs. However, by 2050, and assuming 2017 ATB Mid Cost scenario cost declines, DPV would be competitive in most U.S. counties (80\%). The level of competitiveness will ultimately depend on local combinations of quality of solar resource, retail electricity prices, and policy. Critically, we also find that select regions, particularly the Pacific Northwest and portions of the South could remain unfavorable to DPV-sourced electricity well into the middle of this century.

Projections from the NREL dGen model, the EIA Cash Flow Adoption Model, and the EIA Hurdle Rate Adoption Model generally agree in levels of deployment in the near term, with cumulative deployment by 2027 anticipated to be slightly more than $50 \mathrm{GW}$ in a Reference case. After 2027, the models results are not aligned on the long-term outlook; while the EIA Cash Flow and NREL dGen models suggests cumulative deployment of $148 \mathrm{GW}-165 \mathrm{GW}$, the EIA Hurdle model projected as much as $227 \mathrm{GW}$ of deployment.

We also explore several dimensions to modeling uncertainty, including the choice of which realworld phenomena to represent, how results change through a retrospective consideration, and the quantification of uncertainty derived from stochastic processes within the dGen model. We find that (1) stochastic processes that populate customer profiles in dGen may introduce significant uncertainty in simulations with insufficient sampling rates (Figure ES-3 and Figure 11) and (2) model variance decreased at larger geographic scales due to the aggregation of many smaller sampling processes.

The analysis conducted for this report is relatively static and does not capture the full range of factors influencing electricity markets. Nevertheless, it is intended to be instructive of the range of potential DPV deployment should grid conditions remain similar to today's. Future work could consider other potentially disruptive factors, such as influence of electric vehicles, energy storage, and competition between utility-scale, community-scale, and distributed-scale solar energy systems. Perhaps most significant are endogenous changes; that is, evolution in policy and market structure as a response to the expansion of DPV to better reflect the value of distributed generation. For instance, distribution grid integration limits could limit the actual deployable potential or introduce new system integration costs not considered in this analysis. 
Our findings suggest financial attractiveness of DPV primarily depends on sustained PV cost reductions and is strongly influenced by future energy policy. With continued cost reductions and policy encouraging customer adoption, DPV deployment could grow faster than it ever has before by the middle of the century. Alternatively, if DPV incentives and policies expire in the coming decades, DPV growth may level off. As technology advances, new revenues channels become available to DPV, state policies and incentives are revised, and new data becomes available, updated analyses will likely be needed to continue to inform those exploring and planning for possible futures. 


\section{References}

ABB. 2016. “ABB Velocity Suite.” http://new.abb.com/enterprise-software/energyportfoliomanagement/market-intelligence-services/velocity-suite.

Barbose, Galen. 2017. Putting the Potential Rate Impacts of Distributed Solar into Context. Berkeley, CA: Lawrence Berkeley National Laboratory. LBNL-1007060.

Barbose, Galen and Naïm Darghouth. 2017. Tracking the Sun 10: The Installed Price of Residential and Non-Residential Photovoltaic Systems in the United States. Berkeley, CA: Lawrence Berkeley National Laboratory. http://etapublications.lbl.gov/sites/default/files/tracking_the_sun_10_report.pdf.

Barbose, Galen, John Miller, Ben Sigrin, Emerson Reiter, Karlynn Cory, Joyce McLaren, Joachim Seel, Andrew Mills, Naïm Darghouth, and Andrew Satchwell. 2016. On the Path to SunShot: Utility Regulatory and Business Model Reforms for Addressing the Financial Impacts of Distributed Solar on Utilities. Golden, CO: National Renewable Energy Laboratory. NREL/TP-6A20-65670; LBNL-1004371. https://www.nrel.gov/docs/fy16osti/65638.pdf.

Bass, F.M. 1969. A new product growth for model consumer durables. Manag. Sci., 15 (5) (1969), pp. 215-227, 10.1287/mnsc.15.5.215

Bevan, Luke and Donovan, Charles, Firm Power Parity: A Framework for Understanding the Disruptive Threat of Solar + Storage (September 4, 2017). http://dx.doi.org/10.2139/ssrn.3031992

Bird, Lori, J. McLaren, J. Heeter, C. Linvill, J. Shenot, R. Sedano, and J. Migden-Ostrander. Regulatory Considerations Associated with the Expanded Adoption of Distributed Solar. 2013. Golden, CO: National Renewable Energy Laboratory. NREL/TP-6A20-60613. https://www.nrel.gov/docs/fy14osti/60613.pdf.

Blair, Nate, Aron P. Dobos, Janine Freeman, Ty Neises, Michael Wagner, Tom Ferguson, Paul Gilman, and Steven Janzou. 2014. System Advisor Model, SAM 2014.1.14: General Description. Golden, CO: National Renewable Energy Laboratory. NREL/TP-6A20-61019. https://www.nrel.gov/docs/fy14osti/61019.pdf.

Bolinger, Mark, Ryan Wiser, Karlynn Cory, and Ted James. 2009. PTC, ITC, or Cash Grant? An Analysis of the Choice Facing Renewable Power Projects in the United States. NREL/TP6A20-45359. https://www.nrel.gov/docs/fy09osti/45359.pdf.

Brazilian, Morgan, Ijeoma Onyeij, Michael Liebreich, Ian MacGill, Jennifer Chase, Jigar Shah, Dolf Gielen, et al. 2013. "Re-Considering the Economics of Photovoltaic Power." Renewable Energy 53(May 2013): 329-338. http://www.sciencedirect.com/science/article/pii/S0960148112007641?via\%3Dihub.

Cole, Wesley, Haley Lewis, Ben Sigrin, and Robert Margolis. 2016. "Interactions of Rooftop PV Deployment with the Capacity Expansion of the Bulk Power System.” Applied Energy 168 (April 2016): 473-481. doi:10.1016/j.apenergy.2016.02.004. 
Cole, Wesley, Trieu Mai, James Richards, Paritosh Das, and Paul Donohoo-Vallett. 2017. 2017 Standard Scenarios Report: A U.S. Electricity Sector Outlook. Golden, CO: National Renewable Energy Laboratory. NREL/TP-6A20-68548. https://www.nrel.gov/docs/fy18osti/68548.pdf.

Davidson, Carolyn, and Robert Margolis. 2015. PV Quote Data: New Insights into PV Product Variation. Golden, CO: National Renewable Energy Laboratory. NREL/TP-6A20- 64792.

Davidson, Carolyn, Pieter Gagnon, Paul Denholm, and Robert Margolis. 2015. Nationwide Analysis of U.S. Commercial Building Solar Photovoltaic (PV) Breakeven Conditions. Golden, CO: National Renewable Energy Laboratory. NREL/TP-6A20-64793. https://www.nrel.gov/docs/fy16osti/64793.pdf.

De Martini, Paul, Lorenzo Kristov, and Lisa Schwartz. 2015. Distribution Systems in a High Distributed Energy Resources Future. Berkeley, CA: Lawrence Berkeley National Laboratory. LBNL-1003797.

Denholm, Paul, Kara Clark, and Matt O’Connell. 2016. On the Path to SunShot: Emerging Issues and Challenges in Integrating High Levels of Solar into the Electrical Generation and Transmission System. Golden, CO: National Renewable Energy Laboratory. NREL/TP-6A2065800. http://www.nrel.gov/docs/fy16osti/65800.pdf.

Dobos, Aron P. 2014. PVWatts Version 5 Manual. Golden, CO: National Renewable Energy Laboratory. NREL/TP-6A20-62641. https://www.nrel.gov/docs/fy14osti/62641.pdf.

DOE (Department of Energy). 2013. “Commercial and Residential Hourly Load Profiles for all TMY3 Locations in the United States.” Buildings Technology Office. https://openei.org/doeopendata/dataset/commercial-and-residential-hourly-load-profiles-for-all-tmy3-locations-in-theunited-states .

Dong, Changgui, Benjamin Sigrin, and Gregory Brinkman. 2017. "Forecasting Residential Solar Photovoltaic Deployment in California.” Technological Forecasting and Social Change 117(C): 251-265.

Dong, Changgui, Ryan Wiser, and Varun Rai. 2014. Incentive Pass-Through for Residential Solar Systems in California. Berkeley, CA: Lawrence Berkeley National Laboratory. LBNL6927E.

DSIRE (Database of State Incentives for Renewables \& Efficiency). 2017. "Database of State Incentives for Renewables \& Efficiency.” Accessed in 2017 for multiple queries: http://www.dsireusa.org/.

EIA (U.S. Energy Information Administration). 2013. Assessing the Economic Value of New Utility-Scale Electricity Generation Projects. July 2013.

https://www.eia.gov/renewable/workshop/gencosts/pdf/lace-lcoe_070213.pdf.

—. 2012. Commercial Buildings Energy Consumption Survey (CBECS). https://www.eia.gov/consumption/commercial/. 
—. 2009. Residential Energy Consumption Survey (RECS).

https://www.eia.gov/consumption/residential/data/2009.

Eurek, Kelly, Wesley Cole, David Bielen, Nate Blair, Stuart Cohen, Bethan Frew, Jonathan Ho, et al. 2016. Regional Energy Deployment System (ReEDS) Model Documentation: Version 2016. Golden, CO: National Renewable Energy Laboratory. NREL/TP-6A20-67067. https://www.nrel.gov/docs/fy17osti/67067.pdf.0

Fares, Robert L., and Carey W. King. 2017. "Trends in Transmission, Distribution, and Administration Costs for U.S. Investor-Owned Electric Utilities.” Energy Policy 105: 354-362. https://doi.org/10.1016/j.enpol.2017.02.036.

Feldman, David, Hoskins, Jack, and Robert Margolis. 2017. Q2/Q3 2017 Solar Industry Update. Golden, CO: National Renewable Energy Laboratory. NREL/PR-6A20-70406. https://www.nrel.gov/docs/fy18osti/70406.pdf.

Gagnon, Pieter, Robert Margolis, Jennifer Melius, Caleb Phillips, and Ryan Elmore. 2016. Rooftop Solar Photovoltaic Technical Potential in the United States: A Detailed Assessment. Golden, CO: National Renewable Energy Laboratory. NREL/TP-6A20-65298.

https://www.nrel.gov/docs/fy16osti/65298.pdf

George, R, S. Wilcox, M. Anderberg, and R. Perez. 2007. National Solar Radiation Database (NSRDB): $10 \mathrm{Km}$ Gridded Hourly Solar Database. Golden, CO: National Renewable Energy Laboratory. NREL/CP-581-41599.

Gorak, Tomas. 2016. Advancing Renewables: Lessons Learned in Hawaii (So Far). 2016. 2016 EUA Energy Conference. July 11-12, 2016. Washington Hilton, Washington D.C.

GTM Research. 2017. 2017 Year in Review, U.S. Solar Market Insight.

Hledik, Ryan, Jim Lazar, and Lisa Schwartz. 2016. Distribution System Pricing with Distributed Energy Resources. Berkeley, CA: Lawrence Berkeley National Laboratory. LBNL-1005180.

Leidos. 2015. Review of Distributed Generation and Combined Heat and Power Technology Performance and Cost Estimates and Analytic Assumptions for the National Energy Modeling System. https://www.eia.gov/analysis/studies/buildings/distrigen/.

Lent, Janice. 2017. “Using Hurdle Models for Long-term Projections of Residential Solar Photovoltaic Systems Installations.” Proceedings of the 2017 American Statistical Association Joint Statistical Meetings (JSM), Baltimore, MD, August 3, 2017. https://ww2.amstat.org/meetings/jsm/2017/onlineprogram/AbstractDetails.cfm?abstractid=322866.

Hagerman, Shelly, Paulina Jaramillo, and M. Granger Morgan. 2016. "Is Rooftop Solar PV at Socket Parity Without Subsidies?” Energy Policy 98(February 2016): 84-94. http://www.sciencedirect.com/science/article/pii/S0301421515301956.

Honeyman, Cory. 2016. U.S. Residential Solar Economic Outlook 2016-2020: Grid Parity, Rate Design, and Net Metering Risk. GTM Research, 
https://www.greentechmedia.com/research/report/us-residential-solar-economic-outlook-20162020\#gs.vrs4U7M.

IRENA (International Renewable Energy Agency). 2012. Renewable Energy Technologies: Cost Analysis Series: Solar Photovoltaics. Volume 1: Power Sector, Issue 4/5. June 2012. http://www.irena.org/DocumentDownloads/Publications/RE_Technologies_Cost_AnalysisSOLAR_PV.pdf.

Jacobs, Mike. 2014. "How Much Does Rooftop Solar Power Cost? Grid Parity Here or Coming in More than Half of U.S. States.” Union of Concerned Scientists. August 20, 2014.

http://blog.ucsusa.org/mike-jacobs/how-much-does-rooftop-solar-power-cost-grid-parity-633.

Mai, Trieu, Cole, Wesley, Lantz, Eric, Cara Marcy, and Benjamin Sigrin. 2016. Impacts of Federal Tax Credit Extensions on Renewable Deployment and Power Sector Emissions.

Golden, CO: National Renewable Energy Laboratory. NREL/TP-6A20-65571.

https://www.nrel.gov/docs/fy16osti/65571.pdf.

Mills, Andrew, and Ryan Wiser. 2012. An Evaluation of Solar Valuation Methods Used in Utility Planning and Procurement Processes. Berkeley, CA: Laboratory Lawrence Berkeley National Laboratory. LBNL-5933E. https://emp.lbl.gov/sites/all/files/lbnl-5933e.pdf.

Moezzi, Mithra, Aaron Ingle, Loren Lutzenhiser, and Benjamin Sigrin. 2017. A Non-Modeling Exploration of Residential Solar Photovoltaic (PV) Adoption and Non-Adoption. Golden, CO: National Renewable Energy Laboratory. NREL/SR-6A20-67727. https://www.nrel.gov/docs/fy17osti/67727.pdf.

Mulkern, Anne C. 2013, December 20. “A Solar Boom So Successful, It's Been Halted.” Scientific American. https://www.scientificamerican.com/article/a-solar-boom-so-successfull-itsbeen-halted/.

Munsel, Mike. 2017, February 15. "U.S. Solar Market Grows 95\% in 2016, Smashes Records. Greentech Media.” Greentech Media. https://www.greentechmedia.com/articles/read/us-solarmarket-grows-95-in-2016-smashes-records.

NCSL (National Conference of State Legislatures). 2016. "State Net Metering Policies.” Last updated November 20, 2017. http://www.ncsl.org/research/energy/net-metering-policyoverview-and-state-legislative-updates.aspx.

Nemet, Gregory F. 2009. "Demand-Pull, Technology-Push, and Government-Led Incentives for Non-Incremental Technical Change.” Research Policy 38(5): 700-709.

NREL (National Renewable Energy Laboratory). 2017. “2017 Annual Technology Baseline.” Golden, CO: National Renewable Energy Laboratory. http://atb.nrel.gov/.

Ong, S., P. Denholm, and N. Clark. 2012. Grid Parity for Residential Photovoltaics in the United States: Key Drivers and Sensitivities. Golden, CO: National Renewable Energy Laboratory. NREL/CP-6A20-54527. https://www.nrel.gov/docs/fy12osti/54527.pdf. 
Palmintier, Bryan, Robert Broderick, Barry Mather, Michael Coddington, Kyri Baker, Fei Ding, Matthew Reno, Matthew Lave, and Ashwini Bharatkumar. 2016. On the Path to SunShot:

Emerging Issues and Challenges in Integrating Solar with the Distribution System. Golden, CO: National Renewable Energy Laboratory. NREL/TP-5D00-65331.

http://www.nrel.gov/docs/fy16osti/65331.pdf.

Paidipati, J., Frantzis, L., Sawyer, H., Kurrasch, A. 2008. Rooftop Photovoltaics Market Penetration Scenarios. Burlington, MA: Navigant Consulting. NREL/SR-581- 42306. http://www.nrel.gov/docs/fy08osti/42306.pdf.

Proudlove, Autumn, Brian Lips, David Sarkisian, and Achyut Shrestha. 2017. The 50 States of Solar: Q3 2017 Quarterly Report. North Carolina Clean Energy Technology Center. https://nccleantech.ncsu.edu/wp-content/uploads/Q3-17_SolarExecSummary_final.pdf.

Rai, Varun, and Benjamin Sigrin. 2013. "Diffusion of Environmentally-Friendly Energy Technologies: Buy versus Lease Differences in Residential PV Markets.” Environmental Research Letters 8(1), 014022.

Reichelstein, Stefan, and Michael Yorston. 2013. “The Prospects for Cost Competitive Solar PV Power.” Energy Policy 55(April 2013): 117-127.

https://www.sciencedirect.com/science/article/pii/S0301421512009688.

Rogers, Everett M. 2003. Diffusion of Innovations. 5th edition. (New York: Free Press, 2003).

Rothfield, Emily. 2010. “Solar Photovoltaic Installation in California: Understanding the Likelihood of Adoption Given Incentives, Electricity Pricing and Consumer Characteristics.” Honors Thesis submitted in partial fulfillment of the requirements for Graduation with Distinction in Economics in Trinity College of Duke University. Durham, North Carolina.

Shah, V. and J. Booream-Phelps. 2014. Initiating Coverage with a BUY. Deutsche Bank Market Research. February 27, 2015.

- 2015. F.I.T.T. for Investors: Crossing the Chasm. Deutsche Bank Market Research. February 27, 2015. http://mdvseia.org/wp-content/uploads/2017/07/solar_report_full_length.pdf

Shahan, Cynthia. 2014. "Residential Solar Cheaper than Grid Electricity in 25 States by 2015, Utility CEO States.” Clean Technica. July 1, 2014.

https://cleantechnica.com/2014/07/01/residential-solar-cheaper-grid-electricity-25-states/.

Sigrin, Ben, and Easan Drury. 2014. Diffusion into New Markets: Economic Returns Required by Households to Adopt Rooftop Photovoltaics. AAAI Energy Market Prediction Symposium. Washington, November 13-15, 2014.

Sigrin, Benjamin, Michael Gleason, Robert Preus, Ian Baring-Gould, and Robert Margolis. 2016. The Distributed Generation Market Demand Model (dGen): Documentation. Golden, CO: National Renewable Energy Laboratory. NREL/TP-6A20-65231. http://www.nrel.gov/docs/fy16osti/65231.pdf. 
SRECTrade (2017) Historic Auction Prices. Accessed November 20, 2017:

http://www.srectrade.com/auction.

Srinivasan, V., and Charlotte H. Mason. 1986. "Technical Note: Nonlinear Least Squares Estimation of New Product Diffusion Models.” Mark. Sci. 5(2, 1986): 169-178, 10.1287/mksc.5.2.169.

Taylor, Margaret. (2008). "Beyond Technology-Push and Demand-Pull: Lessons from California’s Solar Policy.” Energy Economics 30(6): 2829-2854.

U.S. Census Bureau, and American FactFinder. 2017. "2011-2015 American Community Survey.” U.S. Census Bureau's American Community Survey Office, 2015. Accessed October 20, 2017: https://factfinder.census.gov/.

Ventyx. 2012. "Velocity Suite: Electric Company Retail Sales Data Combined by Company.”

Wang, Wenyu, Nanpeng Yu, and Raymond Johnson. 2017. "A Model for Commercial Adoption of Photovoltaic Systems in California.” Journal of Renewable and Sustainable Energy 9(2): 025904 .

Wood, Lisa, Ross Hemphill, John Howat, Ralph Cavanagh, Severin Borenstein, Jeff Deason, and Lisa C. Schwartz. 2016. Recovery of Utility Fixed Costs: Utility, Consumer, Environmental and Economist Perspectives. Berkeley, CA: Lawrence Berkeley National Laboratory. LBNL1005742. 


\section{Appendix A. Low PV Cost Grid Parity Projections}

Table A-1 provides statewide metrics for average savings from LCOE relative to average retail rates and NPVs across all counties in each modeled state and year, assuming significant PV cost reductions. The table also provides the percentage of counties in the state that are in parity according to LCOE savings alone, a positive NPV alone, or the ability to satisfy at least one of these conditions in this scenario.

Table A-1. Projected State-level Grid Parity Metrics for Low Cost scenario

\begin{tabular}{|c|c|c|c|c|c|}
\hline State & Year & $\begin{array}{l}\text { Avg. Retail- } \\
\text { LCOE (c/kWh) }\end{array}$ & Avg. NPV (\$) & $\begin{array}{l}\text { Counties } \\
\text { LCOE < Avg. } \\
\text { Retail (\%) }\end{array}$ & $\begin{array}{c}\text { Counties } \\
\text { NPV > } 0 \text { (\%) }\end{array}$ \\
\hline$A L$ & 2027 & 2.8 & 474 & $100 \%$ & $97 \%$ \\
\hline$A L$ & 2050 & 7.3 & 2,309 & $100 \%$ & $100 \%$ \\
\hline AR & 2027 & 1.3 & 386 & $100 \%$ & $79 \%$ \\
\hline AR & 2050 & 5.5 & 2,115 & $100 \%$ & $88 \%$ \\
\hline$A Z$ & 2027 & 5.7 & 2,433 & $100 \%$ & $100 \%$ \\
\hline$A Z$ & 2050 & 10.1 & 4,177 & $100 \%$ & $100 \%$ \\
\hline CA & 2027 & 10.1 & 5,498 & $100 \%$ & $84 \%$ \\
\hline CA & 2050 & 16.1 & 7,129 & $100 \%$ & $100 \%$ \\
\hline $\mathrm{CO}$ & 2027 & 4.7 & 3,529 & $100 \%$ & $98 \%$ \\
\hline $\mathrm{CO}$ & 2050 & 9.0 & 5,141 & $100 \%$ & $100 \%$ \\
\hline CT & 2027 & 11.9 & 8,210 & $100 \%$ & $100 \%$ \\
\hline CT & 2050 & 18.8 & 9,823 & $100 \%$ & $100 \%$ \\
\hline DC & 2027 & 6.7 & 3,893 & $100 \%$ & $100 \%$ \\
\hline DC & 2050 & 11.9 & 5,505 & $100 \%$ & $100 \%$ \\
\hline DE & 2027 & 4.8 & -773 & $100 \%$ & $0 \%$ \\
\hline DE & 2050 & 9.8 & 1,123 & $100 \%$ & $100 \%$ \\
\hline FL & 2027 & 4.8 & 3,055 & $100 \%$ & $100 \%$ \\
\hline FL & 2050 & 9.4 & 4,668 & $100 \%$ & $100 \%$ \\
\hline GA & 2027 & 3.0 & -2506 & $100 \%$ & $0 \%$ \\
\hline GA & 2050 & 7.6 & -535 & $100 \%$ & $0 \%$ \\
\hline IA & 2027 & 1.8 & 1,547 & $100 \%$ & $98 \%$ \\
\hline IA & 2050 & 6.0 & 3,159 & $100 \%$ & $100 \%$ \\
\hline ID & 2027 & 0.4 & -2223 & $70 \%$ & $0 \%$ \\
\hline ID & 2050 & 4.8 & -287 & $100 \%$ & $39 \%$ \\
\hline IL & 2027 & 1.8 & 916 & $100 \%$ & $100 \%$ \\
\hline IL & 2050 & 6.6 & 183 & $100 \%$ & $97 \%$ \\
\hline IN & 2027 & 2.3 & -364 & $100 \%$ & $15 \%$ \\
\hline IN & 2050 & 6.7 & 1,416 & $100 \%$ & $100 \%$ \\
\hline KS & 2027 & 4.4 & 3,418 & $100 \%$ & $88 \%$ \\
\hline KS & 2050 & 9.0 & 2,608 & $100 \%$ & $90 \%$ \\
\hline KY & 2027 & 0.7 & 10 & $100 \%$ & $37 \%$ \\
\hline $\mathrm{KY}$ & 2050 & 5.1 & 505 & $100 \%$ & $52 \%$ \\
\hline
\end{tabular}




\begin{tabular}{|c|c|c|c|c|c|}
\hline State & Year & $\begin{array}{l}\text { Avg. Retail- } \\
\text { LCOE (c/kWh) }\end{array}$ & Avg. NPV (\$) & $\begin{array}{c}\text { Counties } \\
\text { LCOE < Avg. } \\
\text { Retail (\%) }\end{array}$ & $\begin{array}{c}\text { Counties } \\
\text { NPV > } 0 \text { (\%) }\end{array}$ \\
\hline LA & 2027 & 1.2 & $-1,125$ & $100 \%$ & $19 \%$ \\
\hline LA & 2050 & 5.2 & 584 & $100 \%$ & $39 \%$ \\
\hline MA & 2027 & 11.0 & -408 & $100 \%$ & $0 \%$ \\
\hline MA & 2050 & 17.7 & 1,329 & $100 \%$ & $100 \%$ \\
\hline MD & 2027 & 6.6 & 584 & $100 \%$ & $88 \%$ \\
\hline MD & 2050 & 11.8 & 2,414 & $100 \%$ & $100 \%$ \\
\hline ME & 2027 & 5.3 & $-1,480$ & $100 \%$ & $0 \%$ \\
\hline ME & 2050 & 11.1 & 429 & $100 \%$ & $100 \%$ \\
\hline MI & 2027 & 2.4 & 719 & $100 \%$ & $80 \%$ \\
\hline MI & 2050 & 7.8 & 668 & $100 \%$ & $80 \%$ \\
\hline MN & 2027 & 2.9 & 873 & $100 \%$ & $98 \%$ \\
\hline MN & 2050 & 7.5 & 2,486 & $100 \%$ & $100 \%$ \\
\hline MO & 2027 & 3.0 & -288 & $100 \%$ & $30 \%$ \\
\hline MO & 2050 & 7.5 & 1,484 & $100 \%$ & $80 \%$ \\
\hline MS & 2027 & 2.9 & $-1,199$ & $100 \%$ & $37 \%$ \\
\hline MS & 2050 & 7.5 & 677 & $100 \%$ & $44 \%$ \\
\hline MT & 2027 & 2.1 & 1,852 & $98 \%$ & $86 \%$ \\
\hline MT & 2050 & 6.5 & 3,464 & $100 \%$ & $100 \%$ \\
\hline NC & 2027 & 3.0 & 183 & $100 \%$ & $45 \%$ \\
\hline NC & 2050 & 7.4 & 1,857 & $100 \%$ & $100 \%$ \\
\hline ND & 2027 & 1.9 & 168 & $100 \%$ & $83 \%$ \\
\hline ND & 2050 & 6.3 & 1,822 & $100 \%$ & $100 \%$ \\
\hline NE & 2027 & 2.9 & 2,884 & $100 \%$ & $99 \%$ \\
\hline NE & 2050 & 7.1 & 1,154 & $100 \%$ & $98 \%$ \\
\hline NH & 2027 & 8.5 & 3,406 & $100 \%$ & $100 \%$ \\
\hline NH & 2050 & 15.4 & 1,440 & $100 \%$ & $100 \%$ \\
\hline NJ & 2027 & 7.7 & 2,687 & $100 \%$ & $100 \%$ \\
\hline NJ & 2027 & 7.7 & 2,687 & $100 \%$ & $100 \%$ \\
\hline NM & 2027 & 4.9 & 5,276 & $100 \%$ & $100 \%$ \\
\hline NM & 2050 & 9.0 & 6,888 & $100 \%$ & $100 \%$ \\
\hline NV & 2027 & 3.9 & 530 & $100 \%$ & $82 \%$ \\
\hline NV & 2050 & 8.2 & 2,400 & $100 \%$ & $100 \%$ \\
\hline NY & 2027 & 8.5 & 359 & $100 \%$ & $39 \%$ \\
\hline NY & 2050 & 14.8 & 2,121 & $100 \%$ & $100 \%$ \\
\hline $\mathrm{OH}$ & 2027 & 2.0 & 2,999 & $100 \%$ & $100 \%$ \\
\hline $\mathrm{OH}$ & 2050 & 7.0 & 4,845 & $100 \%$ & $100 \%$ \\
\hline OK & 2027 & 1.5 & 872 & $100 \%$ & $92 \%$ \\
\hline OK & 2050 & 5.6 & 2,622 & $100 \%$ & $100 \%$ \\
\hline OR & 2027 & 1.7 & $-1,237$ & $97 \%$ & $0 \%$ \\
\hline OR & 2050 & 6.1 & 259 & $100 \%$ & $64 \%$ \\
\hline PA & 2027 & 2.0 & 2,015 & $100 \%$ & $100 \%$ \\
\hline
\end{tabular}




\begin{tabular}{|c|c|c|c|c|c|}
\hline State & Year & $\begin{array}{l}\text { Avg. Retail- } \\
\text { LCOE (c/kWh) }\end{array}$ & Avg. NPV (\$) & $\begin{array}{c}\text { Counties } \\
\text { LCOE < Avg. } \\
\text { Retail (\%) }\end{array}$ & $\begin{array}{c}\text { Counties } \\
\text { NPV > } 0 \text { (\%) }\end{array}$ \\
\hline PA & 2050 & 7.3 & 3,858 & $100 \%$ & $100 \%$ \\
\hline $\mathbf{R I}$ & 2027 & 11.2 & 3,931 & $100 \%$ & $100 \%$ \\
\hline $\mathbf{R I}$ & 2050 & 17.9 & 1,904 & $100 \%$ & $100 \%$ \\
\hline SC & 2027 & 3.1 & 1,327 & $100 \%$ & $63 \%$ \\
\hline SC & 2050 & 7.7 & 1,673 & $100 \%$ & $63 \%$ \\
\hline SD & 2027 & 3.0 & -792 & $100 \%$ & $2 \%$ \\
\hline SD & 2050 & 7.5 & 1,098 & $100 \%$ & $85 \%$ \\
\hline TN & 2027 & 2.8 & -239 & $100 \%$ & $43 \%$ \\
\hline $\mathrm{TN}$ & 2050 & 7.2 & 1,519 & $100 \%$ & $93 \%$ \\
\hline TX & 2027 & 2.9 & 2,938 & $100 \%$ & $92 \%$ \\
\hline $\mathrm{TX}$ & 2050 & 7.0 & 4,677 & $100 \%$ & $98 \%$ \\
\hline UT & 2027 & 2.5 & 3,780 & $100 \%$ & $97 \%$ \\
\hline UT & 2050 & 6.6 & 1,364 & $100 \%$ & $97 \%$ \\
\hline VA & 2027 & 2.3 & 552 & $100 \%$ & $61 \%$ \\
\hline VA & 2050 & 6.9 & 1,015 & $100 \%$ & $97 \%$ \\
\hline VT & 2027 & 7.4 & 397 & $100 \%$ & $93 \%$ \\
\hline VT & 2050 & 13.6 & 2,117 & $100 \%$ & $100 \%$ \\
\hline WA & 2027 & -1.2 & -2694 & $23 \%$ & $0 \%$ \\
\hline WA & 2050 & 3.2 & $-1,063$ & $100 \%$ & $5 \%$ \\
\hline WI & 2027 & 4.2 & 2,911 & $100 \%$ & $99 \%$ \\
\hline WI & 2050 & 9.1 & 4,523 & $100 \%$ & $100 \%$ \\
\hline wV & 2027 & 0.3 & 1,433 & $87 \%$ & $96 \%$ \\
\hline WV & 2050 & 4.8 & 1,405 & $100 \%$ & $100 \%$ \\
\hline WY & 2027 & 1.5 & 3,337 & $100 \%$ & $91 \%$ \\
\hline WY & 2050 & 5.5 & 5,060 & $100 \%$ & $100 \%$ \\
\hline
\end{tabular}




\section{Appendix B. Mid PV Cost Grid Parity Projections}

Table B-1 provides statewide metrics for average savings from LCOE relative to average retail rates and NPVs across all counties in each modeled state and year, assuming mid case PV cost reductions. The table also provides the percent counties in the states that are at parity according to LCOE savings alone, a positive NPV alone, or the ability to satisfy at least one of these conditions in this scenario.

Table B-1. Projected State-level Grid Parity Metrics for Mid Cost scenario

\begin{tabular}{|c|c|c|c|c|c|}
\hline State & Year & $\begin{array}{l}\text { Avg. Retail- } \\
\text { LCOE (c/kWh) }\end{array}$ & Avg. NPV, \$ & $\begin{array}{c}\text { Counties } \\
\text { LCOE < Avg. } \\
\text { Retail, \% }\end{array}$ & $\begin{array}{l}\text { Counties } \\
\text { NPV }>0, \%\end{array}$ \\
\hline$A L$ & 2027 & 0.6 & $-1,470$ & $100 \%$ & $0 \%$ \\
\hline$A L$ & 2050 & 6.4 & 1,697 & $100 \%$ & $100 \%$ \\
\hline AR & 2027 & -0.9 & $-1,624$ & $0 \%$ & $0 \%$ \\
\hline AR & 2050 & 4.6 & 1,274 & $100 \%$ & $79 \%$ \\
\hline$A Z$ & 2027 & 4.1 & 682 & $100 \%$ & $93 \%$ \\
\hline$A Z$ & 2050 & 9.4 & 3,855 & $100 \%$ & $100 \%$ \\
\hline CA & 2027 & 8.0 & 3,830 & $100 \%$ & $84 \%$ \\
\hline CA & 2050 & 15.3 & 7,319 & $100 \%$ & $100 \%$ \\
\hline $\mathrm{CO}$ & 2027 & 2.8 & 1,664 & $100 \%$ & $98 \%$ \\
\hline $\mathrm{CO}$ & 2050 & 8.3 & 4,365 & $100 \%$ & $98 \%$ \\
\hline CT & 2027 & 9.6 & 6,345 & $100 \%$ & $100 \%$ \\
\hline CT & 2050 & 17.9 & 9,046 & $100 \%$ & $100 \%$ \\
\hline DC & 2027 & 4.6 & 2,049 & $100 \%$ & $100 \%$ \\
\hline DC & 2050 & 11.0 & 4,750 & $100 \%$ & $100 \%$ \\
\hline DE & 2027 & 2.5 & $-2,666$ & $100 \%$ & $0 \%$ \\
\hline DE & 2050 & 8.9 & 575 & $100 \%$ & $100 \%$ \\
\hline FL & 2027 & 2.8 & 1,198 & $100 \%$ & $87 \%$ \\
\hline FL & 2050 & 8.6 & 3,900 & $100 \%$ & $100 \%$ \\
\hline GA & 2027 & 0.8 & $-1,432$ & $100 \%$ & $0 \%$ \\
\hline GA & 2050 & 6.7 & 2,062 & $100 \%$ & $100 \%$ \\
\hline IA & 2027 & -0.3 & -320 & $6 \%$ & $19 \%$ \\
\hline IA & 2050 & 5.1 & 2,382 & $100 \%$ & $100 \%$ \\
\hline ID & 2027 & -2.1 & $-4,287$ & $0 \%$ & $0 \%$ \\
\hline ID & 2050 & 3.8 & -858 & $100 \%$ & $0 \%$ \\
\hline IL & 2027 & -0.7 & $-1,292$ & $0 \%$ & $1 \%$ \\
\hline IL & 2050 & 5.6 & -403 & $100 \%$ & $1 \%$ \\
\hline IN & 2027 & 0.1 & $-2,206$ & $64 \%$ & $14 \%$ \\
\hline IN & 2050 & 5.8 & 860 & $100 \%$ & $95 \%$ \\
\hline KS & 2027 & 2.5 & 1,481 & $100 \%$ & $88 \%$ \\
\hline KS & 2050 & 8.2 & 2,017 & $100 \%$ & $88 \%$ \\
\hline $\mathrm{KY}$ & 2027 & -1.7 & $-2,036$ & $0 \%$ & $11 \%$ \\
\hline KY & 2050 & 4.0 & -136 & $100 \%$ & $37 \%$ \\
\hline
\end{tabular}




\begin{tabular}{|c|c|c|c|c|c|}
\hline State & Year & $\begin{array}{l}\text { Avg. Retail- } \\
\text { LCOE (c/kWh) }\end{array}$ & Avg. NPV, \$ & $\begin{array}{c}\text { Counties } \\
\text { LCOE < Avg. } \\
\text { Retail, \% }\end{array}$ & $\begin{array}{c}\text { Counties } \\
\text { NPV }>0, \%\end{array}$ \\
\hline LA & 2027 & -0.9 & $-3,004$ & $0 \%$ & $0 \%$ \\
\hline LA & 2050 & 4.3 & -91 & $100 \%$ & $39 \%$ \\
\hline MA & 2027 & 8.8 & $-2,168$ & $100 \%$ & $0 \%$ \\
\hline MA & 2050 & 16.8 & 1,120 & $100 \%$ & $100 \%$ \\
\hline MD & 2027 & 4.5 & $-1,263$ & $100 \%$ & $13 \%$ \\
\hline MD & 2050 & 10.9 & 1,868 & $100 \%$ & $100 \%$ \\
\hline ME & 2027 & 2.7 & $-3,457$ & $100 \%$ & $0 \%$ \\
\hline ME & 2050 & 10.0 & 95 & $100 \%$ & $75 \%$ \\
\hline MI & 2027 & -0.4 & $-1,469$ & $13 \%$ & $6 \%$ \\
\hline MI & 2050 & 6.7 & 49 & $100 \%$ & $72 \%$ \\
\hline MN & 2027 & 0.7 & $-1,000$ & $98 \%$ & $3 \%$ \\
\hline MN & 2050 & 6.5 & 1,701 & $100 \%$ & $100 \%$ \\
\hline MO & 2027 & 0.9 & $-2,175$ & $100 \%$ & $0 \%$ \\
\hline MO & 2050 & 6.6 & 868 & $100 \%$ & $76 \%$ \\
\hline MS & 2027 & 0.6 & $-3,204$ & $100 \%$ & $0 \%$ \\
\hline MS & 2050 & 6.5 & 24 & $100 \%$ & $44 \%$ \\
\hline MT & 2027 & -0.2 & -21 & $54 \%$ & $71 \%$ \\
\hline MT & 2050 & 5.6 & 2,680 & $100 \%$ & $96 \%$ \\
\hline NC & 2027 & 0.8 & $-1,761$ & $99 \%$ & $20 \%$ \\
\hline NC & 2050 & 6.5 & 1,043 & $100 \%$ & $52 \%$ \\
\hline ND & 2027 & -0.4 & $-1,755$ & $15 \%$ & $0 \%$ \\
\hline ND & 2050 & 5.3 & 1,017 & $100 \%$ & $98 \%$ \\
\hline NE & 2027 & 0.8 & 957 & $100 \%$ & $80 \%$ \\
\hline NE & 2050 & 6.3 & 646 & $100 \%$ & $100 \%$ \\
\hline NH & 2027 & 5.9 & 1,248 & $100 \%$ & $100 \%$ \\
\hline NH & 2050 & 14.2 & 1,067 & $100 \%$ & $100 \%$ \\
\hline NJ & 2027 & 5.5 & 856 & $100 \%$ & $100 \%$ \\
\hline NJ & 2050 & 12.5 & 4,045 & $100 \%$ & $100 \%$ \\
\hline NM & 2027 & 3.3 & 3,402 & $100 \%$ & $100 \%$ \\
\hline NM & 2050 & 8.4 & 6,104 & $100 \%$ & $100 \%$ \\
\hline NV & 2027 & 1.9 & $-1,457$ & $100 \%$ & $0 \%$ \\
\hline NV & 2050 & 7.4 & 1,861 & $100 \%$ & $94 \%$ \\
\hline NY & 2027 & 6.0 & $-1,481$ & $100 \%$ & $15 \%$ \\
\hline NY & 2050 & 13.8 & 1,600 & $100 \%$ & $100 \%$ \\
\hline $\mathrm{OH}$ & 2027 & -0.7 & 855 & $1 \%$ & $92 \%$ \\
\hline $\mathrm{OH}$ & 2050 & 5.9 & 3,947 & $100 \%$ & $100 \%$ \\
\hline OK & 2027 & -0.6 & $-1,162$ & $17 \%$ & $0 \%$ \\
\hline OK & 2050 & 4.7 & 1,771 & $100 \%$ & $96 \%$ \\
\hline OR & 2027 & -0.6 & $-2,799$ & $42 \%$ & $0 \%$ \\
\hline OR & 2050 & 5.2 & 337 & $100 \%$ & $67 \%$ \\
\hline
\end{tabular}




\begin{tabular}{|c|c|c|c|c|c|}
\hline State & Year & $\begin{array}{l}\text { Avg. Retail- } \\
\text { LCOE (c/kWh) }\end{array}$ & Avg. NPV, \$ & $\begin{array}{c}\text { Counties } \\
\text { LCOE < Avg. } \\
\text { Retail, \% }\end{array}$ & $\begin{array}{c}\text { Counties } \\
\text { NPV }>0, \%\end{array}$ \\
\hline PA & 2027 & -0.7 & -127 & $13 \%$ & $48 \%$ \\
\hline PA & 2050 & 6.1 & 2,962 & $100 \%$ & $100 \%$ \\
\hline $\mathbf{R} \mathbf{I}$ & 2027 & 9.0 & 2,058 & $100 \%$ & $100 \%$ \\
\hline $\mathbf{R} \mathbf{I}$ & 2050 & 17.0 & 1,694 & $100 \%$ & $100 \%$ \\
\hline SC & 2027 & 0.9 & -684 & $100 \%$ & $30 \%$ \\
\hline SC & 2050 & 6.7 & 1,062 & $100 \%$ & $63 \%$ \\
\hline SD & 2027 & 0.8 & $-2,722$ & $100 \%$ & $0 \%$ \\
\hline SD & 2050 & 6.6 & 559 & $100 \%$ & $74 \%$ \\
\hline $\mathrm{TN}$ & 2027 & 0.6 & $-2,109$ & $100 \%$ & $0 \%$ \\
\hline $\mathrm{TN}$ & 2050 & 6.3 & 920 & $100 \%$ & $87 \%$ \\
\hline TX & 2027 & 1.0 & 1,044 & $92 \%$ & $83 \%$ \\
\hline $\mathrm{TX}$ & 2050 & 6.2 & 4,017 & $100 \%$ & $96 \%$ \\
\hline UT & 2027 & 0.4 & 1,753 & $76 \%$ & $97 \%$ \\
\hline UT & 2050 & 5.8 & 898 & $100 \%$ & $97 \%$ \\
\hline VA & 2027 & 0.0 & $-1,490$ & $47 \%$ & $7 \%$ \\
\hline VA & 2050 & 6.0 & 391 & $100 \%$ & $61 \%$ \\
\hline VT & 2027 & 5.0 & $-1,379$ & $100 \%$ & $0 \%$ \\
\hline VT & 2050 & 12.6 & 1,826 & $100 \%$ & $100 \%$ \\
\hline WA & 2027 & -3.9 & $-4,434$ & $3 \%$ & $3 \%$ \\
\hline WA & 2050 & 2.1 & $-1,146$ & $100 \%$ & $8 \%$ \\
\hline WI & 2027 & 1.9 & 1,037 & $100 \%$ & $63 \%$ \\
\hline WI & 2050 & 8.1 & 3,739 & $100 \%$ & $100 \%$ \\
\hline WV & 2027 & -2.2 & -576 & $2 \%$ & $29 \%$ \\
\hline WV & 2050 & 3.7 & 772 & $100 \%$ & $89 \%$ \\
\hline WY & 2027 & -0.7 & 1,333 & $4 \%$ & $83 \%$ \\
\hline WY & 2050 & 4.7 & 6 & $100 \%$ & $100 \%$ \\
\hline
\end{tabular}




\section{Appendix C. High PV Cost Grid Parity Projections}

Table C-1 provides statewide metrics for average savings from LCOE relative to average retail rates and NPVs across all counties in each modeled state and year, assuming no PV cost reductions. The table also provides the percent of counties in the states that are in parity according to LCOE savings alone, a positive NPV alone, or the ability to satisfy at least one of these conditions in this scenario.

Table C-1. Projected State-level Grid Parity Metrics for High Cost scenario

\begin{tabular}{|c|c|c|c|c|c|}
\hline State & Year & $\begin{array}{l}\text { Avg. Retail- } \\
\text { LCOE (c/kWh) }\end{array}$ & Avg. NPV (\$) & $\begin{array}{l}\text { Counties } \\
\text { LCOE < Avg. } \\
\text { Retail (\%) }\end{array}$ & $\begin{array}{c}\text { Counties } \\
\text { NPV > } 0(\%)\end{array}$ \\
\hline$A L$ & 2027 & -6.3 & $-7,676$ & $0 \%$ & $0 \%$ \\
\hline$A L$ & 2050 & -3.7 & $-6,948$ & $0 \%$ & $0 \%$ \\
\hline AR & 2027 & -7.8 & $-7,770$ & $0 \%$ & $0 \%$ \\
\hline AR & 2050 & -5.6 & $-7,770$ & $0 \%$ & $0 \%$ \\
\hline$A Z$ & 2027 & -1.2 & $-5,187$ & $0 \%$ & $0 \%$ \\
\hline$A Z$ & 2050 & 1.7 & $-4,005$ & $100 \%$ & $0 \%$ \\
\hline CA & 2027 & 1.5 & $-1,750$ & $95 \%$ & $33 \%$ \\
\hline CA & 2050 & 5.9 & $-1,011$ & $100 \%$ & $50 \%$ \\
\hline $\mathrm{CO}$ & 2027 & -3.0 & $-4,267$ & $0 \%$ & $0 \%$ \\
\hline CO & 2050 & -0.3 & $-4,267$ & $39 \%$ & $0 \%$ \\
\hline CT & 2027 & 2.5 & 357 & $100 \%$ & $100 \%$ \\
\hline CT & 2050 & 7.4 & 357 & $100 \%$ & $100 \%$ \\
\hline DC & 2027 & -2.1 & $-3,960$ & $0 \%$ & $0 \%$ \\
\hline DC & 2050 & 1.3 & $-3,960$ & $100 \%$ & $0 \%$ \\
\hline DE & 2027 & -4.5 & $-8,801$ & $0 \%$ & $0 \%$ \\
\hline DE & 2050 & -1.3 & $-7,981$ & $0 \%$ & $0 \%$ \\
\hline FL & 2027 & -3.5 & $-4,798$ & $0 \%$ & $0 \%$ \\
\hline FL & 2050 & -0.5 & $-4,798$ & $10 \%$ & $0 \%$ \\
\hline GA & 2027 & -6.2 & $-10,924$ & $0 \%$ & $0 \%$ \\
\hline GA & 2050 & -3.5 & $-10,145$ & $0 \%$ & $0 \%$ \\
\hline IA & 2027 & -7.1 & $-6,306$ & $0 \%$ & $0 \%$ \\
\hline IA & 2050 & -4.8 & $-6,306$ & $0 \%$ & $0 \%$ \\
\hline ID & 2027 & -9.9 & $-10,873$ & $0 \%$ & $0 \%$ \\
\hline ID & 2050 & -7.6 & $-10,000$ & $0 \%$ & $0 \%$ \\
\hline IL & 2027 & -8.5 & $-8,175$ & $0 \%$ & $0 \%$ \\
\hline IL & 2050 & -5.9 & $-9,719$ & $0 \%$ & $0 \%$ \\
\hline IN & 2027 & -7.0 & $-8,107$ & $0 \%$ & $0 \%$ \\
\hline IN & 2050 & -4.5 & $-7,316$ & $0 \%$ & $0 \%$ \\
\hline KS & 2027 & -3.8 & $-4,670$ & $0 \%$ & $0 \%$ \\
\hline KS & 2050 & -0.9 & $-6,332$ & $11 \%$ & $0 \%$ \\
\hline KY & 2027 & -9.4 & $-8,480$ & $0 \%$ & $0 \%$ \\
\hline KY & 2050 & -7.1 & $-9,108$ & $0 \%$ & $0 \%$ \\
\hline
\end{tabular}




\begin{tabular}{|c|c|c|c|c|c|}
\hline State & Year & $\begin{array}{l}\text { Avg. Retail- } \\
\text { LCOE (c/kWh) }\end{array}$ & Avg. NPV (\$) & $\begin{array}{l}\text { Counties } \\
\text { LCOE < Avg. } \\
\text { Retail (\%) }\end{array}$ & $\begin{array}{c}\text { Counties } \\
\text { NPV > } 0(\%)\end{array}$ \\
\hline LA & 2027 & -7.6 & $-9,038$ & $0 \%$ & $0 \%$ \\
\hline LA & 2050 & -5.4 & $-8,616$ & $0 \%$ & $0 \%$ \\
\hline MA & 2027 & 1.7 & $-7,978$ & $100 \%$ & $0 \%$ \\
\hline MA & 2050 & 6.4 & $-6,626$ & $100 \%$ & $0 \%$ \\
\hline MD & 2027 & -2.4 & $-7,204$ & $0 \%$ & $0 \%$ \\
\hline MD & 2050 & 1.0 & $-6,412$ & $92 \%$ & $0 \%$ \\
\hline ME & 2027 & -5.5 & $-9,843$ & $0 \%$ & $0 \%$ \\
\hline ME & 2050 & -1.9 & $-8,580$ & $0 \%$ & $0 \%$ \\
\hline MI & 2027 & -9.1 & $-8,297$ & $0 \%$ & $0 \%$ \\
\hline MI & 2050 & -6.1 & $-9,276$ & $0 \%$ & $0 \%$ \\
\hline MN & 2027 & -6.4 & $-6,980$ & $0 \%$ & $0 \%$ \\
\hline MN & 2050 & -3.7 & $-6,980$ & $0 \%$ & $0 \%$ \\
\hline MO & 2027 & -5.9 & $-8,217$ & $0 \%$ & $0 \%$ \\
\hline MO & 2050 & -3.3 & $-7,482$ & $0 \%$ & $0 \%$ \\
\hline MS & 2027 & -6.4 & $-9,574$ & $0 \%$ & $0 \%$ \\
\hline MS & 2050 & -3.8 & $-8,902$ & $0 \%$ & $0 \%$ \\
\hline MT & 2027 & -7.3 & $-6,001$ & $0 \%$ & $0 \%$ \\
\hline MT & 2050 & -4.8 & $-6,001$ & $0 \%$ & $0 \%$ \\
\hline NC & 2027 & -6.0 & $-7,932$ & $0 \%$ & $0 \%$ \\
\hline NC & 2050 & -3.4 & $-7,932$ & $0 \%$ & $0 \%$ \\
\hline ND & 2027 & -7.6 & $-7,866$ & $0 \%$ & $0 \%$ \\
\hline ND & 2050 & -5.2 & $-7,866$ & $0 \%$ & $0 \%$ \\
\hline NE & 2027 & -5.6 & $-5,167$ & $0 \%$ & $0 \%$ \\
\hline NE & 2050 & -3.1 & $-7,449$ & $0 \%$ & $0 \%$ \\
\hline NH & 2027 & -2.6 & $-5,501$ & $0 \%$ & $0 \%$ \\
\hline NH & 2050 & 1.9 & $-7,933$ & $100 \%$ & $0 \%$ \\
\hline NJ & 2027 & -1.4 & $-4,974$ & $0 \%$ & $0 \%$ \\
\hline NJ & 2050 & 2.4 & $-4,144$ & $100 \%$ & $0 \%$ \\
\hline NM & 2027 & -2.0 & $-2,577$ & $0 \%$ & $0 \%$ \\
\hline NM & 2050 & 0.7 & $-2,577$ & $97 \%$ & $0 \%$ \\
\hline NV & 2027 & -4.2 & $-7,838$ & $0 \%$ & $0 \%$ \\
\hline NV & 2050 & -1.5 & $-6,965$ & $0 \%$ & $0 \%$ \\
\hline NY & 2027 & -1.8 & $-7,344$ & $10 \%$ & $0 \%$ \\
\hline NY & 2050 & 2.4 & $-6,697$ & $100 \%$ & $0 \%$ \\
\hline $\mathrm{OH}$ & 2027 & -9.0 & $-5,855$ & $0 \%$ & $0 \%$ \\
\hline $\mathrm{OH}$ & 2050 & -6.2 & $-5,855$ & $0 \%$ & $0 \%$ \\
\hline OK & 2027 & -7.2 & $-7,572$ & $0 \%$ & $0 \%$ \\
\hline OK & 2050 & -5.0 & $-7,572$ & $0 \%$ & $0 \%$ \\
\hline OR & 2027 & -8.0 & $-8,018$ & $0 \%$ & $0 \%$ \\
\hline OR & 2050 & -5.5 & $-7,402$ & $0 \%$ & $0 \%$ \\
\hline
\end{tabular}




\begin{tabular}{|c|c|c|c|c|c|}
\hline State & Year & $\begin{array}{l}\text { Avg. Retail- } \\
\text { LCOE (c/kWh) }\end{array}$ & Avg. NPV (\$) & $\begin{array}{c}\text { Counties } \\
\text { LCOE < Avg. } \\
\text { Retail (\%) }\end{array}$ & $\begin{array}{c}\text { Counties } \\
\text { NPV > } 0(\%)\end{array}$ \\
\hline PA & 2027 & -9.3 & $-6,831$ & $0 \%$ & $0 \%$ \\
\hline PA & 2050 & -6.4 & $-6,831$ & $0 \%$ & $0 \%$ \\
\hline $\mathbf{R I}$ & 2027 & 2.0 & $-3,922$ & $100 \%$ & $0 \%$ \\
\hline $\mathbf{R I}$ & 2050 & 6.8 & $-6,054$ & $100 \%$ & $0 \%$ \\
\hline SC & 2027 & -6.0 & $-7,034$ & $0 \%$ & $0 \%$ \\
\hline SC & 2050 & -3.3 & $-7,800$ & $0 \%$ & $0 \%$ \\
\hline SD & 2027 & -6.1 & $-8,893$ & $0 \%$ & $0 \%$ \\
\hline SD & 2050 & -3.5 & $-7,755$ & $0 \%$ & $0 \%$ \\
\hline TN & 2027 & -6.4 & $-8,111$ & $0 \%$ & $0 \%$ \\
\hline $\mathrm{TN}$ & 2050 & -3.8 & $-7,446$ & $0 \%$ & $0 \%$ \\
\hline TX & 2027 & -5.2 & $-5,041$ & $0 \%$ & $0 \%$ \\
\hline $\mathrm{TX}$ & 2050 & -2.8 & $-4,538$ & $0 \%$ & $0 \%$ \\
\hline UT & 2027 & -6.0 & $-4,639$ & $0 \%$ & $0 \%$ \\
\hline UT & 2050 & -3.6 & $-7,674$ & $0 \%$ & $0 \%$ \\
\hline VA & 2027 & -7.4 & $-7,923$ & $0 \%$ & $0 \%$ \\
\hline VA & 2050 & -4.8 & $-8,597$ & $0 \%$ & $0 \%$ \\
\hline VT & 2027 & -2.9 & $-7,213$ & $0 \%$ & $0 \%$ \\
\hline VT & 2050 & 1.1 & $-6,053$ & $100 \%$ & $0 \%$ \\
\hline WA & 2027 & -12.6 & $-10,123$ & $0 \%$ & $0 \%$ \\
\hline WA & 2050 & -10.5 & $-9,580$ & $0 \%$ & $0 \%$ \\
\hline WI & 2027 & -5.2 & $-4,942$ & $0 \%$ & $0 \%$ \\
\hline WI & 2050 & -2.2 & $-4,942$ & $0 \%$ & $0 \%$ \\
\hline WV & 2027 & -10.2 & $-6,922$ & $0 \%$ & $0 \%$ \\
\hline WV & 2050 & -7.9 & $-8,121$ & $0 \%$ & $0 \%$ \\
\hline WY & 2027 & -7.4 & $-4,996$ & $0 \%$ & $0 \%$ \\
\hline WY & 2050 & -5.2 & $-4,996$ & $0 \%$ & $0 \%$ \\
\hline
\end{tabular}




\section{Appendix D. dGen 2050 DPV Projections}

Table D-1. dGen 2050 DPV Projections

\begin{tabular}{|c|c|c|c|c|c|c|}
\hline $\begin{array}{l}\text { Scenario } \\
\text { Sector }\end{array}$ & $\begin{array}{c}\text { Customer } \\
\text { Base } \\
\text { (1000s) }\end{array}$ & $\begin{array}{l}\text { Number of } \\
\text { Adopters } \\
\text { (1000s) }\end{array}$ & $\begin{array}{l}\text { Developable } \\
\text { Market } \\
\text { Adoption } \\
(\%)\end{array}$ & $\begin{array}{l}\text { Total Market } \\
\text { Adoption } \\
\text { (\%) }\end{array}$ & Capacity(GW) & $\begin{array}{l}\text { Yearly } \\
\text { Energy } \\
\text { (TWh) }\end{array}$ \\
\hline \multicolumn{7}{|l|}{ Reference } \\
\hline Commercial & 6,643 & 1,213 & 20 & 18 & 42.6 & 59.8 \\
\hline Industrial & 902 & 176 & 21 & 20 & 9.2 & 12.7 \\
\hline \multirow[t]{2}{*}{ Residential } & 78,713 & 20,917 & 32 & 27 & 96.0 & 129.2 \\
\hline & 86,258 & 22,306 & 31 & 26 & 148 & 202 \\
\hline \multicolumn{7}{|l|}{ No CPP } \\
\hline Commercial & 6,885 & 1,171 & 19 & 17 & 40.8 & 57.0 \\
\hline Industrial & 918 & 170 & 20 & 18 & 8.9 & 12.2 \\
\hline \multirow[t]{2}{*}{ Residential } & 78,713 & 19,236 & 30 & 24 & 91.7 & 122.1 \\
\hline & 86,516 & 20,577 & 29 & 24 & 141 & 191 \\
\hline \multicolumn{7}{|l|}{$\begin{array}{l}\text { Low Oil/Gas } \\
\text { Price }\end{array}$} \\
\hline Commercial & 6,670 & 1,198 & 20 & 18 & 42.1 & 59.0 \\
\hline Industrial & 887 & 170 & 21 & 19 & 9.0 & 12.3 \\
\hline \multirow[t]{2}{*}{ Residential } & 78,713 & 20,397 & 32 & 26 & 93.7 & 125.6 \\
\hline & 86,270 & 21,765 & 30 & 25 & 145 & 197 \\
\hline \multicolumn{7}{|l|}{$\begin{array}{l}\text { High Oil/Gas } \\
\text { Price }\end{array}$} \\
\hline Commercial & 6,569 & 1,295 & 22 & 20 & 46.2 & 65.2 \\
\hline Industrial & 958 & 196 & 22 & 20 & 10.2 & 14.2 \\
\hline \multirow[t]{2}{*}{ Residential } & 78,713 & 22,841 & 35 & 29 & 104.2 & 140.8 \\
\hline & 86,240 & 24,332 & 34 & 28 & 161 & 220 \\
\hline \multicolumn{7}{|l|}{$\begin{array}{l}\text { Low Economic } \\
\text { Growth }\end{array}$} \\
\hline Commercial & 6,377 & 1,188 & 21 & 19 & 41.8 & 58.8 \\
\hline Industrial & 784 & 167 & 23 & 21 & 8.8 & 12.2 \\
\hline \multirow[t]{2}{*}{ Residential } & 78,713 & 20,625 & 32 & 26 & 93.9 & 126.2 \\
\hline & 85,874 & 21,980 & 31 & 26 & 145 & 197 \\
\hline \multicolumn{7}{|l|}{$\begin{array}{l}\text { High Economic } \\
\text { Growth }\end{array}$} \\
\hline Commercial & 6,892 & 1,259 & 20 & 18 & 44.5 & 62.6 \\
\hline Industrial & 1,045 & 188 & 20 & 18 & 9.7 & 13.4 \\
\hline Residential & 78,713 & 21,613 & 33 & 27 & 100.4 & 135.3 \\
\hline
\end{tabular}




\begin{tabular}{|c|c|c|c|c|c|c|}
\hline $\begin{array}{l}\text { Scenario } \\
\text { Sector }\end{array}$ & $\begin{array}{l}\text { Customer } \\
\text { Base } \\
\text { (1000s) }\end{array}$ & $\begin{array}{l}\text { Number of } \\
\text { Adopters } \\
\text { (1000s) }\end{array}$ & $\begin{array}{c}\text { Developable } \\
\text { Market } \\
\text { Adoption } \\
(\%)\end{array}$ & $\begin{array}{c}\text { Total Market } \\
\text { Adoption } \\
(\%)\end{array}$ & Capacity(GW) & $\begin{array}{l}\text { Yearly } \\
\text { Energy } \\
\text { (TWh) }\end{array}$ \\
\hline & 86,650 & 23,060 & 32 & 27 & 155 & 211 \\
\hline \multicolumn{7}{|l|}{$\begin{array}{l}\text { Low Oil/Gas } \\
\text { Resource and } \\
\text { Technology }\end{array}$} \\
\hline Commercial & 6,565 & 1,357 & 23 & 21 & 49.7 & 70.2 \\
\hline Industrial & 898 & 198 & 24 & 22 & 10.4 & 14.6 \\
\hline \multirow[t]{2}{*}{ Residential } & 78,713 & 24,487 & 38 & 31 & 110.8 & 150.7 \\
\hline & 86,176 & 26,042 & 37 & 30 & 171 & 235 \\
\hline \multicolumn{7}{|l|}{$\begin{array}{l}\text { High Oil/Gas } \\
\text { Resource and } \\
\text { Technology }\end{array}$} \\
\hline Commercial & 6,738 & 1,105 & 18 & 16 & 37.8 & 53.3 \\
\hline Industrial & 898 & 159 & 19 & 18 & 8.2 & 11.2 \\
\hline \multirow[t]{2}{*}{ Residential } & 78,713 & 18,850 & 29 & 24 & 86.5 & 115.7 \\
\hline & 79,611 & 20,114 & 28 & 23 & 133 & 180.2 \\
\hline
\end{tabular}




\section{Appendix E. EIA Cash Flow Adoption Model DPV Projections}

Table E-1. EIA Cash Flow Adoption Model DPV Projections

\begin{tabular}{|c|c|c|c|c|c|c|}
\hline Scenario & Sector ${ }^{\mathrm{a}}$ & $\begin{array}{l}\text { Number of } \\
\text { Adopters } \\
\text { (1000s) }\end{array}$ & $\begin{array}{c}\text { Capacity } \\
\text { (GW) }\end{array}$ & $\begin{array}{l}\text { Annual } \\
\text { Generation } \\
\text { (TWh) }\end{array}$ & $\begin{array}{l}\text { Annual } \\
\text { Utility } \\
\text { Electricity } \\
\text { Sales } \\
\text { (TWh) }\end{array}$ & $\begin{array}{c}\text { Percent of } \\
\text { Electricity } \\
\text { Demand Met } \\
\text { through DPV } \\
(\%)\end{array}$ \\
\hline \multicolumn{7}{|c|}{ Results with Residential Cash Flow Adoption Model Applied } \\
\hline \multirow[t]{3}{*}{ Reference } & Residential & 13,231 & 116 & 169 & 1,602 & $8 \%$ \\
\hline & Commercial & 1,110 & 49 & 70 & 1,620 & $4 \%$ \\
\hline & Total & 14,341 & 165 & 239 & 3,222 & $6 \%$ \\
\hline \multirow{3}{*}{$\begin{array}{l}\text { Reference-No } \\
\text { CPP }\end{array}$} & Residential & 12,385 & 107 & 157 & 1,694 & $7 \%$ \\
\hline & Commercial & 1,066 & 48 & 67 & 1,684 & $4 \%$ \\
\hline & Total & 13,451 & 155 & 225 & 3,377 & $6 \%$ \\
\hline \multirow{3}{*}{$\begin{array}{l}\text { High Oil and Gas } \\
\text { Resource and } \\
\text { Tech. }\end{array}$} & Residential & 12,242 & 106 & 155 & 1,666 & $7 \%$ \\
\hline & Commercial & 1,056 & 47 & 67 & 1,648 & $4 \%$ \\
\hline & Total & 13,298 & 153 & 222 & 3,314 & $6 \%$ \\
\hline \multirow{3}{*}{$\begin{array}{l}\text { Low Oil and Gas } \\
\text { Resource and } \\
\text { Tech. }\end{array}$} & Residential & 14,768 & 130 & 190 & 1,523 & $10 \%$ \\
\hline & Commercial & 1,182 & 53 & 74 & 1,597 & $4 \%$ \\
\hline & Total & 15,950 & 183 & 265 & 3,120 & $7 \%$ \\
\hline \multirow{3}{*}{$\begin{array}{l}\text { High Oil and Gas } \\
\text { Price }\end{array}$} & Residential & 13,861 & 122 & 178 & 1,551 & $9 \%$ \\
\hline & Commercial & 1,142 & 51 & 72 & 1,604 & $4 \%$ \\
\hline & Total & 15,003 & 173 & 250 & 3,155 & $7 \%$ \\
\hline \multirow{3}{*}{$\begin{array}{l}\text { Low Oil and Gas } \\
\text { Price }\end{array}$} & Residential & 13,107 & 114 & 167 & 1,622 & $8 \%$ \\
\hline & Commercial & 1,094 & 49 & 69 & 1,628 & $4 \%$ \\
\hline & Total & 14,201 & 163 & 236 & 3,251 & $6 \%$ \\
\hline \multirow{3}{*}{$\begin{array}{l}\text { Low Economic } \\
\text { Growth }\end{array}$} & Residential & 10,601 & 91 & 133 & 1,533 & $7 \%$ \\
\hline & Commercial & 1,074 & 48 & 67 & 1,555 & $4 \%$ \\
\hline & Total & 11,676 & 139 & 200 & 3,088 & $6 \%$ \\
\hline \multirow{3}{*}{$\begin{array}{l}\text { High Economic } \\
\text { Growth }\end{array}$} & Residential & 13,914 & 122 & 179 & 1,673 & $8 \%$ \\
\hline & Commercial & 1,155 & 52 & 73 & 1,684 & $4 \%$ \\
\hline & Total & 15,068 & 174 & 252 & 3,357 & $6 \%$ \\
\hline
\end{tabular}

a The industrial sector does not model DPV generation in NEMS; it is assumed that all non-residential DPV is allocated to the commercial sector. 


\section{Appendix F. EIA Hurdle Rate Adoption Model DPV Projections}

Table F-1. EIA Hurdle Rate Adoption Model DPV Projections

\begin{tabular}{|c|c|c|c|c|c|c|}
\hline Scenario & Sector ${ }^{a}$ & $\begin{array}{l}\text { Number of } \\
\text { Adopters } \\
(1000 \mathrm{~s})\end{array}$ & $\begin{array}{l}\text { Capacity } \\
\text { (GW) }\end{array}$ & $\begin{array}{c}\text { Annual } \\
\text { Generation } \\
\text { (TWh) }\end{array}$ & $\begin{array}{c}\text { Annual } \\
\text { Utility } \\
\text { Electricity } \\
\text { Sales (TWh) }\end{array}$ & $\begin{array}{c}\text { Percent of } \\
\text { Electricity } \\
\text { Demand } \\
\text { Met } \\
\text { through } \\
\text { DPV (\%) }\end{array}$ \\
\hline & \multicolumn{5}{|c|}{ Results with Residential Hurdle Rate Adoption Model Applied } & \\
\hline \multirow[t]{3}{*}{ Reference } & Residential & 35,484 & 177 & 263 & 1,519 & $13 \%$ \\
\hline & Commercial & 1,110 & 49 & 70 & 1,620 & $4 \%$ \\
\hline & Total & 36,594 & 227 & 333 & 3,139 & $9 \%$ \\
\hline \multirow[t]{3}{*}{ Reference-No CPP } & Residential & 35,082 & 175 & 260 & 1,598 & $13 \%$ \\
\hline & Commercial & 1,066 & 48 & 67 & 1,684 & $4 \%$ \\
\hline & Total & 36,148 & 223 & 328 & 3,282 & $8 \%$ \\
\hline \multirow{3}{*}{$\begin{array}{l}\text { High Oil and Gas } \\
\text { Resource and } \\
\text { Tech. }\end{array}$} & Residential & 35,671 & 178 & 265 & 1,569 & $13 \%$ \\
\hline & Commercial & 1,056 & 47 & 67 & 1,648 & $4 \%$ \\
\hline & Total & 36,727 & 226 & 332 & 3,216 & $8 \%$ \\
\hline \multirow{3}{*}{$\begin{array}{l}\text { Low Oil and Gas } \\
\text { Resource and } \\
\text { Tech. }\end{array}$} & Residential & 35,536 & 178 & 263 & 1,460 & $13 \%$ \\
\hline & Commercial & 1,182 & 53 & 74 & 1,597 & $4 \%$ \\
\hline & Total & 36,718 & 230 & 338 & 3,057 & $9 \%$ \\
\hline \multirow{3}{*}{$\begin{array}{l}\text { High Oil and Gas } \\
\text { Price }\end{array}$} & Residential & 34,503 & 173 & 256 & 1,483 & $13 \%$ \\
\hline & Commercial & 1,142 & 51 & 72 & 1,604 & $4 \%$ \\
\hline & Total & 35,645 & 223 & 328 & 3,087 & $9 \%$ \\
\hline \multirow{3}{*}{$\begin{array}{l}\text { Low Oil and Gas } \\
\text { Price }\end{array}$} & Residential & 36,292 & 181 & 269 & 1,532 & $13 \%$ \\
\hline & Commercial & 1,094 & 49 & 69 & 1,628 & $4 \%$ \\
\hline & Total & 37,386 & 230 & 338 & 3,161 & $9 \%$ \\
\hline \multirow{3}{*}{$\begin{array}{l}\text { Low Economic } \\
\text { Growth }\end{array}$} & Residential & 27,703 & 139 & 203 & 1,469 & $11 \%$ \\
\hline & Commercial & 1,074 & 48 & 67 & 1,555 & $4 \%$ \\
\hline & Total & 28,777 & 186 & 271 & 3,024 & $8 \%$ \\
\hline
\end{tabular}




\begin{tabular}{llcrrrr}
\hline Scenario & Sector & $\begin{array}{c}\text { Number of } \\
\text { Adopters } \\
(\mathbf{1 0 0 0 s )}\end{array}$ & $\begin{array}{c}\text { Capacity } \\
\text { (GW) }\end{array}$ & $\begin{array}{c}\text { Annual } \\
\text { Generation } \\
\text { (TWh) }\end{array}$ & $\begin{array}{c}\text { Annual } \\
\text { Utility } \\
\text { Electricity } \\
\text { Sales (TWh) }\end{array}$ & $\begin{array}{c}\text { Percent of } \\
\text { Electricity } \\
\text { Demand } \\
\text { Met } \\
\text { through } \\
\text { DPV (\%) }\end{array}$ \\
\hline $\begin{array}{l}\text { High Economic } \\
\text { Growth }\end{array}$ & Residential & 40,509 & 203 & 302 & 1,566 & $14 \%$ \\
& Commercial & 1,155 & 52 & 73 & 1,684 & $4 \%$ \\
\hline & Total & $\mathbf{4 1 , 6 6 4}$ & 254 & 375 & $\mathbf{3 , 2 5 0}$ & $\mathbf{9 \%}$ \\
\hline
\end{tabular}

a The industrial sector does not model DPV generation in NEMS; it is assumed that all non-residential DPV is allocated to the commercial sector. 